\title{
HIV Prevention
}

Citation for published version (APA):

Okafor, U. O. (2018). HIV Prevention: Brothel leaders as facilitators of consistent condom use by female sex workers in Abuja, Nigeria. [Doctoral Thesis, Maastricht University]. Datawyse / Universitaire Pers Maastricht. https://doi.org/10.26481/dis.20180131uoo

\section{Document status and date:}

Published: 01/01/2018

DOI:

10.26481/dis.20180131uoo

Document Version:

Publisher's PDF, also known as Version of record

\section{Please check the document version of this publication:}

- A submitted manuscript is the version of the article upon submission and before peer-review. There can be important differences between the submitted version and the official published version of record.

People interested in the research are advised to contact the author for the final version of the publication, or visit the DOI to the publisher's website.

- The final author version and the galley proof are versions of the publication after peer review.

- The final published version features the final layout of the paper including the volume, issue and page numbers.

Link to publication

\footnotetext{
General rights rights.

- You may freely distribute the URL identifying the publication in the public portal. please follow below link for the End User Agreement:

www.umlib.nl/taverne-license

Take down policy

If you believe that this document breaches copyright please contact us at:

repository@maastrichtuniversity.nl

providing details and we will investigate your claim.
}

Copyright and moral rights for the publications made accessible in the public portal are retained by the authors and/or other copyright owners and it is a condition of accessing publications that users recognise and abide by the legal requirements associated with these

- Users may download and print one copy of any publication from the public portal for the purpose of private study or research.

- You may not further distribute the material or use it for any profit-making activity or commercial gain

If the publication is distributed under the terms of Article $25 \mathrm{fa}$ of the Dutch Copyright Act, indicated by the "Taverne" license above, 


\section{HIV PREVVENIION BROTHEL LEADERS AS FACILITATORS OF CONSISTENT CONDOM USE BY FEMALE SEX WORKERS IN ABUJA, NIGERIA}

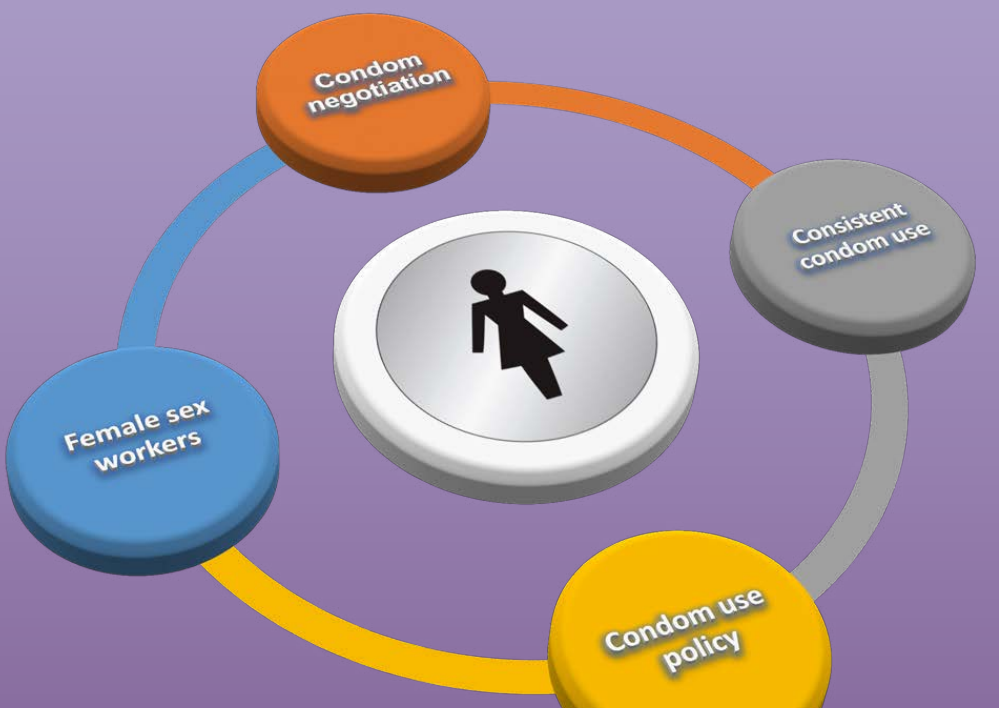

Uchenna Onyekachi Okafor 


\section{Credits}

Production: Datawyse I Universitaire Pers Maastricht

(C) Uchenna O. Okafor, Maastricht, 2018

ISBN: 9789461597946

The research presented in this thesis was conducted at the School for Public Health and Primary Care (CAPHRI), Department of Health Promotion, Maastricht University. The research reported in this dissertation was supported by a fellowship grant from the Netherlands ministry of foreign affairs through Nuffic.

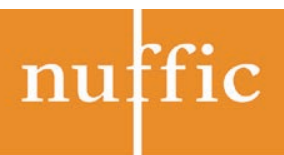




\title{
HIV PREVENTION
}

\section{BROTHEL LEADERS AS FACILITATORS \\ OF CONSISTENT CONDOM USE BY FEMALE SEX WORKERS IN ABUJA, NIGERIA}

\section{Dissertation,}

to obtain the degree of Doctor at Maastricht University, on the authority of the

Rector Magnificus, Prof. Dr. Rianne M. Letschert in accordance with the decision of the Board of Deans, to be defended in public on

Wednesday, $31^{\text {st }}$ of January 2018, at 16:00 hours

\author{
By
}

\section{Uchenna Onyekachi Okafor}




\section{Promotor}

Prof dr H.W. Van den Borne

\section{Co-promotor}

Dr Rik Crutzen

Dr Sylvia Adebajo, Population Council International, Nigeria

\section{Assessment Committee}

Prof. dr. N.K. de Vries, (Chair)

Prof. dr. G. Kok

Prof. dr. H. de Vries

Dr. J. Alaii (USAID, Uganda)

Prof.dr.H.J.C.de Vries (Academisch Medisch Centrum, Amsterdam) 


\section{TABLE OF CONTENT}

Chapter 1

Chapter 2

Chapter 3

Chapter 4

Chapter 5

Chapter 6

Chapter 7

References

Summary

Valorization

Acknowledgments

Curriculum Vitae
General Introduction

5

Prevalence and high-risk behaviour of young brothel and non-brothel

13 based female sex workers in Nigeria

A systematic review of behavioural interventions promoting condom use 27 among female sex workers in sub-Saharan Africa

Using brothel leadership to promote condom use among brothel based 59 Female Sex Workers in Abuja, Nigeria: Study Protocol for a Cluster Randomized Pilot Trial

A Cluster Randomised Pilot Trial Using Brothel Leadership to Improve 71 Condom Use among Brothel based Female Sex Workers in Abuja, Nigeria

Perspectives of brothel leaders and HIV prevention experts on the role 91 of gatekeepers on improving condom use by Female Sex Workers in Abuja, Nigeria

General Discussion 

CHAPTER 1

General Introduction 


\section{Chapter 1}

This chapter describes the dynamics and impact of the HIV epidemic and the efforts made thus far towards its prevention with focus on interventions promoting consistent condom use by Female Sex Workers (FSWs) in Sub-Saharan Africa and then specifically, on research with brothel based FSWs in Nigeria to improve their condom use behaviour with all their sexual partners. The aim and objectives of the research conducted in this thesis as well as the methodology and framework are also presented.

\section{Global Context of the HIV Epidemic}

In the past two decades, tremendous progress has been made in curbing the spread of HIV with significant reduction in the number of new infections globally. However, major challenges still exist as an estimated 2.1 million new HIV infections occurred worldwide in 2015 alone, adding up to a total of 36.7 million people living with HIV (UNAIDS, 2016). The burden of the epidemic varies across regions and countries with sub-Saharan Africa being the most severely affected, with an estimated 1 in every 25 adults (4.4\%) living with HIV. This accounts for nearly $70 \%$ of the people living with HIV/AIDS worldwide (UNAIDS, 2014, 2016).

Novel approaches are needed to reverse the spread, which includes focusing on key populations driving the epidemic i.e. sex workers, injecting drug users and men who have sex with men and the adoption of multifaceted prevention efforts using established high-impact interventions tailored to specific types of behaviours, by sex, age, population, settings and contexts (WHO, 2016c). The approaches adopted for the HIV prevention successes recorded in Cambodia, India and Thailand with the implementation of the $100 \%$ condom use programs and the enterprising efforts to reach key populations with HIV services in China and Ukraine are some examples of novel approaches that are adaptable (WHO, 2015). The Sonagachi FSW project in India, illustrates that implementing HIV prevention activities with a structural focus is feasible when the social drivers of HIV (e.g. lack of female empowerment, gender norms) and structural contexts are identified and addressed in a tailored way for the needs and contexts of the target community (Huang, Muessig, Zhang, \& Mamanb, 2015; Jana, Basu, Rotheram-Borus, \& Newman, 2004). Sex workers are female, male and transgender adults who sell consensual sexual services in return for cash or payment in kind, and who may sell sex formally or informally, regularly or occasionally (UNAIDS, 2009b). 
Globally, sex workers have been identified as a key population whose sexual activities with their clients and partners contribute to fuelling the HIV epidemic in the general population. The current global health sector strategy on HIV advocates that all the populations at risk for HIV infection be reached with services on time in order to address the inequities that persist globally (WHO, 2016b). HIV prevalence among sex workers and their clients is about 10-20 folds higher than among the general population (WHO, 2011). Seventeen of the top 18 countries where HIV prevalence among sex workers exceeds $20 \%$ are in sub-Saharan Africa with the median HIV prevalence at $20 \%$ compared to the global median of $3.9 \%$ (UNAIDS, 2014).

The high-risk practices of sex workers, including intravenous drug use and multiple sexual partnerships, as well as the high prevalence of other sexually transmitted infections (STIs) contribute to the high infection rates found within this group (Steen, Wheeler, Gorgens, Mziray, \& Dallabetta, 2015). Sex workers infected with other STIs (especially ulcerative STIs) are more likely to transmit HIV (Prüss-Ustün et al., 2013). High rates of partner change increase the potential for onward transmission of HIV from an infected sex worker, their partners and those within their sexual networks (WHO, 2011). Female sex workers are particularly vulnerable as they often neglect to use condoms with their boyfriends and regular partners and several studies have provided some reasons for this (Kayembe et al., 2008; Patterson, Semple, Fraga., Bucardo, \& De la Torre, 2006; Varga, 1997). Reasons given for non-use of condoms by FSWs include the need for psychological distinctions between work and private lives (Ulibarri et al., 2012), fostering feelings of trust and intimacy with steady partners (Murray et al., 2007), and the fear that suggesting condoms with their steady partners might reinforce their frequently stigmatized sex worker status (Outwater, Nkyama, Lwihula, O'Connor, \& Leshabari, 2000).

\section{Public health implications of HIV/AIDS in Nigeria}

Nigeria is the most populous country in Africa with an estimated population of over 140 million (National Population Commission, 2014). The HIV prevalence in Nigeria is second highest globally after South Africa with the number of people living with HIV estimated at over 3.2 million (NACA, 2014). 


\section{Chapter 1}

HIV prevalence in the country is highest amongst identified at-risk populations including FSWs (Ezirim, Ogungbemi, Daniel, Blanchard, \& Ezire, 2015). Nigeria has a mixed epidemic with varied prevalence and transmission dynamics across the different regions and populations. FSWs, their clients and regular partners have been identified to be at significant risk of HIV infection in the country (FMOH, 2014). A quarter of a century has gone by since the first case of HIV in Nigeria. In 1999 Nigeria's president made HIV/AIDs a priority agenda for the country and created the National Action Committee on Aids now known as the National Agency for the Control of AIDs (NACA) to coordinate the HIV response in the country (World Bank, 2012). The first National HIV/AIDS strategic plan (HEAP- HIV/AIDS Emergency Action Plan 2001-3) was developed in 2000/2001. The most recent, the five-year HIV/AIDs strategic plan for 2010-2015, focuses on prevention for most at risk populations as well as preventing mother to child transmission (NACA, 2010). Programs focusing on a combination of interventions addressing the multifaceted issues and specifically targeting high risk populations, including FSWs and other segments of the general population, are perceived to be required to control the HIV epidemic (NACA, 2014).

In Nigeria, FSWs, injecting drug users and men who have sex with men contribute about 23\% of new HIV infections and together with their partners contribute $40 \%$ of new infections in the country (NACA, 2014). FSWs alone have a national prevalence of $19.4 \%$, it is therefore strategic to design targeted prevention activities for FSWs and their partners to slow down HIV transmission among them and the wider population. These efforts should address socio-cultural barriers influencing their vulnerability to HIV/AIDS and also increase their access to public health services (Kerrigan, Wirtz, et al., 2013). A size estimation exercise for FSWs carried out in eight states in Nigeria in 2012 estimated there were 126,489 FSWs in these states with the Federal Capital Territory (FCT) of the country having 24,376 FSWs; this figure may be underestimated as the frequent activities of the police towards cracking down on FSWs and sex work establishments hinders identification (Ikpeazu, Momah-Haruna, Mari, Thompson, \& Ogungbemi, 2014).

Existing literature reveals two main sub-types of female sex work in Nigeria in terms of their work environment; Brothel based FSWs (BB FSWs) and Non-Brothel based FSWs (NBB FSWs) (NACA, 2014). BB FSWs live and work in residences with rooms that clients and sex 
NBB FSWs include street, home and venue-based sex workers who solicit for clients and provide sexual services in streets and public places such as hotels, bars, restaurants and nightclubs. Power structures for NBB FSWs are different and less dependent on the rules and confinement of the brothel owners, pimps and managers (Kerrigan, Fonner, Stromdahl, \& Kennedy, 2013). It is important that interventions consider this diversity as well as the contextual and social factors influencing the sexual behaviours of FSWs within these settings (Fang, Li, \& Yang, 2007; Zhang, Temmerman, Li, Luo, \& Luchters, 2013). The most recent surveillance data in the country show the national HIV prevalence in Nigeria at $3.4 \%(\mathrm{FMOH}$, 2013 ) and the prevalence among BB and NBB FSWs at approximately $19.4 \%$ and $8.6 \%$ respectively. The BB FSWs' HIV prevalence is twice that of their NBB counterparts and over six folds higher than that of the general population $(\mathrm{FMOH}, 2014)$. This underscores the importance of HIV prevention programming for FSWs, especially those working in brothels.

Correct and consistent condom use remains one of the most effective methods of preventing sexual transmission of HIV with its reported efficacy as high as 96\% (Fitch et al., 2002; Weller, 2002). Promotion of consistent condom use is core to HIV prevention programming and is cost-effective and acceptable as a public health approach for population level prevention (Roger, 2016; Smith, Powers, Kashuba, \& Cohen, 2011). Improving consistent condom use by FSWs with all partner types is key to reducing the spread of HIV (Bukenya, Vandepitte, \& Kwikiriza, 2013; Zhao, Wang, Fang, Li, \& Stanton, 2008). Interventions should therefore, aim to address barriers to condom use by FSWs targeting not only the individual level factors, but also social and community factors that influence HIV transmission and condom use within this population in Nigeria and globally (Jana et al., 2004; Varga, 1997). Investigations of interaction between condom use behaviour, individual-level social-cognitive factors and environmental factors have identified related barriers and facilitators of consistent condom use for relevant target groups (Hong, Fang, Li, Liu, \& Li, 2008; Yang et al., 2005). FSWs may not have sufficient control over factors within their immediate social and physical environment and these often compound their individual level risks factors. For example, availability and affordability of condoms, prevalent gender related power plays influencing condom use negotiation and gate keeper attitudes and beliefs (Urada, Morisky, Hernandez, \& Strathdee, 2013). 


\section{Chapter 1}

\section{Environmental Factors influencing FSW Condom Use}

Environmental factors exist at various levels that influence HIV transmission and prevention efforts. These include interpersonal, organizational, community and sociocultural factors (Kok et al., 2015). The interpersonal/community level for FSWs include brothel owners, managers and chairladies who are crucial agents that facilitate the existence of appropriate conditions conducive for improved self-efficacy, the adoption of required preventive behaviour and the provision of appropriate support and materials (Okafor, Crutzen, Adebajo, Okekearu, \& van Den Borne, 2017). The attitudes, beliefs and practices of these gatekeepers can influence the immediate environment of the FSW and consequently their adoption of consistent condom use behaviours (Urada et al., 2013).

Sociocultural factors, including punitive laws, policies and societal norms, can limit the civil, social and economic rights of sex workers such as their access to health care, employment conditions, gender inequities, stigma and discrimination. The cost of condoms and the availability of condoms at the brothels are also pertinent factors influencing the adoption of consistent condom use behaviours by FSWs with their sexual partners (Jie et al., 2012). A detailed understanding of how these environmental factors operate is needed for the development of targeted and effective interventions. An environment that makes it easier to adopt health promoting behaviour is important in facilitating change in behaviour of FSWs and has been advocated for by researchers in recent times leading to a gradual shift towards a combination approach addressing both individual and environmental factors (Kerrigan et al., 2003).

An Influential group within the FSW's immediate social and physical environment are the gatekeepers; these are defined as persons who manage FSWs (e.g., managers, chairladies, owners of establishments and brothels). They have a reciprocal financial relationship with FSWs and rely on FSWs to make money. Conversely, FSWs depend on gatekeepers for their financial opportunities (Yang et al., 2005). Only a limited number of studies have documented the role these gatekeepers play in HIV risk reduction for FSWs especially in sub-Saharan Africa. Previous studies in Thailand and China showed an association between FSWs' condom use behaviours and the characteristics of their workplaces, the attitudes of the gatekeepers or their working conditions (Li, Li, Stanton, Fang, \& Zhao, 2010; Visrutaratna \& Lindan, 1995; Yang et al., 2005; Zang, Li, \& Hong, 2014). 
A study by Yang et al. in China showed a strong linkage between the attitudes of gatekeepers' (managers or owners of the establishments) and FSWs' condom use (Yang et al., 2005). Li et al. suggest that enhancing gatekeepers' support may be important to the design of multidimensional programs targeting and overcoming structural barriers, including condom availability, social norms, and distribution of resources and power (Li et al., 2010). Previous studies in Asia have explored the association between condom use among FSWs and social or environmental factors including their working environment and perceived support from gatekeepers (Hong et al., 2008; Morisky, Tiglao, \& Sneed, 1998; Yang et al., 2005). Social support for condom use has been found to be positively associated with HIV preventive behaviours including condom use among women and FSWs (Dandona et al., 2015; Hong et al., 2008; Li et al., 2010).

Available studies were mostly conducted in Asia and there remains a lack of research on environmental support for FSWs' in Nigeria and sub-Saharan Africa as a whole, particularly regarding environmental support that includes condom access through managerial and social support. Studies in Nigeria primarily focus on consistent condom use, with limited or nonexistent data on how gatekeepers in sex work establishments influence condom use. The scale of the HIV epidemic in Nigeria necessitates the exploration in this study to inform effective environmental-structural interventions to reduce HIV risks among FSWs in Nigeria, especially for Brothel Based (BB) FSWs.

\section{Aim and Objectives}

The aim of this study is to provide insights into the influence(s) of key environmental agents on improving condom use amongst FSWs. To achieve this aim, the following specific objectives were formulated:

(1) To explore differences in HIV prevalence and sexual risk behaviours of brothel and nonbrothel based FSWs in Nigeria described in Chapter 2.

(2) To identify behavioural interventions used in promoting condom use among FSWs in subSaharan Africa: a systematic review described in Chapter 3.

(3) To understand and assess the feasibility of using brothel leadership to improve consistent and correct condom use among brothel based FSWs in Abuja, Nigeria: study protocol and results of a cluster randomized pilot trial described in Chapters 4 and 5. 
(4) To identify stakeholders' perceptions of using gatekeepers of FSWs to enhance HIV prevention efforts: an interview study described in Chapter 6.

Finally, the general discussion (chapter 7) provides insights into the incorporation of gatekeepers within the immediate environment of FSWs in HIV prevention interventions to address factors influencing FSW condom use in Nigeria. 


\section{CHAPTER 2}

Prevalence and high-risk behaviour of young brothel and non-brothel based

female sex workers 


\title{
Chapter 2
}

\begin{abstract}
Female sex workers have been identified as a core group in the transmission of HIV and other sexually transmitted infections (STIs). Young female sex workers are particularly more vulnerable to HIV due to the combination of vulnerabilities associated with their youth and the sex work they engage in. This study aims to give more insight into HIV prevalence and sexual risk behaviour of young female sex workers in Nigeria, by focusing on the differences between brothel based and non-brothel based young female sex workers. Data was obtained from the Nigeria Integrated Biological and Behavioural Surveillance Survey (IBBSS) for high-risk groups conducted in 2010. HIV prevalence and risk behaviour data for young brothel based and non-brothel based female sex workers aged 15-24 years for nine states was extracted and analysed. A total of 1796 young female sex workers were interviewed during the survey, 746 (41.5\%) were brothel based while 1050 (58.5\%) were non-brothel based. The HIV prevalence was higher among brothel based female sex workers compared to their non-brothel based counterparts (21.0\% vs. 15.5\%). Female sex workers residing in brothels reported less condom use with boyfriends (26.3\% vs. $45.5 \%)$ and casual partners $(55.1 \%$ vs.61.1\%) than the nonbrothel based female sex workers while risk of HIV infection due to injecting drug use was higher for non-brothel based compared to brothel based female sex workers (6.6\% vs. 1.2\%). Existing and future interventions on HIV prevention should focus on empowering young female sex workers with innovative and sustainable approaches aimed at improving their health and wellbeing.
\end{abstract}

\section{Published as:}

Okafor, U. O., Crutzen, R., Okekearu, I., Adebajo, S., \& Borne, H. (2017). HIV prevalence and high risk behaviour of young brothel and non-brothel based female sex workers in Nigeria. BMC Research Notes 10, 380. doi:10.1186/s13104-017-2712-8 
Young people are a vulnerable sub-population with regard to HIV infection and other related sexual risk behaviours. According to the 2006 population and housing census in Nigeria, young people between $10-24$ years constitute $31.7 \%$ of the 140 million population of the country (National Population Commission, 2014). In 2010, nearly half of the 3.1 million Nigerians living with HIV were between 15 and 24 years old (NACA, 2010) and young women aged 2024 bore a high HIV burden with HIV prevalence of 3.2\%, very close to the national population prevalence of $3.4 \%$ (FMOH, 2013). The findings from the 2012 national HIV/AIDS reproductive and health survey showed that among young persons aged $15-19$ years, 37\% of the females compared to $20 \%$ of the males had engaged in sex with median age at first sex for young women in the rural areas at 15 years compared to 17 years for their male counterparts (FMOH, 2013).

Female Sex Workers (FSWs) have been identified as a core group in the transmission of HIV and other sexually transmitted infections (STIs). Many risk factors contribute to the spread of HIV within FSW networks including their high-risk behaviours, sexual practices and the high prevalence of STIs (Zhang et al., 2013). These high-risk behaviours and sexual practices include large number of clients, intravenous drug use, excessive alcohol intake, unprotected sex with clients and the existence of non-paying sexual partners; boyfriend and husbands (Platt, Jolley, et al., 2013; Zhang et al., 2013). In addition, the vulnerabilities faced by FSWs relate not only to their individual risk behaviours but also to broader societal and community factors, including gender inequalities, gender-related violence, social marginalization, criminalized work environments and limited exposure to social opportunities and health services (Ahonsi et al., 2014). These individual and societal factors create a web of vulnerabilities that facilitate the spread of HIV within this population.

Young FSWs are particularly more vulnerable to HIV due to a combination of vulnerabilities associated with their youth and the sex work they engage in. Early sexual debut exposes an individual to the risk of acquiring STIs (UNFPA, 2003), because the individual is yet to acquire the necessary sex education and social exposure to navigate prevalent gender power 


\section{Chapter 2}

imbalances and violence successfully (Ahonsi et al., 2014; Scorgie et al., 2012). In Nigeria, societal norms and gender inequalities exist which increase the vulnerabilities faced by young women especially regarding sexual and reproductive health issues (Ahonsi et al., 2014). According to a 2013 global review, $35 \%$ of women worldwide have experienced either physical and/or sexual intimate partner or non-partner violence (WHO, 2013). The 2013 national demographic and health survey for Nigeria estimates sexual violence against women during their lifetime at $7 \%$ and this is more widespread amongst the more vulnerable female population within the society including young FSWs (FMOH, 2013).

In Nigeria, typologies of FSWs are differentiated mainly by the location from which their sex work is carried out; Brothel Based (BB) and Non-Brothel Based (NBB) FSWs. BB FSWs live and work in brothels under the supervision and rules of managers and other power structures existing within the brothel. NBB FSWs include street, home and venue based sex workers who solicit for clients and provide sexual services in streets and public places such as hotels, bars, restaurants and nightclubs. Power structures for NBB FSWs are different and less dependent on the rules and confinement of the brothel owners, pimps and managers (Kerrigan, Fonner, et al., 2013). This study aims to provide more insights into HIV prevalence and high-risk behaviour of young FSWs in Nigeria focusing on the differences between BB and NBB FSWs and is an essential first element of a needs assessment for future HIV prevention interventions (Bartholomew, Parcel, Kok, Gottlieb, \& Fernández, 2011).

\section{Methods}

This study entailed secondary analysis of data extracted from the Integrated Biological and Behavioural Surveillance Survey (IBBSS) for high-risk groups conducted in 2010 (FMOH, 2010). HIV prevalence and risk behaviour data for young BB and NBB FSWs aged 15-24 years for nine states were analysed.

\section{Sampling}

Eight Nigerian states (Lagos, Kano, Kaduna, Benue, Nasarawa, Edo, Anambra and Cross River) and the FCT were selected for the study. To be eligible for recruitment into this study, participants had to be females aged between 15-24 years who received money or other 
valuable gifts/incentives in exchange for sexual favours. A Time Location Sampling (TLS) technique was used to select NBB FSWs. The TLS is a form of cluster sampling that contains both time and location dimensions, it is suitable for obtaining information on hard to reach populations (Karon \& Wejnert, 2012). Working through relevant NGOs and government health staff in different cities/towns, the list of streets, bars, nightclubs and hotels where NBB FSW usually congregate was updated.

The BB FSWs were selected using a two-stage cluster sampling technique. First, a list of brothels where FSW work was drawn and information was collected on the approximate number of FSW present to permit an estimate of cumulative measure of size. Secondly, clusters were selected using probability proportionate to size (PPS) with a fixed number of FSWs recruited from each cluster. The cluster size of the brothel based FSWs was five and 50 clusters were selected in each state.

\section{Ethical Issues}

Participation in the survey was strictly voluntary and no incentives were provided. To guarantee anonymity, no forms of nominal and biometric identifiers were included in the questionnaires. Informed consent was obtained from each participant. Due to the illegal nature of sex work in the country, respondents did not want to sign a consent form. Instead, the interviewer explained the study to the participants and obtained verbal consent for the behavioural and biological components of the study and accompanied the participant to the counsellor-tester for HIV tests. All components of the study received ethical approval from the Nigerian Institute for Medical Research's (NIMR) Institutional Review Board in Nigeria and the Family Health International's (FHI) Protection of Human Subjects Committee.

\section{Measures}

The primary independent variable for the study was the FSW typology: BB or NBB FSWs. Other secondary independent variables include:

Highest educational level achieved: Respondents were asked their highest level of education out of seven options - 'never attended school', 'Qur'anic education', 'some primary', 
'completed primary', 'some secondary', 'completed secondary education', and 'tertiary' education.

'Main reason for going into sex work: Ten possible scenarios based on pre-identified circumstances were used to describe this: 'financial gain', 'unemployment', 'pleasure', 'marital frustration', 'divorced/separated', 'widowed', 'incest/abused', 'others', 'don't know' and 'no response'.

Clients and duration of sex work: clients and duration of sex work was measured using the following: how many customers/clients did you have last day worked, last 7 days how many customers/clients did you have, length of time engaged in sex work in months.

Dependent variables were condom use behaviours of interest and HIV prevalence of both populations. The study assessed participants with the following questions and reported those who responded with 'yes' or 'every time' to any of the following questions:

- Have you had sex with a cohabiting partner within the last 12 months?

- The last time you had sex with a cohabiting partner was condom used?

- Have you had sex with boyfriend within the past 12 months?

- The last time you had sex with boyfriend was a condom used?

- Have you had sex with a casual partner within the last 12 months?

- The last time you had sex with a casual partner was a condom used?

- Within the last 30 days how often did you use condom with your clients?

- Do you charge more for sex without condom?

- Has a client forced you to have sex without condom?

- Are you at risk of HIV infection due to use injectable narcotics?

\section{Analysis}

IBM statistics software SPSS version 20 was used for the extraction and analysis of the data. Descriptive analysis was conducted to characterize the study population of young FSWs (1524 years). This was followed by bivariate analyses (i.e., Chi square tests and independent samples t-test) to examine associations between typology of FSW and selected sexual risk behaviour of the FSWs as well as their socio-demographic variables. 


\section{Results}

A total of 1796 female sex workers comprising BB FSWs (41.5\%) and NBB FSWs (58.5\%) aged 15-24 years were interviewed during the survey. A higher proportion of NBB FSWs $(60.1 \%)$ had at least completed secondary education than the BB FSWs $(35.5 \%)(p<0.001)$. Over three-quarters of both BB and NBB FSWs reported going into sex work for financial gains. When compared to NBB FSWs, BB FSWs reported higher number of clients on last day worked (6 vs. 10) and in the last seven days (16 vs. 36). However, there was no difference between BB and NBB FSWs in the reported mean duration of sex work: 20.0 (SD 16.6) and $21.2(\mathrm{SD} 15.4)$ months respectively $(\mathrm{p}=0.12)$.

The HIV prevalence was significantly higher among BB FSWs compared to the NBB FSWs $(21.0 \%$ vs. $15.5 \%)(\mathrm{p}=0.01)$. A higher percentage of NBB FSWs $(45.0 \%)$ than BB FSW $(26.3 \%)$ reported condom use with a cohabiting partner at last sex act $(\mathrm{p}=0.01)$. The majority of the respondents in both groups reported condom use during last sex act. BB FSWs reported less condom use with boyfriends $(26.3 \%$ vs. $45.5 \%)(\mathrm{P}<0.001)$ and casual partners $(55.1 \%$ vs. $61.1 \%)(\mathrm{p}<0.001)$ than NBB FSWs. However, fewer BB FSWs $(4.0 \%)$ than NBB FSWs $(9.5 \%)$ who reported having sex without condoms within the last 30 days charged higher for sex without condom $(\mathrm{p}<0.001)$. A significantly high proportion of NBB FSWs $(17.0 \%)$ than BB FSW $(7.3 \%)$ reported being forced by clients to have sex without condom $(p<0.001)$ and a higher percentage of NBB FSWs $(6.6 \%)$ than BB FSWs $(1.2 \%)$ are at risk of HIV due to their use of injectable narcotics $(\mathrm{p}=0.002)$. 
Table 1: Characteristics of NBB and BB FSWs aged 15-24 years

\begin{tabular}{|c|c|c|c|c|}
\hline Variables & $\begin{array}{l}\text { BB \% } \\
(n=746)\end{array}$ & $\begin{array}{l}\text { NBB \% } \\
(n=1050)\end{array}$ & $\mathbf{X}^{2}$ & $P$ \\
\hline \multicolumn{5}{|c|}{ Highest educational level achieved } \\
\hline Never Attended School & 3.8 & 1.2 & \multirow[t]{7}{*}{155.1} & \multirow[t]{7}{*}{$<0.001$} \\
\hline Qur'anic Education & 0.7 & 0.6 & & \\
\hline Some Primary & 5.6 & 3.0 & & \\
\hline Completed Primary & 13.0 & 5.8 & & \\
\hline Some Secondary & 41.4 & 29.3 & & \\
\hline Completed Secondary & 33.1 & 44.1 & & \\
\hline Tertiary & 2.4 & 16.0 & & \\
\hline \multicolumn{5}{|c|}{ Main reason for going into sex work } \\
\hline Financial Gain & 76.0 & 82.2 & \multirow[t]{10}{*}{36.5} & \multirow[t]{10}{*}{$<0.001$} \\
\hline Unemployment & 8.7 & 7.0 & & \\
\hline Pleasure & 3.4 & 5.2 & & \\
\hline Marital Frustration & 4.5 & 2.1 & & \\
\hline Divorced/Separated & 2.1 & 0.6 & & \\
\hline Widowed & 0.3 & 0.3 & & \\
\hline Incest/Abused & 1.4 & 0.5 & & \\
\hline Others & 1.8 & 0.3 & & \\
\hline Don't Know & 0.3 & 0.4 & & \\
\hline No response & 1.6 & 1.4 & & \\
\hline $\begin{array}{l}\text { Clients and duration of sex } \\
\text { work }\end{array}$ & BB M(SD) & NBB M(SD) & $t$ & $P$ \\
\hline $\begin{array}{l}\text { How many Customers/clients } \\
\text { did you have last day worked }\end{array}$ & $9.6(19.8)$ & $6.0(18.8)$ & 3.86 & $<0.001$ \\
\hline $\begin{array}{l}\text { Last } 7 \text { days how many } \\
\text { customers/clients do you have }\end{array}$ & $36.2(26.1)$ & $16.4(24.6)$ & 16.29 & $<0.001$ \\
\hline $\begin{array}{l}\text { Duration of sex work in } \\
\text { months }\end{array}$ & $20.0(16.6)$ & $21.2(15.4)$ & 1.55 & 0.12 \\
\hline
\end{tabular}


Table 2: HIV prevalence and sexual risk behaviour of BB and NBB FSWs

\begin{tabular}{|l|l|l|l|l|}
\hline Variables & $\begin{array}{l}\text { BB } \\
\text { \% }\end{array}$ & $\begin{array}{l}\text { NBB } \\
\text { \% }\end{array}$ & $\mathbf{X}^{\mathbf{2}}$ & $\boldsymbol{P}$ \\
\hline Prevalence of HIV & 21.0 & 15.5 & 8.68 & 0.01 \\
\hline Had sex with a cohabiting partner & 11.6 & 10.1 & 0.94 & 0.33 \\
\hline $\begin{array}{l}\text { Last time you had sex with a cohabiting } \\
\text { partner was a condom used }\end{array}$ & 42.4 & 23.5 & 8.88 & 0.01 \\
\hline $\begin{array}{l}\text { Had sex with Boyfriend within the past } \\
\text { 12 months }\end{array}$ & 71.1 & 76.4 & 6.43 & 0.01 \\
\hline $\begin{array}{l}\text { Last time you had sex with a boyfriend } \\
\text { was a condom used }\end{array}$ & 26.3 & 45.5 & 55.81 & $<0.001$ \\
\hline $\begin{array}{l}\text { Had sex with a casual partner within } \\
\text { the past 12 months }\end{array}$ & 10.8 & 20.3 & 28.71 & $<0.001$ \\
\hline $\begin{array}{l}\text { Last time had sex with a casual partner } \\
\text { was a condom used }\end{array}$ & 55.1 & 61.1 & 3.01 & 0.39 \\
\hline $\begin{array}{l}\text { Last time you had sex was a condom } \\
\text { used }\end{array}$ & 97.8 & 93.2 & 22.45 & $<0.001$ \\
\hline $\begin{array}{l}\text { Within the last 30 days how often did } \\
\text { you use condoms with your clients }\end{array}$ & 91.1 & 77.9 & 59.09 & $<0.001$ \\
\hline $\begin{array}{l}\text { Do you charge more for sex without } \\
\text { condom }\end{array}$ & 4.0 & 9.5 & 23.50 & $<0.001$ \\
\hline $\begin{array}{l}\text { Has a client forced you to have sex } \\
\text { without condom }\end{array}$ & 7.3 & 16.9 & 39.30 & $<0.001$ \\
\hline $\begin{array}{l}\text { At risk of HIV due to use of injectable } \\
\text { narcotics }\end{array}$ & 1.2 & 6.6 & 9.98 & 0.002 \\
\hline
\end{tabular}

* Boyfriends are non-commercial sexual partners of FSWs who do not reside with the FSW while Cohabiting partners are non-commercial sexual partners in a marital or non-marital relationship who reside with the FSW. 


\section{Chapter 2}

This study highlights differences in high-risk behaviour and HIV prevalence of BB and NBB FSWs aged 15-24 years. The number of NBB FSWs within the sampled population was higher than the BB FSWs. This may be attributed to the social stigma associated with living in a brothel and being tagged an FSW. In addition, sex workers are marginalized socially and economically within the society and this makes it undesirable to reside in brothels that are publicly identified as sex work establishments. In addition, most NBB FSWs often times engage in other activities unrelated to sex work and do not want to be tagged openly as sex workers (Shiva \& Sanjeev, 2015).

The daily and weekly number of clients for BB FSWs was higher compared to the NBB FSWs. Risk of HIV and other sexually transmitted infections increases with higher frequency of sexual acts and higher number of sexual partners (National Population Commission, 2014; Odek et al., 2009). The higher number of clients for BB FSWs in this study may have increased their risk to HIV and other sexually transmitted infections. Some of the differences between BB FSWs and NBB FSWs can be ascribed to the environmental and social mechanisms within their work setting as well as socio-demographic indices pertinent to each group. BB FSWs work in more confined settings and often have to pay stipends to the social structures within the brothel system i.e. chairladies and/or brothel owners. Such a system that focuses more on how much money is made than on reducing sexual risk taking by the FSWs promotes HIV and STI risks. Power structures and environmental factors also influence the sexual behaviour of FSWs i.e. behaviour of pimps, brothel managers and law enforcement agents and this can significantly affect the outcome of interventions targeted at FSWs and their sexual behaviours. The need to target and integrate these structures and factors within prevention interventions addressing the behaviour and activities of these environmental agents will enhance the outcome of these interventions (Kerrigan, Fonner, et al., 2013).

Inconsistent condom use with boyfriends and regular partners observed within this study is consistent with other studies that have reported similar trends by FSWs (Murray et al., 2007; Odek et al., 2009; Scorgie et al., 2012; Ulibarri et al., 2012; Zhang et al., 2013). The higher level of inconsistent condom use by FSWs in brothels may further buttress the need to target 
them specifically with HIV prevention interventions tailored towards address issues specific to their inconsistent condom use which could compromise efforts made thus far in combating the HIV epidemic in sub-Saharan Africa (Peterman, Lin, \& Newman, 2000). Reasons adduced for inconsistent condom use by FSWs with regular partners cite 'trust' and 'feelings of intimacy' as the primary reasons for lack of condom use as well as the need to create a psychological distinction between their personal and work life (Ulibarri et al., 2012).

A higher proportion of NBB FSWs reported being forced to have sex without condoms compared to the BB FSWs. The communal structure of the brothels may discourage and reduce incidents of sexual violence within the brothel by partners and/or clients. With the gender inequalities and gender power plays that abound within the society especially among vulnerable groups of women, FSWs are often exposed to sexual violence and rape from intimate-partners and clients. The lack of a communal structure for the NBB FSWs makes them easier preys to sexual violence and also harder to reach with HIV prevention interventions. Risk of HIV infection due to the use of injectable narcotics exists for both BB and NBB FSWs. Injecting drug use by FSWs increase their risk of HIV infection through the sharing of injecting equipment and the increased likelihood of unprotected sex while under the influence of drugs or experiencing withdrawal (Le et al., 2015).

An analysis of the educational attainment of the two groups also shows lower educational attainment for the BB FSWs with a lower percentage of them having completed both secondary and tertiary education compared to their NBB counterparts. Previous studies report an association between low educational attainment, HIV risk perception and sexual risk behaviour (Odek et al., 2009; WHO, 2013) especially with regards to self-efficacy and assertiveness for consistent condom use. Financial gain and unemployment were the main reasons cited for going into sex work by both groups thus showing that the prevalent poverty within the society influences the choice of engaging in sex work by FSWs. Many people in Nigeria live in poverty and lack not only money, but also assets and skills. Therefore, in striving to get basic needs they may indulge in risky behaviours, such as commercial sex. This is consistent with reports from other studies demonstrating that poverty and economic deprivation make vulnerable 


\section{Chapter 2}

women who are without jobs turn to sex work as a means of livelihood to take care of themselves, their families and relatives (Mbirimtengerenji, 2007; Odek et al., 2009).

\section{Limitations}

A key limitation of this study is the use of self-reported data, which may have resulted in underreporting of risk behaviour due to social stigma and social desirability bias (i.e. for indices like condom use). Thus, the percentage of inconsistent condom use might be even higher than has been shown by this study. Moreover, the hidden nature of the FSW population makes it possible that some of the FSWs in the sampled locations were missed thus making the sampling frame incomplete. However, the sample size for the study and the multiple locations used mitigates the potential impact this might have had on our findings. The study did not focus strongly on the power structures around the FSWs that influence their risk profile. These power structures include the brothel owners, chairladies, managers and pimps who largely determine the environment in the brothels within which sex work is carried out.

\section{Conclusion}

FSWs in Nigeria are at high risk of HIV and STIs and are a core group for HIV prevention efforts. Existing and future interventions should focus on empowering FSWs towards improving their health and wellbeing. BB and NBB FSWS are the main FSW subgroups targeted for HIV prevention programs within the country and understanding the dynamics and vulnerabilities within the two groups will enhance intervention quality and ensure activities are tailored to meet their needs and vulnerabilities. BB FSWs show higher risk profiles with regards to number of clients as well as condom use with boyfriends and casual partners within this study. These are important risk factors that should be keenly considered in HIV prevention interventions for this subgroup. The higher HIV prevalence for BB compared to NBB FSWs illustrates the need to incorporate activities and strategies aimed at addressing relevant highrisk behaviours as well as the need to empower them to deal with the environmental and social intricacies and inequalities prevalent within their work place. 
Behaviour change interventions designed to positively change high-risk behaviours amongst FSWs should adopt strategies that address identified vulnerabilities at the individual and environmental levels within this group. Power structures within the environment of the FSWs should also be included in prevention interventions and the effect of these prevention focused activities measured and documented. 



\section{CHAPTER 3}

A systematic review of behavioural interventions promoting condom use among female sex workers in sub-Saharan Africa 


\title{
Chapter 3
}

\begin{abstract}
The objective of the review was to search electronic literature for behavioural interventions promoting condom use amongst female sex workers in sub-Saharan Africa. A search of four electronic bibliographic databases from 1990 to September 2016 limited to articles published in English was carried out. Studies that evaluated behavioural interventions to increase condom use among female sex workers were selected and reviewed. Data were extracted on effectiveness, condom use, intervention content, and process outcomes. Twenty eligible articles describing 18 interventions in sub-Saharan Africa on HIV prevention with condom use as an outcome measure were identified. Most of the behavioural interventions incorporated a combination of approaches; health education by peers, health workers and project staff as well as activities by brothel owners and brothel managers. Most studies showed effectiveness of these interventions on condom use with paying clients. Five studies measuring condom use with regular non-paying partners recorded less consistent condom use with these partners. This review illustrates the existence of sufficient evidence showing the effectiveness of behavioural interventions targeting correct and consistent condom use by female sex workers.
\end{abstract}

\section{Published as:}

Okafor, U. O., Crutzen, R., Aduak, Y., Adebajo, S., \& Van den Borne, H. W. (2017). Behavioural interventions promoting condom use among female sex workers in sub-Saharan Africa: a systematic review. African Journal of Aids research, 16(3), 257-268. doi:10.2989/16085906.2017.1358753 
The HIV epidemic in sub-Saharan Africa continues to have significant effects on sex work populations with Female Sex Workers (FSWs) being disproportionately affected (Prüss-Ustün et al., 2013). A systematic review and meta-analysis conducted in low and middle income countries showed the HIV prevalence for FSWs at $12 \%$ with the odds of being HIV infected at $13 \cdot 5$ (95\% CI 10·0-18 1) (Baral et al., 2012). The prevalence of HIV within FSW populations in sub-Saharan Africa (SSA) is higher than the prevalence observed in women in the general population. In South Africa, the HIV prevalence for FSWs is $45.1 \%$ compared to $25.3 \%$ in the general female population of reproductive age; $61.2 \%$ compared to $21.4 \%$ in Zimbabwe; $33.7 \%$ compared to $4.5 \%$ in Nigeria; and $45.1 \%$ compared to $7.7 \%$ in Kenya (Baral et al., 2012; Vandepitte et al., 2006).

For the purpose of this review, the definition of sex work by UNAIDS was used: "Any agreement between two or more persons in which the objective is exclusively limited to the sexual act and ends with that and which involves preliminary negotiations for a price" (UNAIDS, 2000). This definition excludes transactional sex, which is the exchange of favours, gifts or money for sexual activity. Those who engage in transactional sex do not necessarily self-identify as sex workers or clients (Stoebenau, Heise, Wamoyi, \& Bobrova, 2016) while sex workers clearly identify what they do as work or "business" which is very distinct from their non-work lives (Chatterji, Murray, London, \& Angelwicz, 2005; WHO, 2011).

Unprotected sex and multiple sexual partnerships are important risk factors in HIV transmission. In sub-Saharan Africa and most regions of the world, heterosexual transmission accounts for most HIV infections (UNAIDS, 2011). Prevention approaches for the reduction of sexual transmission of HIV are important in curbing the spread of the virus and the promotion of correct and consistent condom use continues to be an effective means of preventing sexual transmission of HIV particularly for sex workers (Charania et al., 2011). The effectiveness of condoms is hinged upon its consistent use as well as its non-breakage or slippage during sexual acts. Despite the effectiveness of early anti-retroviral treatment (Treatment as prevention) and other ARV related biomedical methods for the reduction of HIV transmission for people living with HIV (PLWH) and their partners, condom promotion 


\section{Chapter 3}

remains core to HIV prevention programming and is cost effective and acceptable as a public health approach for population level prevention (Roger, 2016; Wilton \& Broeckaert, 2013). Condom use by FSWs with their regular and non-paying partners is lower than with their paying partners and this compromises HIV prevention efforts for the group (Bukenya et al., 2013; Zhao et al., 2008). Barriers to condom use by FSWs are multi-faceted and targeting the individual level alone will not suffice. Strategies addressing individual, social and gender issues related to HIV transmission and condom use within this population are necessary (Jana et al., 2004; Varga, 1997; Zhang et al., 2011). Combining multiple prevention approaches composed of complementary biomedical, structural and behavioural strategies is recommended by UNAIDs for HIV prevention interventions especially those targeted at FSWs (UNAIDS, 2010). Behavioural interventions are designed to influence the actions under taken by an individual facilitating changes at the individual level as well as within networks and associated communities (Kok et al., 2015).

To date, only a few systematic reviews provide data on FSWs and their sexual behaviour in sub-Saharan Africa. Previous systematic reviews which have addressed relevant HIV-related issues globally and within sub-Saharan Africa on FSWs include; sex work, sexual risk factors for HIV and facility based sexual and reproductive health (Dhana et al., 2014; Scorgie et al., 2012); size estimates of the FSW population globally (Vandepitte et al., 2006); sex workers' mobility (Platt, Grenfell, et al., 2013); community empowerment approaches (Kerrigan, Fonner, et al., 2013; Moore et al., 2014); STIs and their control (Cwikel, Lazer, Press, \& Lazer, 2008)), impact of interventions on condom use in varied sexual partnerships i.e. youths, married/steady, casual and commercial (Foss, Hossain, Vickerman, \& Watts, 2007); and HIV prevention interventions in low and middle income countries in general (Hong \& Li, 2008; Shahmanesh, Patel, Mabey, \& Cowan, 2008).

A previous review (Chersich et al., 2013) examined studies in sub-Saharan Africa aimed at reducing HIV transmission amongst FSWs. It broadly examined studies evaluating HIV prevention strategies for FSWs within sub-Saharan Africa but did not focus on behavioural interventions assessing the effectiveness and process outcomes related to condom use. FSWs bear a disproportionate HIV burden in sub-Saharan African and the effectiveness of correct 
and consistent condom use in the prevention of sexual transmission of HIV has been shown in various studies (Bukenya et al., 2013; Charania et al., 2011; Fitch et al., 2002; Weller, 2002). It is therefore crucial to review the design and effectiveness of behavioural interventions for FSWs in sub-Saharan Africa aimed at improving correct and consistent condom use to inform future research needs in HIV prevention programs. This review examines the intervention settings, delivery methods, intervention components and effect outcomes of behavioural interventions to improve correct and consistent condom use outcomes for the reduction of the sexual transmission of HIV among FSWs in sub-Saharan Africa providing a new perspective on post intervention condom use by FSWs and their sexual partners.

\section{Method}

A systematic review of behavioural interventions evaluating condom use outcomes was conducted to obtain insights into the effectiveness of different approaches adopted in interventions for the prevention of sexual transmission of HIV amongst FSWs in sub-Saharan Africa.

\section{Search Strategy}

Relevant studies were identified by conducting a comprehensive search of multiple databases; PubMed, CINAHL, Web of Science and PsycINFO. For all these databases consulted, the same sets of keywords were used to extract studies from the database. The first set included key words related to sex work (e.g. commercial sex worker, female sex worker, sex worker) and the second set included key words related to condom use, interventions, behaviour, STI or safe sex. A key word from the first set and a key word from the second set had to be in the title or abstract of the study. The search was limited to articles in English, published between 1990 and September 2016 as most studies published before 1990 will not reflect the current circumstances and realities of the HIV epidemic within the region. Documentation of significant achievements in HIV prevention and management gained prominence in the nineties and has continuously evolved since then.

Titles and abstracts of the identified studies were exported into an Endnote X6 reference manager. Furthermore, a hand-search of references cited in all eligible studies and previous 


\section{Chapter 3}

reviews was conducted to obtain additional articles (Chersich et al., 2013; Luchters et al., 2008; Steen et al., 2000; Williams, Lamson, Efem, Weir, \& Lamptey, 1992).

\section{Study Selection}

Effect studies were eligible for inclusion if they were conducted among FSWs in any subSaharan African country; reported condom use as one of the behavioural outcome measures; were peer reviewed primary research studies (e.g. editorials were excluded); described the evaluation of the intervention - independent of the design, although limited to quantitative data. During the selection of studies, it became apparent that some authors made a distinction between FSWs who self-identified as sex workers and those who did not. FSWs who selfidentified as sex workers were the participants of interest and data from FSWs who did not self-identify were excluded. The judgement of authors was relied upon in the inclusion of studies based on their definition of the sex workers. For studies in which the authors did not identify this, we assessed the article for eligibility.

The selection of eligible articles from the databases was carried out and disagreements resolved by discussion until consensus was reached on relevant articles. The extent of agreement by both researchers was reflected by the kappa statistics of 0.66 showing good agreement in the selection of eligible studies (Cochrane, 2011). The selection procedure consisted of three rounds: screening titles, screening abstracts, and full text analysis. A conservative approach was used; if one of the two researchers was in doubt based on the title, the article was taken to the next round assessing the abstract. If one of the two researchers were in doubt based on the abstract, the article was taken to the next round assessing the full text. The screening of the articles from the references was carried out by $\mathrm{UO}$ and $\mathrm{RC}$, using the same procedure as described above.

\section{Data Extraction and Analysis}

Data extraction was carried out by two researchers (UO and RC) using a data extraction form which extracted outcome measures (both effectiveness and process measures), target group, intervention setting, country, intervention and control description, study design, duration and follow up measures (Table 1). As a result of not excluding studies based on their design, a 
heterogeneous set of studies was included in this review. The quality of the selected studies was assessed using the Effective Public Health Practice Project tool (EPHPP, 2009) by ranking based on the study design conforming to the EPHPP quality checklist (i.e. 1. Randomised controlled trial - RCT; 2. Controlled clinical trial-CCT; 3. Cohort analytic (two groups); 4. Case-control; 5. Cohort (one group); 6. Time series). The Preferred Reporting Items for Systematic Reviews and Meta-Analyses (PRISMA) checklist was used to standardize the review approach and ensure relevant aspects of the review were included.

\section{Results}

\section{Search outcome}

The electronic search of the databases yielded 4,737 hits, after automated removal of duplicates, 4506 articles remained for the title review (Figure 1). Of these, 4,318 articles were excluded based on title and another 100 articles were excluded based on the abstract. A total of 97 articles were left for full text analysis. This analysis yielded 17 eligible articles from the search. An in-depth review of the references of some identified articles within the search yielded additional 3 articles that met the eligibility criteria.

\section{Study Design}

The EPHPP quality checklist was used to assess and categorise the design of the studies into four groups; five of the studies were evaluated using an RCT approach while the other interventions were evaluated using; one group pre/post-tests $(n=10)$, two group pre/post-tests $(n=2)$, and time series design $(n=3)$. Loss to follow-up was reported in 12 out of the 18 interventions with the attrition rates ranging from 6\%-63\%. Interventions having longer implementation timeframes (i.e., above one year) had higher attrition rates than interventions with short implementation timeframes.

\section{Effectiveness}

The 20 eligible articles described 18 behavioural interventions on HIV prevention with condom use as an outcome measure and the interventions were carried out with FSWs within subSaharan African countries. Fifteen interventions within this review reported significant increase in (male) condom use. 
Chapter 3

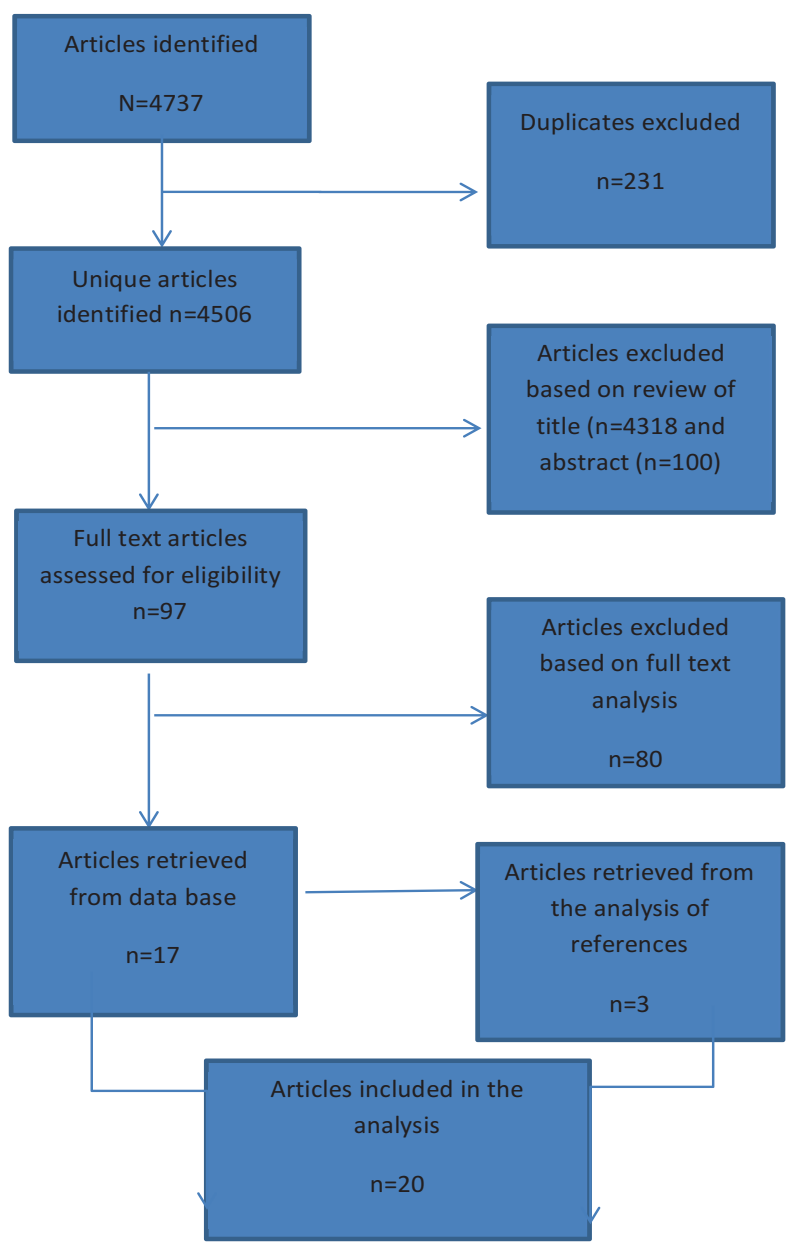

Figure 1: Study Selection Flow Chart 
The intervention strategies used for the behavioural components of the studies in the review varied. Twelve studies combined various methods for the delivery of condom use messages (Asamoah-Adu et al., 1994; Carney, Petersen Williams, \& Parry, 2016; Feldblum et al., 2005; Ghys et al., 2002; Luchters et al., 2008; Nagot et al., 2005; Ngugi et al., 2007; Ngugi, Wilson, Sebstad, Plummer, \& Moses, 1996; Parcesepe et al., 2016; Pickering, Quigley, Pépin, Todd, \& Wilkins, 1993 ; Williams et al., 2003; Williams et al., 1992). The methods used included peer education, health education by project staff and in one study (Williams et al., 1992) (brothel managers and owners were included. Ten studies used peer education for delivery of condom use messages while six studies within the review used only health or program staff for the delivery of condom use messages (Laga et al., 1994; Ray, van De Wijgert, Mason, Ndowa, \& Maposhere, 2001; Steen et al., 2000; Thomsen et al., 2006; Walden, Mwangulube, \& Makhumula-Nkhoma, 1999; Wechsberg, Luseno, Lam, Parry, \& Morojele, 2006).

Acceptability and increase in female condom use was measured in three of these studies in South Africa (Wechsberg et al., 2006), Zimbabwe (Ray et al., 2001) and Kenya (Thomsen et al., 2006) and all these three studies showed increases in female condom use after the intervention. Acceptability and increased use of female condom were self-reported using structured questionnaires. A focus group discussion conducted in one of the studies showed that the main barrier to female condom use was clients distrust of the unfamiliar method (Ray et al., 2001). All the studies used questionnaires as the quantitative method to assess outcomes and some studies validated the quantitative outcomes with qualitative studies (Ray et al., 2001; Walden et al., 1999).

Two studies in Gambia (Pickering et al., 1993 ) and South Africa (Williams et al., 2003) showed no overall increase in condom use. The Gambian study recorded an initial increase in the first month and a subsequent decrease over the remaining five months of the intervention. Five studies evaluated the condom use outcomes for paying partners, boyfriends and/or nonpaying intimate partners (Feldblum et al., 2005; Odek et al., 2009; Ray et al., 2001; Steen et al., 2000; Thomsen et al., 2006); most showed increase in condom use with both partners with the odds of condom use with clients being higher than with regular non-paying partners. Considerable loss to follow up was reported in some of the studies with a few showing high 


\section{Chapter 3}

attrition rates of greater than 50\% (Feldblum et al., 2005; Ngugi et al., 2007; Ray et al., 2001; Walden et al., 1999; Williams et al., 2003).

The interventions evaluated had different time frames ranging from one month to four years. Seven studies measured increased condom use at intervals within the intervention time frame ranging from six months to three years (Laga et al., 1994; Ngugi et al., 2007; Odek et al., 2009; Pickering et al., 1993 ; Ray et al., 2001; Steen et al., 2000). Six of these seven studies showed increased condom use during the intervention time frame. 


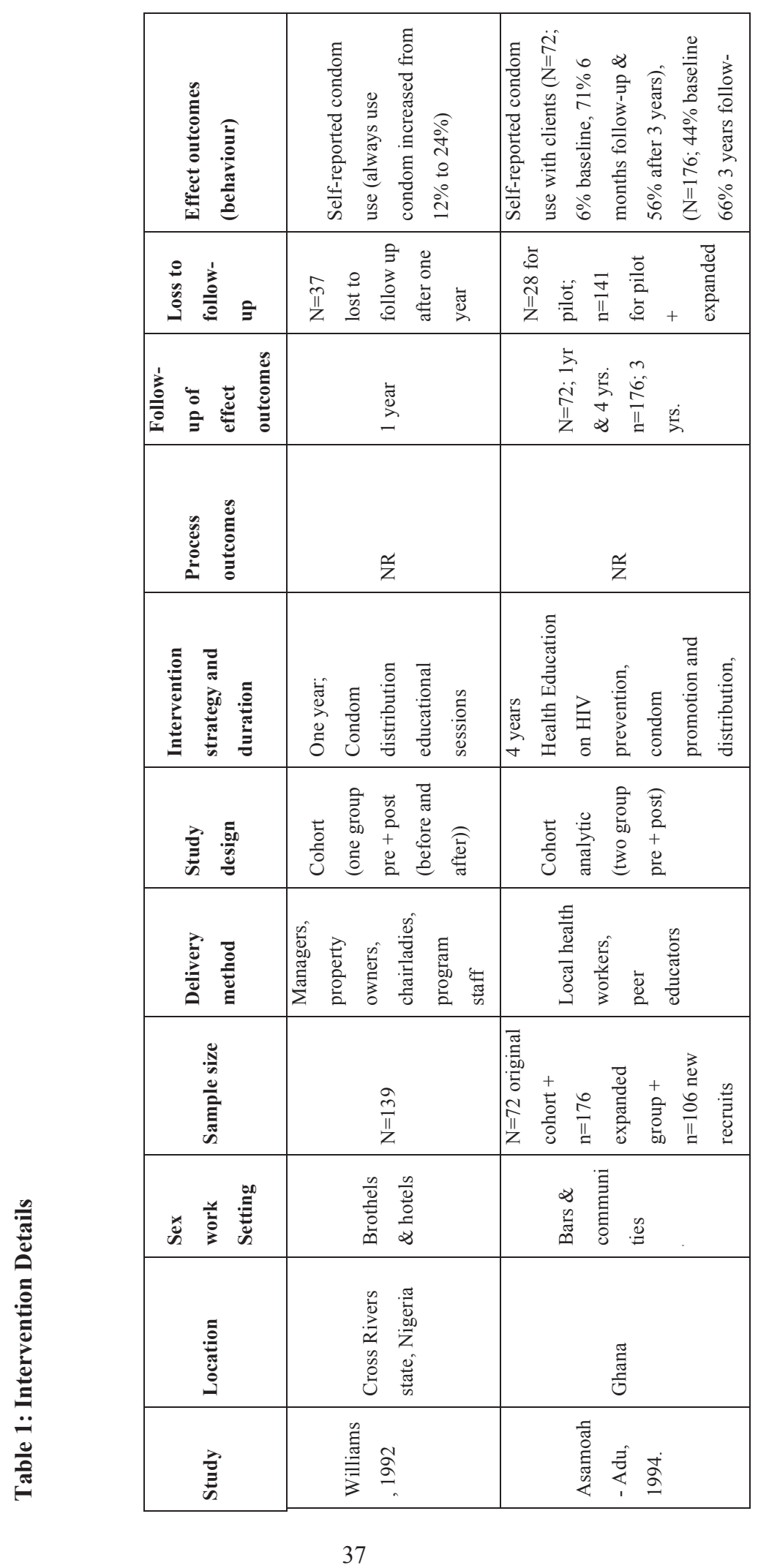




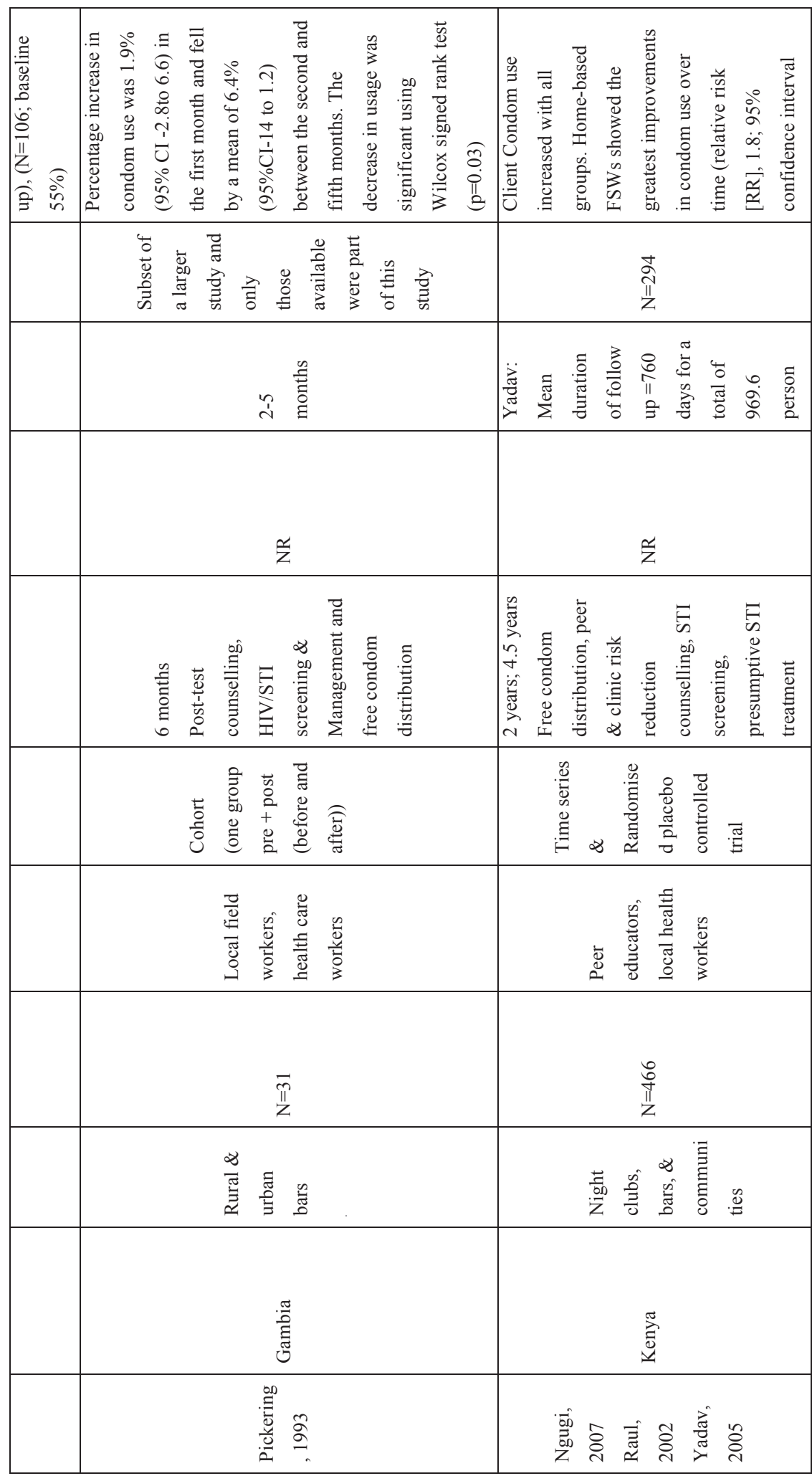




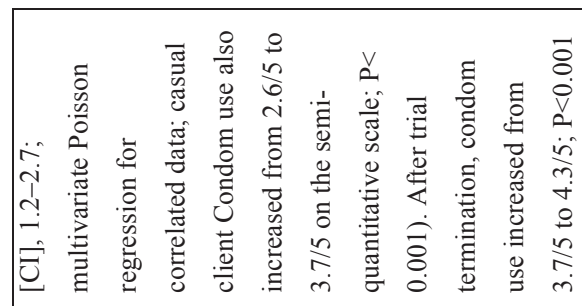

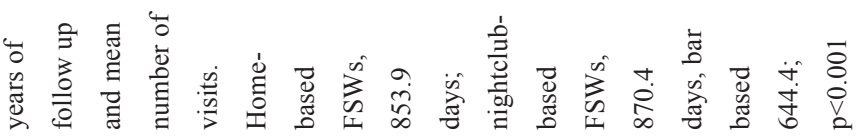




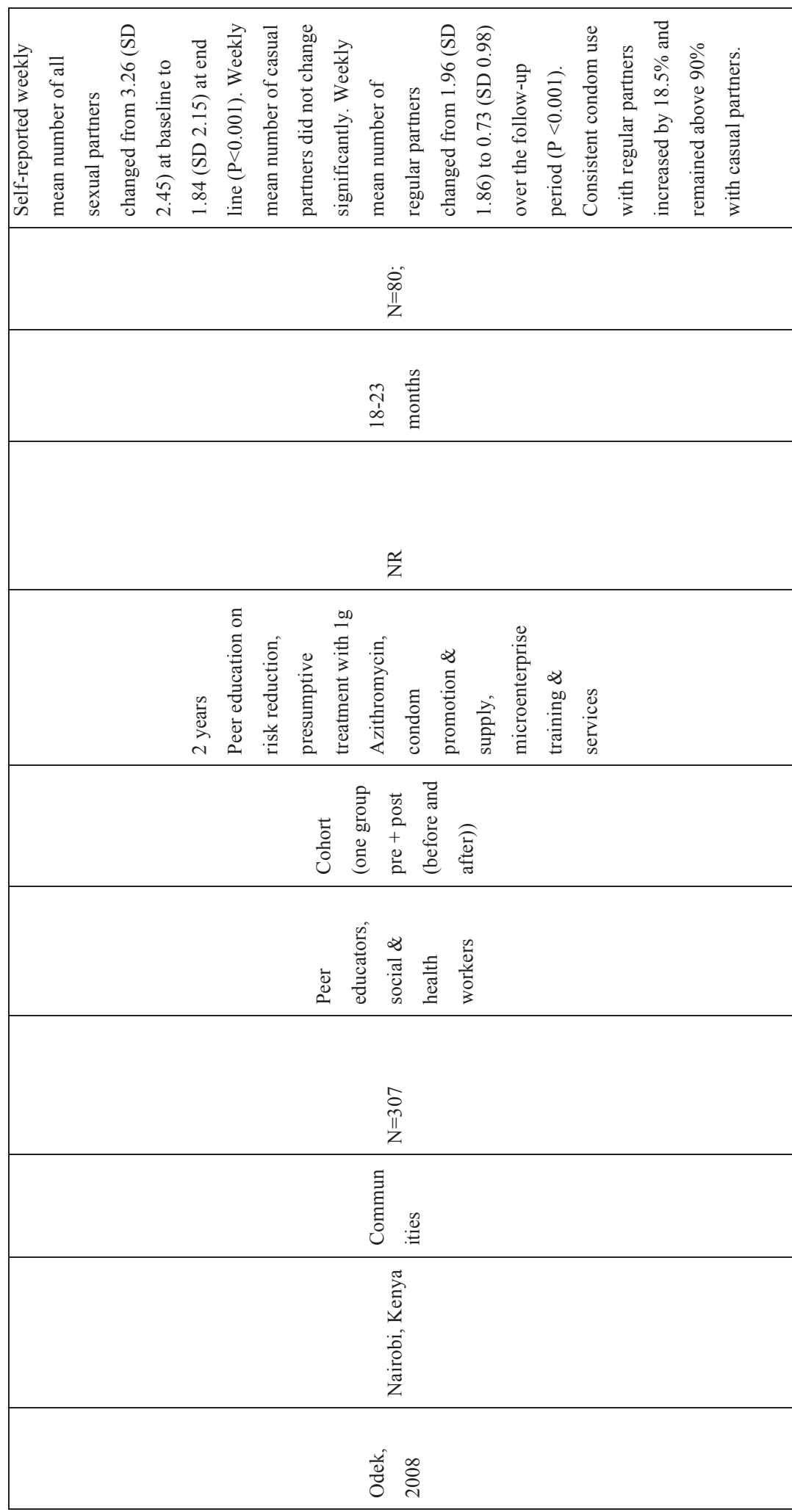




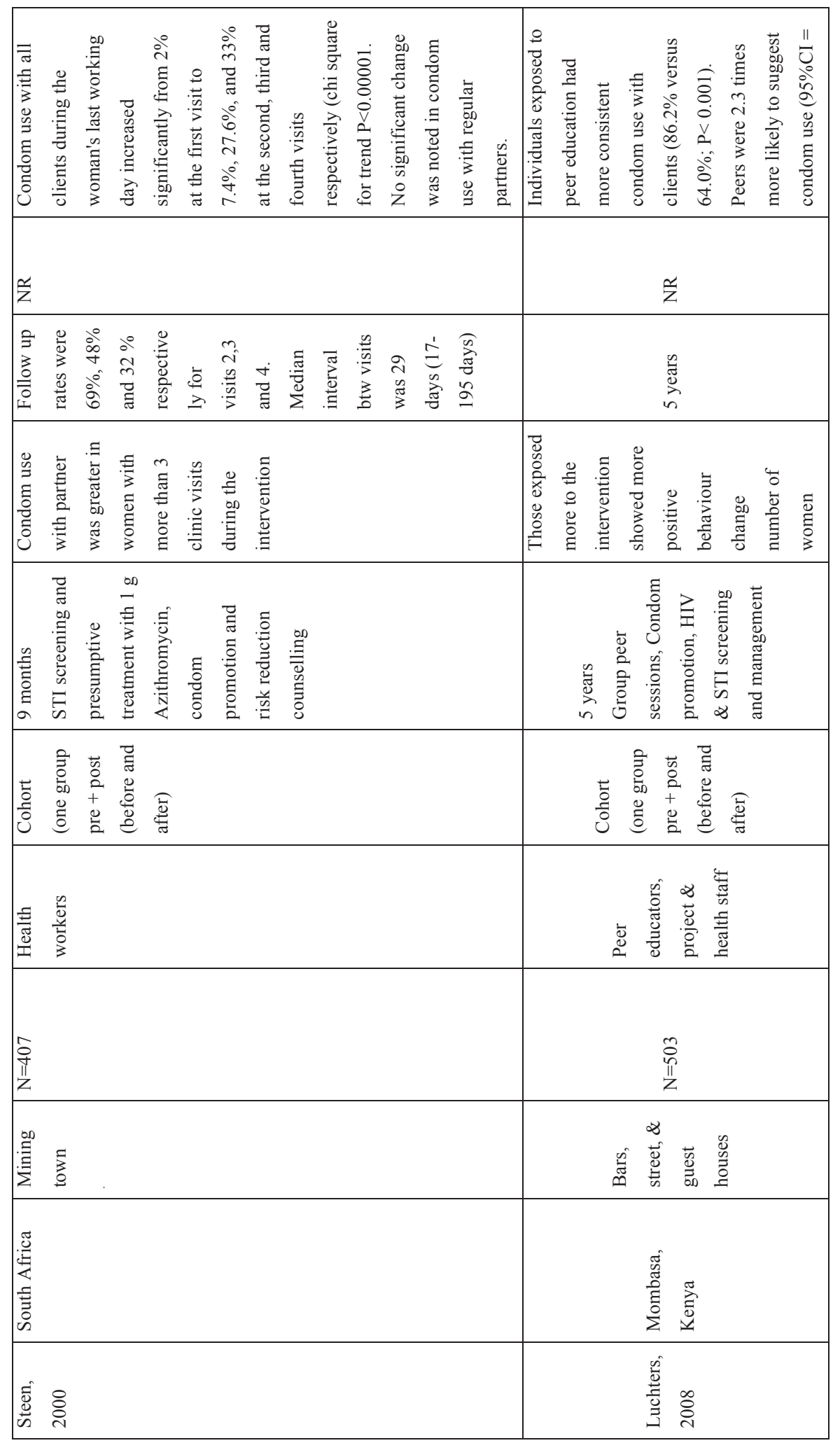




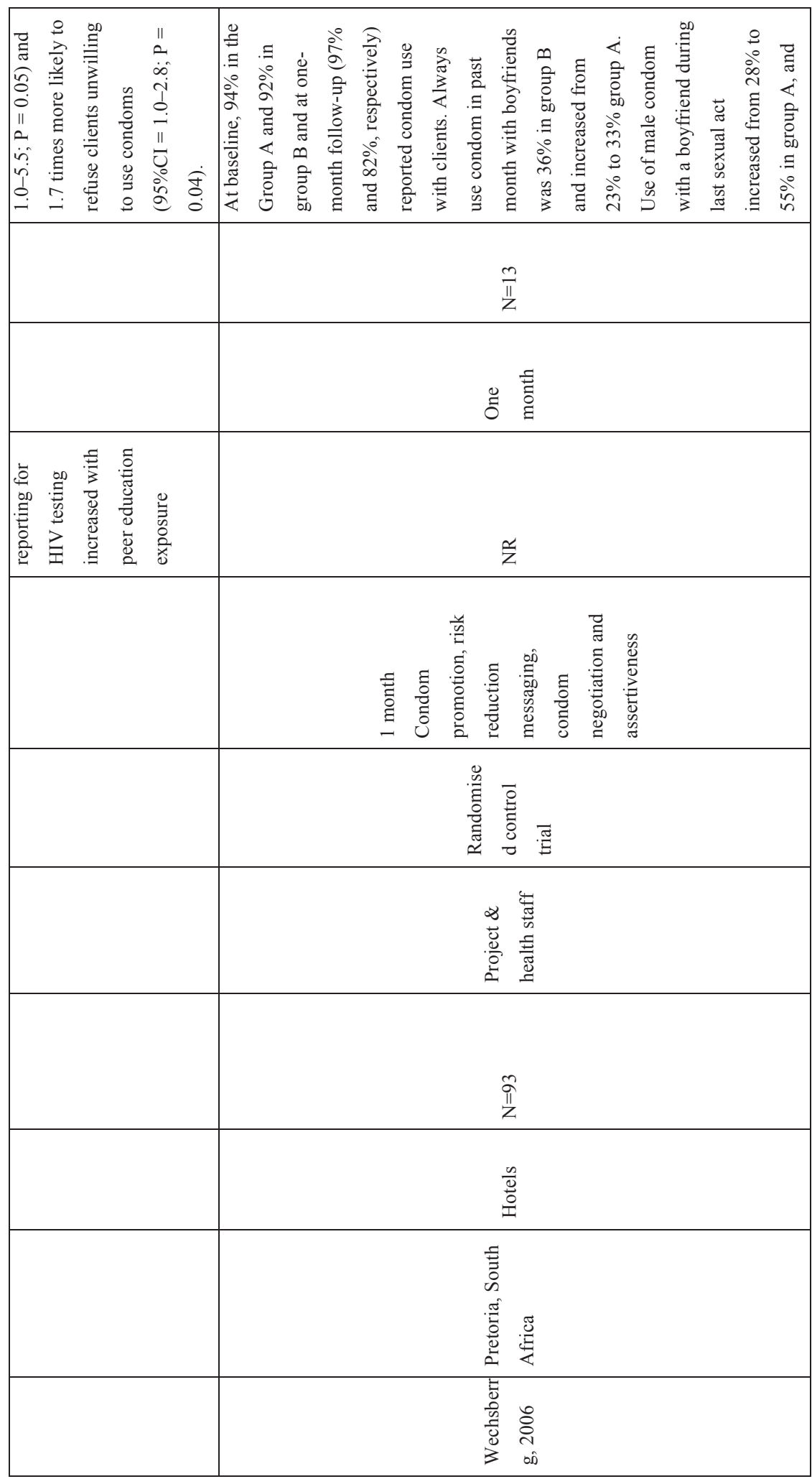




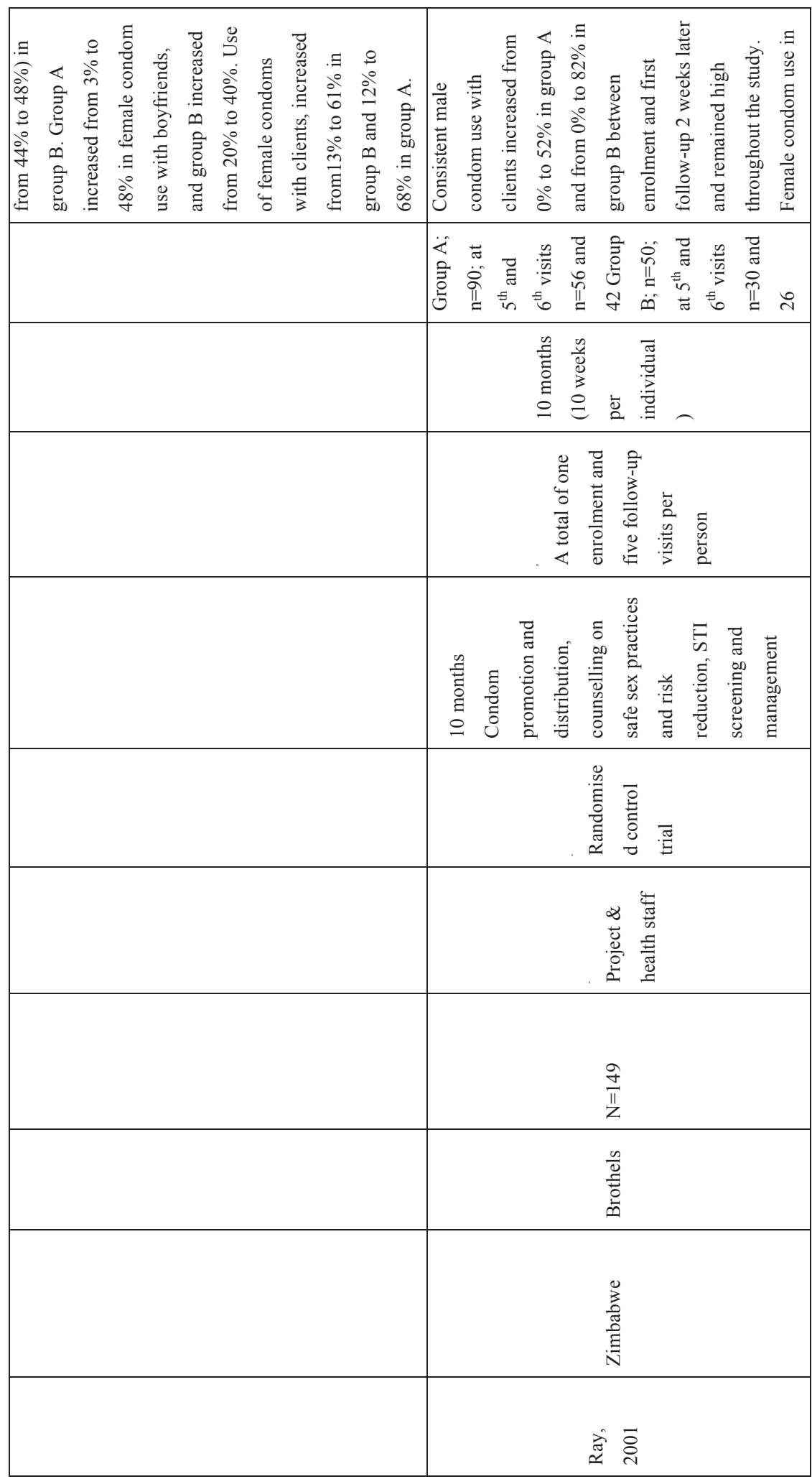




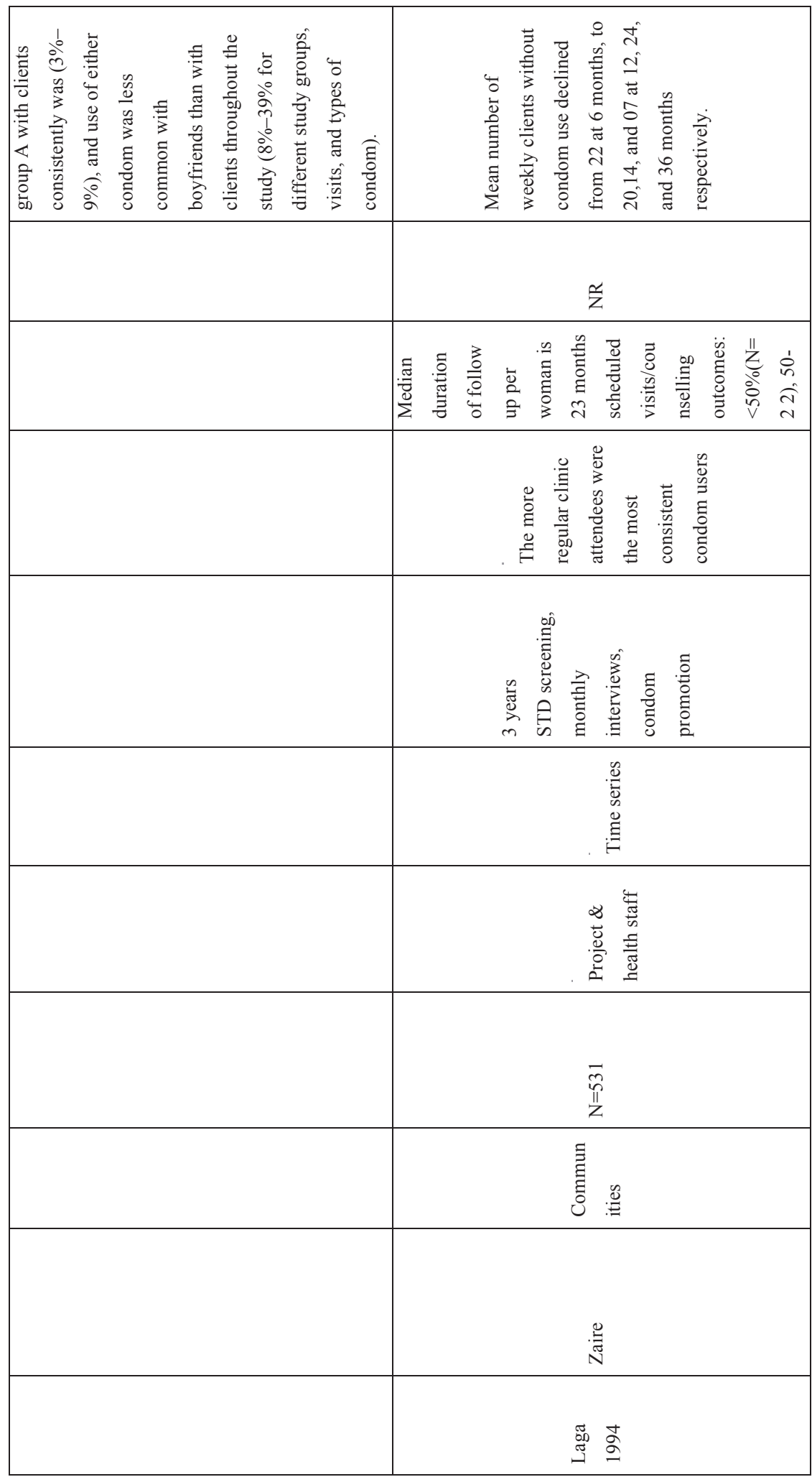




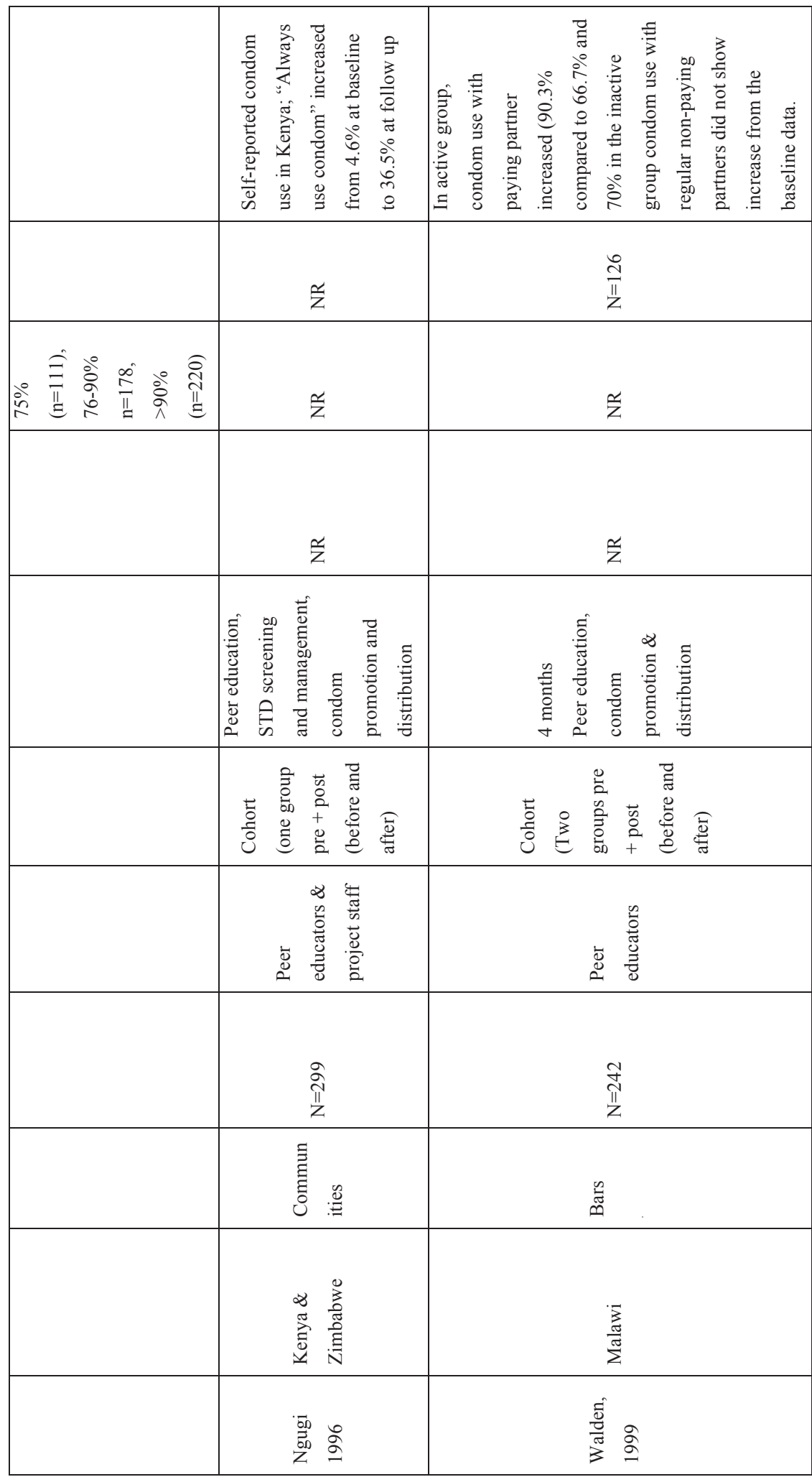




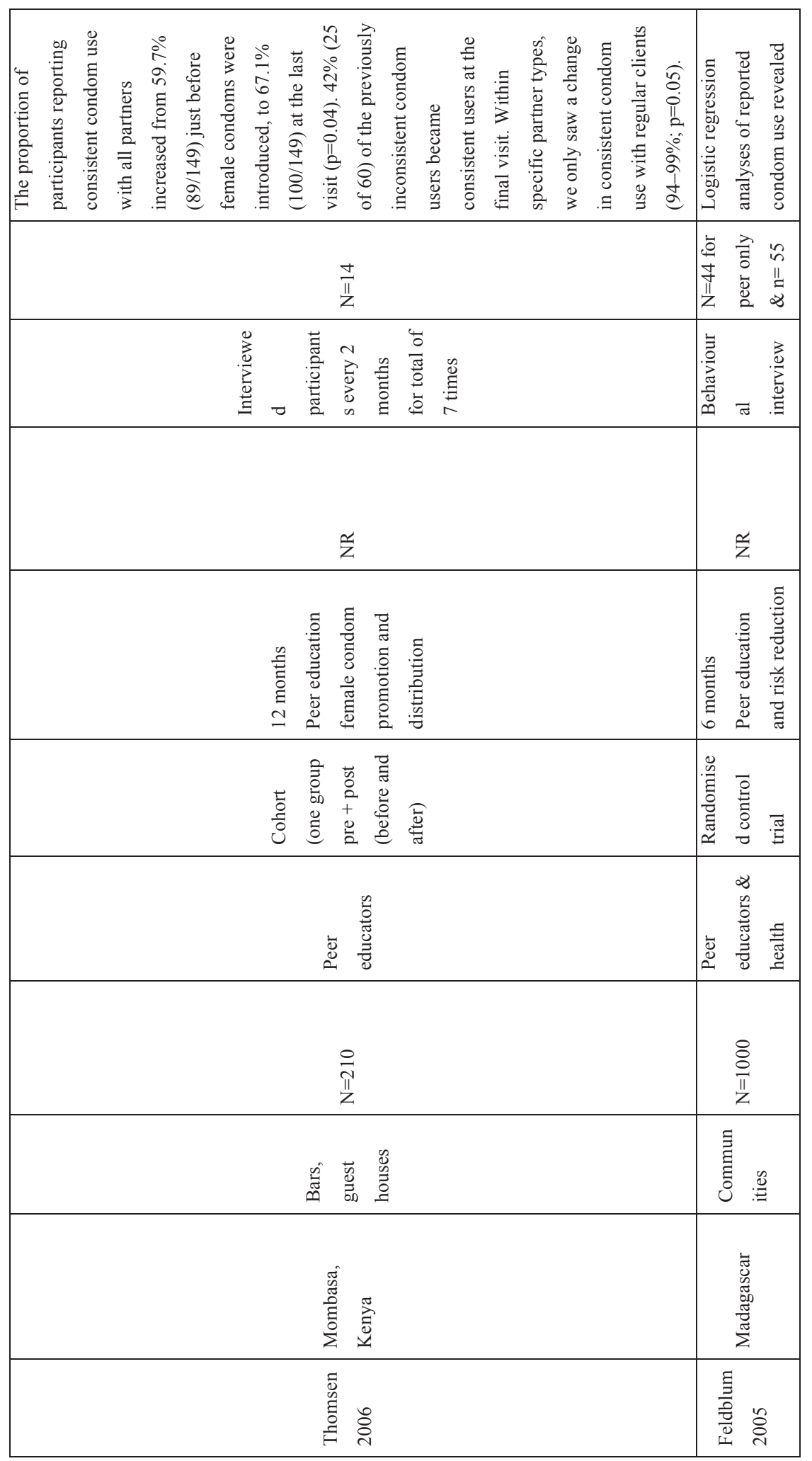




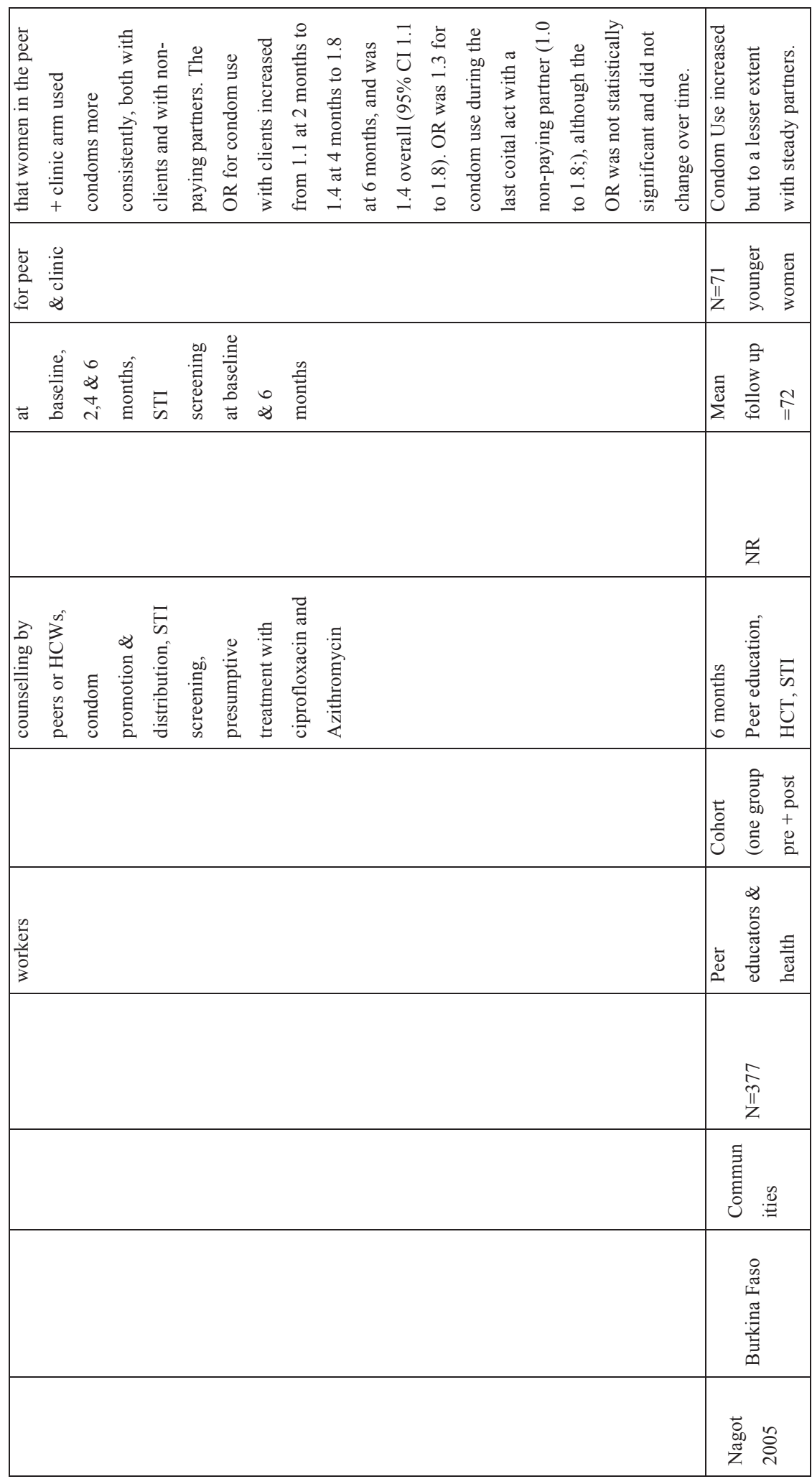




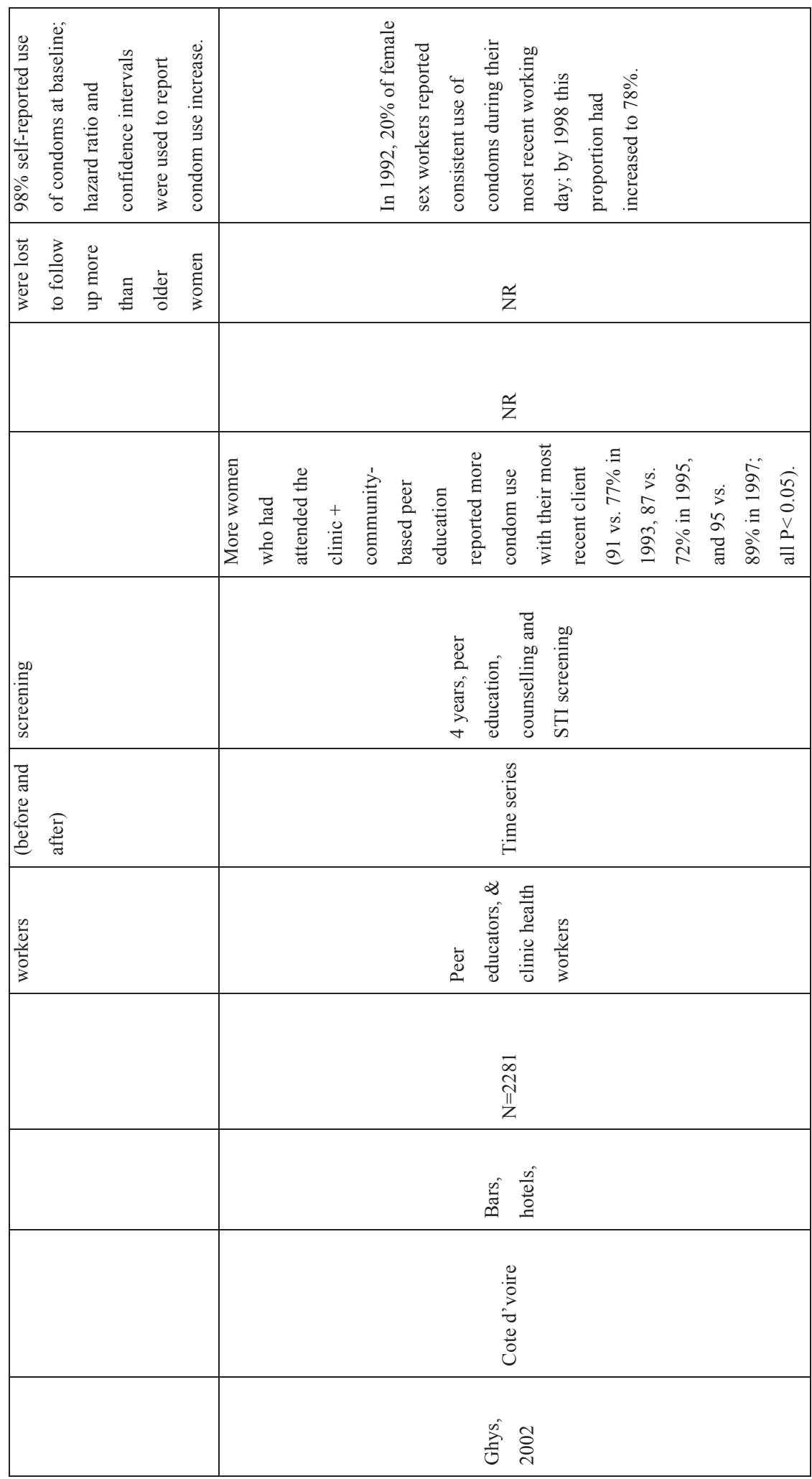




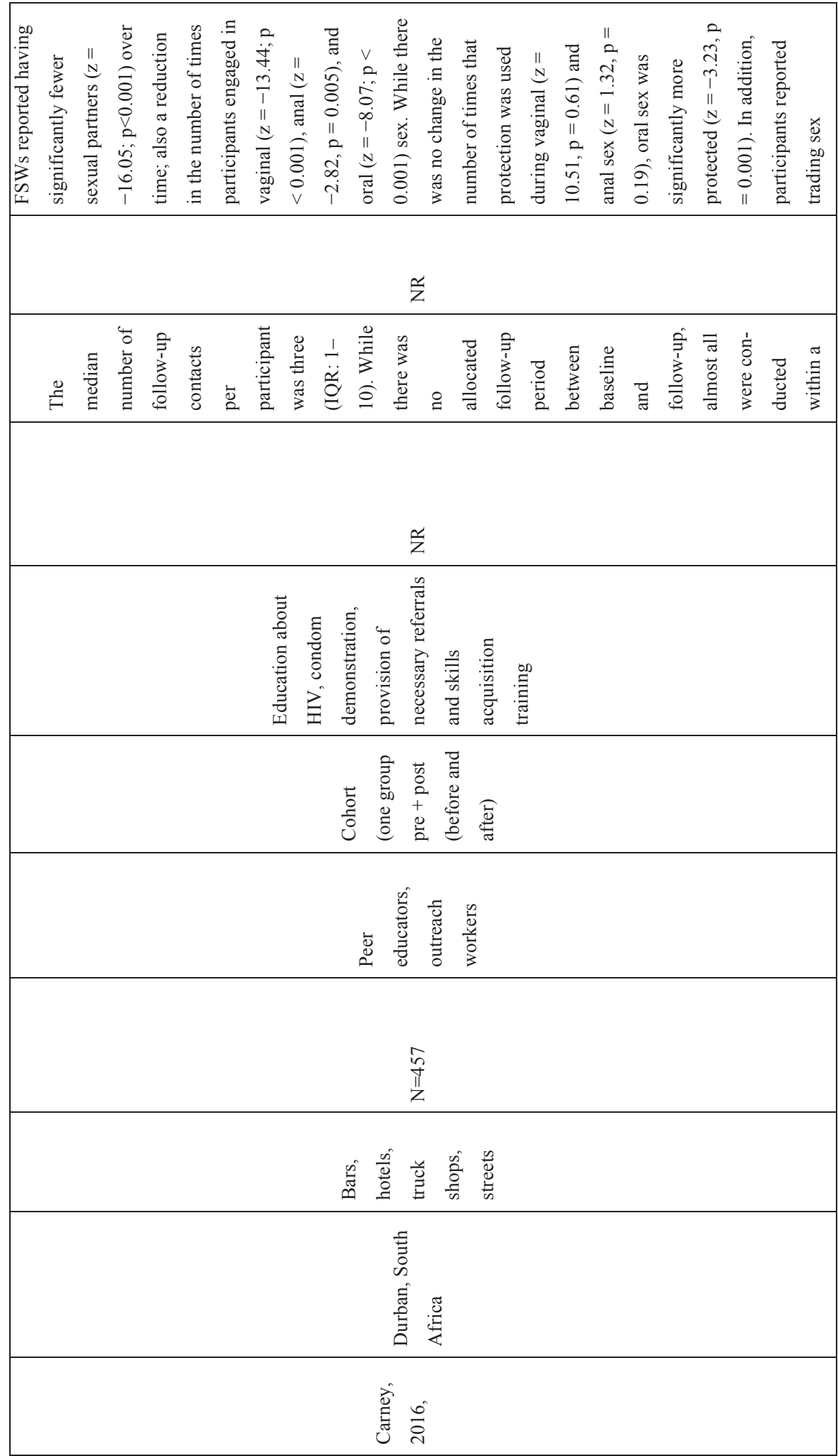




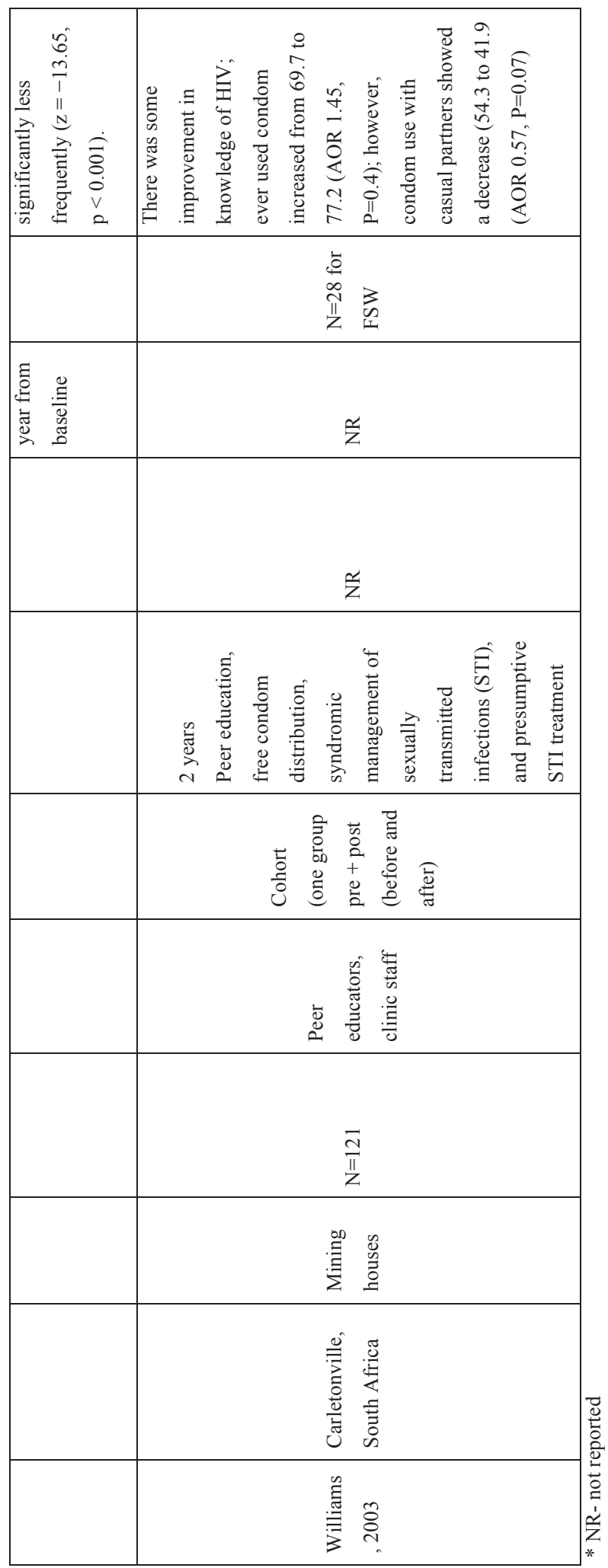


A systematic review of behavioural interventions promoting condom use among FSWs in SSA

\section{Intervention Content}

The intervention settings included brothels, bars, hotels, mining towns, clinics or communities where FSW reside. The intervention contents did not differ based on sex work setting or sex work type, however, a few studies (Feldblum et al., 2005; Ngugi et al., 2007; Odek et al., 2009; Steen et al., 2000; Williams et al., 2003; Yadav, Saskin, \& Ngugi, 2005) combined behavioural interventions with presumptive treatment of STIs. Few studies reported the behavioural contents of the interventions and these include distribution of Information, Education and Communication (IEC) materials on sexual risk reduction and consistent condom use (Feldblum et al., 2005; Ghys et al., 2002; Wechsberg et al., 2006), educational and skills building sessions (Asamoah-Adu et al., 1994; Odek et al., 2009; Williams et al., 1992), post-test counselling, risk reduction sessions, condom promotion and distribution using peer mediation approaches and counselling by health staff (Asamoah-Adu et al., 1994; Feldblum et al., 2005; Laga et al., 1994; Luchters et al., 2008; Nagot et al., 2005; Ngugi et al., 2007; Ngugi et al., 1996; Odek et al., 2009; Pickering et al., 1993 ; Ray et al., 2001; Steen et al., 2000; Thomsen et al., 2006; Walden et al., 1999).

In one study, key influencers within the FSW environment were used for condom promotion and the dissemination of risk reduction messages i.e. brothel owners and managers (Williams et al., 1992). Two studies combined community empowerment activities within the behavioural interventions (Carney et al., 2016; Odek et al., 2009), however, the added value of these components in relation to increased condom use were not evaluated in any of the studies.

\section{Process outcomes}

Process outcomes were reported by some interventions within this review. Five studies conducted in Zaire (Laga et al., 1994), Cote d'Ivoire (Ghys et al., 2002) and Kenya (Ngugi et al., 2007; Odek et al., 2009; Raul et al., 2002; Yadav et al., 2005) linked the process outcomes to the effectiveness of the interventions. Condom use with different FSW partner types (boyfriends, non-paying partners and paying clients) were evaluated in some interventions. Increased consistent use of condoms with clients of FSWs was 


\section{Chapter 3}

reported in some studies, with some studies showing a decline (Pickering et al., 1993 ) or no significant increase (Steen et al., 2000; Williams et al., 2003). Some studies measured the increase in condom use for different FSW partner types and consistent condom use was less with intimate partners of FSWs (boyfriends and non-paying regular partners) compared to paying clients (Feldblum et al., 2005; Nagot et al., 2005; Ngugi et al., 2007; Odek et al., 2009; Raul et al., 2002; Ray et al., 2001; Steen et al., 2000; Thomsen et al., 2006; Wechsberg et al., 2006). Exposure to the interventions, number of clinic visits and number of peer-mediated sessions attended by the FSWs were linked to increase in condom use with paying clients, boyfriends and non-paying partners within five interventions (Ghys et al., 2002; Laga et al., 1994; Luchters et al., 2008; Odek et al., 2009; Steen et al., 2000).

\section{Discussion}

Correct and consistent condom use has been identified as an effective means of preventing sexual transmission of HIV (Zhao et al., 2008). However, it is suggested that its effectiveness can be limited by breakage and slippage during sexual acts due to incorrect use, although none of the included studies mentioned this explicitly. Measuring this outcome is key in determining the effectiveness of condom promotion activities within behavioural interventions (Asamoah-Adu et al., 1994).

The interventions measured self-reported condom use outcomes and all but two (Pickering et al., 1993 ; Williams et al., 2003) studies reported significant increases in condom use with clients of FSWs. Condom use with the different FSW partner types were evaluated within the studies; regular non-paying partners, boyfriends and paying partners. Condom use with regular non-paying partners and boyfriends were reported to be lower and less consistent than condom use with paying partners. This finding is consistent with other studies reporting similar outcomes in condom use by FSWs with regular or non-paying clients (Johnson, von Haefton, Fishbeina, Kasprzykb, \& Montanob, 2001; Kayembe et al., 2008; Stoebenau, Hindin, Nathanson, Rakotoarison, \& Razafintsalama, 2009; Voeten, Egesah, Varkevisser, \& Habbema, 2007; Wang et al., 2007). This trend could compromise on-going efforts to address the HIV epidemic in 
sub-Saharan Africa. A possible explanation for inconsistent condom use by FSWs with steady partners compared to paying clients may be the need to create a psychological distinction between their personal life and work life; Another explanation may be the fear of rejection by their steady partners and the fear of humiliation and physical violence (Ulibarri et al., 2012; Varga, 1997). Gender-based power imbalances within these relationships may also constrain the FSW's ability to negotiate condom use out of fear of violent retribution (Ulibarri, Strathdee, Lozada, \& Magis-Rodriguez, 2010) Hence, it is important that behavioural interventions prioritize steady partners of FSWs and adopt approaches to address the reasons and vulnerabilities associated with inconsistent condom use with them.

The Treatment as Prevention (TASP) approach for the reduction of HIV transmission rates by increasing identification, treatment and care has shown some potential. However, correct and consistent condom use remains a more effective approach since the effectiveness of treatment as prevention relies heavily on treatment adherence. Poor access to health care by FSWs, stigma, costs and drug resistant HIV strains continue to hinder treatment outcomes (Bekker et al., 2015). An over statement of this approach can also result in negative public health impacts by encouraging more risky sexual behaviour by FSWs and reversing achievements made thus far in the use of other effective HIV prevention approaches like correct and consistent condom use (Smith et al., 2011; Venkatesh, Flanigan, \& Mayer, 2011; WHO, 2016a).

The content of the behavioural interventions reviewed was diverse and included condom promotion, distribution and risk reduction; provision of information using peer educators, distribution of IEC materials as well as counselling sessions on HIV testing and risk reduction with health workers or program staff. The intervention types and delivery methods used did not vary with sex work type or setting. Alternatively, the ease of reach and participation in intervention activities differed with sex work settings. Sex workers within enclosed locations are easier to reach for sustained periods compared to those scattered within a community or town (Kerrigan, Fonner, et al., 2013; NACA, 2014). A delivery method common to most of the interventions within 


\section{Chapter 3}

this review is the peer mediation for risk reduction and condom promotion activities with free condoms provided by peers and health workers. Only one study deploying this method reported non-sustained increase in condom use within the intervention timeframe. This supports the findings from similar studies that condom promotion and distribution is an effective component of interventions aimed at increasing condom use among FSWs (Charania et al., 2011; Sandoy, Zyaambo, Michelo, \& Fylkesnes, 2012) with additional benefits offered when mediated by peers (Adu-Oppong, Grimes, Ross, Risser, \& Kessie, 2007; Weller, 2002; Zhao et al., 2008). The inclusion of brothel owners, manager and pimps in condom promotion activities was adopted in only one study with demonstrated increase in condom use. Some studies have explored associations between condom use and social or environmental factors, including influence of gatekeepers and the working environment of FSWs ( $\mathrm{Li}$ et al., 2010; Morisky, Stein, Chiao, Ksobiech, \& Malow, 2006; Qiao et al., 2015; Yang et al., 2005). These studies showed that combined interventions that educate FSWs and improve gatekeeper support promote positive condom use outcomes in sex work settings as well as create a supportive environment for HIV prevention efforts. A few studies conducted in Kenya (Ngugi et al., 2007; Odek et al., 2009; Williams et al., 2003; Yadav et al., 2005), South Africa (Steen et al., 2000; Williams et al., 2003) and Madagascar (Feldblum et al., 2005) combined HIV/STI screening with presumptive treatment of STIs and condom promotion and reported consistent increase in condom use with clients with one exception which showed a decrease in condom use by casual partners (Williams et al., 2003), These finding extend those of some published studies reporting the possibility that FSWs who know their HIV/STI status take better care of their health by having less sexual partners and using condoms consistently (Zhang et al., 2011; Zhao, Song, \& Ren, 2012).

Various environmental and structural approaches targeted at reducing the vulnerability of FSWs were included within the intervention mix of a few studies within this review. However, no study evaluated their added value in increasing condom use or any other outcome within the intervention. Environmental factors influencing the sexual behaviour of FSWs i.e. behaviour of pimps, brothel managers, and law enforcement 
agents as well as societal norms, laws and policies have been shown in other studies to significantly influence the outcome of interventions targeted at FSWs (Bartholomew et al., 2011). Recommendations by experts indicate that an integrated approach to HIV prevention that incorporate evaluated activities addressing structural and environmental factors in addition to individual factors that increase susceptibility to HIV infection and undermine prevention and treatment efforts is important and should be considered by programmers and researchers (Bekker et al., 2015; Charania et al., 2011; Kerrigan, Fonner, et al., 2013; Seeley et al., 2012; UNAIDS, 2010).

Most studies within the review used the cohort design (pre-test, post-test) in achieving the set outcomes of behaviour change with FSWs. The cohort study by Thomsen et al explained that the high possibility of cross exposure within the small FSW community for the intervention necessitated the selection of the cohort (pre-test post-test) study design (Thomsen et al., 2006). Only three studies employed an RCT design (Feldblum et al., 2005; Ray et al., 2001; Wechsberg et al., 2006) with the control groups being active controls exposed to a standard intervention mix. The intervention groups were exposed to the standard mix and additional intervention activities. When both the control and the intervention groups receive the standard intervention, significant behavioural effects are harder to detect in comparison with a waiting-list control group. Consistent with the three RCT studies and supported by existing literature, effects can only be seen if the intervention uses activities that are not yet part of the standard intervention in the control group (de Bruin et al., 2010).

Although the RCT design is preferred, individual randomisation of sex workers for behavioural interventions is difficult and impracticable within brothels and communities as the behavioural interventions are difficult to individualize. Participants within the same brothel/group can influence their peers irrespective of what type of intervention they receive. Cluster randomisation is more practicable but complicates design and analysis as it introduces dependence among individual units within the intervention. 


\section{Chapter 3}

Loss to follow-up was high in interventions with duration longer than one year mainly due to the high mobility of sex workers. The mobility of the FSW population makes it very difficult to sustain interventions for long periods suggesting that more creative approaches for engaging with sex workers who are mobile could also be considered (e.g., mobile phones, maintaining contact information or setting up linkages with clinics in different cities). For researchers to be able to assess the effectiveness of interventions, the interventions need to be carried out continuously within a particular location to ensure that new entrants to that location are exposed to the intervention and can replace those who have been lost to follow-up. The mobility of sex workers further distorts the validity of some studies especially long-term studies as high attrition rates of about $50 \%$ were reported in some of the studies (Feldblum et al., 2005; Ngugi et al., 2007; Ray et al., 2001; Walden et al., 1999).

\section{Limitations}

A limitation of this systematic review is the exclusion of studies on women who did not self-identify as sex workers. The definitions used by the authors as well as their judgment were relied upon for the exclusion of interventions carried out with high-risk women who were not explicit about the nature of their work and sexual behaviour. The inclusion and exclusion criteria: searching for published studies only as well as only articles published in English might have led to the exclusion of other relevant studies. The use of self-reported data in the studies may have limited the reporting of risk behaviour and condom use outcomes due to social stigma and social desirability bias.

Over the past decade, tremendous changes to HIV programming have occurred in subSaharan Africa. Studies carried out before these changes in HIV programming occurred, may be limited in scope and application due to the low understanding of HIV infection among the population and the limited programming prevalent during the period. 


\section{Recommendation for Research and Practice}

Similar reviews of condom use outcomes in behavioural interventions amongst FSWs in other regions of the world are limited. It is important to explore this further and provide much needed information on the effectiveness of condom promotion activities in these regions to inform future research. The integration of individual, environmental and structural approaches within HIV prevention programming facilitates correct and consistent condom use and other important drivers such as reduction of stigma, discrimination, violence and police harassments (WHO, 2011a). Furthermore, HIVprevention interventions targeting FSWs should address correct and consistent condom use with regular partners as well as their paying clients to enhance prevention efforts against HIV/AIDS.

\section{Conclusion}

Behavioural interventions promoting consistent condom use amongst FSWs have been shown to be effective in the adoption of appropriate condom use behaviours. Consistent and correct use of condom remains one of the most effective methods for the reduction of sexual transmission of HIV. Thus, condom promotion components of behavioural interventions are important to enhance HIV prevention efforts. Sufficient evidence exists illustrating the effectiveness of behavioural interventions targeting consistent condom use by FSWs with their sexual partners. HIV prevention programs should in addition to behavioural interventions with condom use also incorporate other biomedical, social and structural components that address pertinent issues within the sex workers' environment affecting their risks and behaviour. 



\section{CHAPTER 4}

Study Protocol: Using brothel leadership to promote condom use among brothel based Female Sex Workers in Abuja, Nigeria 


\section{Abstract}

The HIV prevalence among female populations involved in sex work in Nigeria has heightened interest in HIV prevention programming for this sub-population with brothel based female sex workers having a prevalence of $27.4 \%$, six times higher than the prevalence in the general population. The clusters in the randomized pilot trial will be brothels and female sex workers residing in the brothels will be the participants of the study. The participants will receive free condom distribution as well as HIV prevention messages on condom use and negotiation skills to increase self-efficacy in handling social and gender power plays within their environment. Twelve brothels will be randomized into experimental and control conditions with a minimum total sample size of 200 participants. Recruitment of participants will be carried out from within the brothels. The control condition will receive a standard intervention consisting of a minimum of six interactive sessions with peer educators engaging their peers through group discussions and one on one interaction using pre-designed HIV prevention messages. The experimental condition will receive the standard intervention as well as interactive sessions with the brothel leadership (chairladies and brothel managers) to facilitate consistent condom use and appropriate condom use policies, conditions and messaging. Both interventions will be delivered over a maximum period of 16 weeks and male and female condoms will be distributed during the intervention. Quantitative assessments will be carried out at baseline and at 16 weeks follow up and the pilot findings will inform feasibility of and sample size estimation for a phase III trial. Consistent condom use outcomes by FSWs within the brothel with all partner types and enhanced self-efficacy for condom negotiation with all partner types will be the primary outcomes for the main study and the feasibility of their measurement will be determined in this pilot trial. Other primary outcomes measured to inform feasibility are recruitment rate, attrition rate and adherence to the intervention. The manuscript describes the protocol for a pilot study to determine the feasibility of a behavioural intervention to improve consistent condom use amongst BB FSWs.

\section{Published as}

Okafor, U. O., Crutzen, R., Adebajo, S., Okekearu, I., \& Borne, H. (2017). Using brothel leadership to promote condom use among brothel based Female Sex Workers in Abuja, Nigeria: Study protocol for a cluster randomized pilot trial. BMC Pilot and Feasibility Studies 3(10). doi:10.1186/s40814-017-0124-0 
The HIV epidemic continues to constitute serious socioeconomic and health challenges in SubSaharan Africa with Nigeria ranked second in the number of people living with HIV/AIDS after South Africa (UNAIDS, 2008). Female Sex Workers (FSWs) have been identified as a key population at risk of HIV transmission and directly, FSWs, injecting drug users and men who have sex with men constitute about $1 \%$ of the adult population but contribute about $23 \%$ of new HIV infections (Adeneye, Adeneye, Mafe, \& Adeiga, 2013; Asowa-Omorodion, 2000). The Integrated Biological and Behavioural Surveillance Survey (IBBSS) conducted by the Federal Ministry of Health in Nigeria in 2010 showed HIV prevalence of $27.4 \%$ and $21.7 \%$ among Brothel Based Female Sex Workers (BB FSWs) and Non-Brothel Based (NBB FSWs) respectively (FMOH, 2010).

Several studies conducted in Nigeria and other countries around the world indicate that the rate of FSW condom use with their steady partners is significantly lower than that with their paying clients (Adeneye et al., 2013; Adu-Oppong et al., 2007; Asowa-Omorodion, 2000; Ulibarri et al., 2012; Wang et al., 2007; Zhao et al., 2008). Steady partners (e.g. boyfriends, husbands, fiancés and regular paying partners) are distinct from clients and have different meanings to FSWs. They often wish to avoid rejection by steady partners in addition to the need to distinguish their work lives from their personal lives and to be trusted and loved (Varga, 1997; Zhao et al., 2008). The inconsistent use of condoms with steady partners is a barrier to effective HIV prevention for FSWs and their partners that needs to be overcome (Ulibarri et al., 2012).

Given the multifaceted nature of environmental factors influencing the sexual behaviour of FSWs in Nigeria, (Ulibarri et al., 2012) an important influential group for BB FSWs is the brothel leadership (brothel owners, managers, chairladies and madams). They are key power structures governing the immediate environment of the FSW and within the brothel sex work setting, they can make access to the sex workers easier and are useful in the communication of key messages and information. These individuals have been shown in some studies to effectively influence the sexual behaviour of FSWs whom they have direct influence over (Gruber von Kerenshazy, 2007; Mckee, Betrand, \& Becker, 2004). 


\section{Chapter 4}

We conducted two different studies as formative research for the development of an intervention aimed at increasing consistent condom use amongst FSWs. A systematic review of literature which showed the limited incorporation and measurement of the effect of using brothel leaders in condom promotion interventions (Okafor, Crutzen, Aduak, Adebajo, \& Van den Borne, 2017) for FSWs and an analysis of secondary data from the Integrated Biological and Behavioural Surveillance Survey (Okafor, Crutzen, Okekearu, Adebajo, \& Van Den Borne, 2017) revealing the vulnerability of the young sub-population of both BB FSWs and NBB FSWs with the BB FSWs showing comparatively higher vulnerability, HIV prevalence and risk profile.

This study aims to use a cluster randomized pilot trial approach to gain more insight into the potential of an intervention using brothel leadership to improve consistent condom use by FSWs residing in brothels. The objectives of this pilot study are to gain insight into:

1. the feasibility of implementing the intervention within brothels;

2. the attrition rate for FSWs residing within the brothels;

3. the potential effect of the intervention on consistent condom use for FSWs within the brothel with all partner types in order to inform a sample size estimation for an adequately powered phase III trial.

\section{Method and Design}

\section{Development process}

For the development of the intervention and to facilitate the design of appropriate activities for all levels of the intervention (individual, interpersonal and organizational levels), the intervention mapping approach was used (Bartholomew et al., 2011). A systematic review of literature and analysis of secondary data on FSWs provided information on the vulnerability of BB FSWs and the availability of limited information on the effect outcomes related to the inclusion of brothel leadership in condom use interventions for FSWs in Nigeria. A planning group was set up consisting of HIV prevention specialists, FSWs and brothel owners. All members of the planning group were engaged directly and several discussion sessions were conducted to obtain more insights into the target population, FSW community, existing programs and strategies successfully deployed for HIV prevention interventions. The HIV specialist panel consisted of seven experts; three females and four males. Five focus group 
discussions were conducted with FSWs residing in brothels within Abuja, Nigeria. An analysis of program details within an existing HIV prevention program; the Strengthening HIV Prevention Services for Most at Risk Populations (SHiPs for MARPS) project was also carried out. The SHiPs for MARPs project is a HIV prevention project in Nigeria funded by USAID and targeted at most at risk populations; FSWs, men who have sex with men and injecting drug users. The behavioural components of the project adopt peer mediated behavioural approaches to promote consistent condom use amongst BB FSWs and this component of the project served as the standard intervention for the pilot study. We brought together eight selected brothel leaders and presented components of the proposed intervention to them to get their insights on its suitability for the brothels. Using all the information obtained, we developed an intervention to improve consistent condom use by BB FSWs.

\section{Theoretical Model}

The theoretical model underlying the intervention process is the Social Cognitive Theory (SCT). The SCT postulates that people and their environment interact continuously and the environment shapes, maintains, and constrains behaviour; but people are not passive in the process, as they can create and change their environments (Glanz \& Viswanath, 2008). The SCT focuses on the individual, community and organizational levels that influence the individuals' power over their behaviour. The individual level is characterized by awareness and motivational determinants (i.e. knowledge, risk perception and self-efficacy). Self-efficacy is crucial in changing health behaviours and is proximal to preparing and deciding to act. The interpersonal/community level includes peer modelling for observational learning to enhance emulation of the desired behaviour by watching the actions and consequences for others who are credible role models of the targeted behaviour. The brothel owners, managers and chairladies are crucial agents at the organizational level to facilitate the existence of appropriate conditions conducive for improved self-efficacy and adoption of the required behaviour by providing appropriate support and materials. Their involvement is useful in facilitating the consistent use of condoms with clients and steady sexual partners of FSWs.

\section{Study Design and Setting}

The study will be conducted in Abuja, Nigeria and intervention components will be evaluated using a cluster randomized pilot trial approach, comparing a standard intervention (i.e., usual 


\section{Chapter 4}

care) to the standard intervention in combination with the brothel leadership intervention. Randomization of the study participants at the brothel level will be carried out to limit contamination between the two intervention groups. Clusters will be brothels with a minimum of 5 FSWs and presence of FSWs aged between 15-24 years of age. The criteria for inclusion into the study include: females who undertake sexual activities with men in return for money or benefits, who reside in brothels, who provide verbal informed consent as well as brothels with chairladies who provide consent for the study.

The structure of the study, key messages, monitoring tools and training slides were developed with information obtained from the formative studies and several meetings with the HIV prevention specialists. The messages and interactions for the intervention will focus on improving consistent condom use and condom negotiation self-efficacy of FSWs residing in brothels. The training of the brothel leaders will be carried out prior to the intervention and peer educators from the pool of trained peer educators within the existing SHiPs for MARPs project will be used. The activities for both the standard and the brothel leadership intervention groups will be implemented for 16 weeks and will include interactive sessions with the peer educators engaging their peers through group discussions and/or one on one interaction using predesigned HIV prevention messages. Male and female condoms will be distributed for free during the intervention period. Various studies have shown that the FSW population is a migrant population with high mobility (Kummarikunta, Mathapati, \& Halli, 2015; Wang, Chen, \& Sharp, 2010) and this poses a challenge during implementation for this target group. To minimize this and facilitate follow up of the girls within the intervention, the intervention will be carried out for 16 weeks and messages will be reinforced using information and communication materials (i.e. posters and leaflets with condom use messages).

\section{Sample size}

Based on recent experience in local brothels, we anticipate that there will be between 5 and 50 FSWs in each brothel. Since this is a pilot study with the aim of providing information on the feasibility, attrition rates and sample size estimates for a larger pilot trial, we aim to recruit 12 brothels. The formula provided by Viechtbauer et al (Viechtbauer et al., 2015) for the calculation of sample size required for a pilot study was applied in the determination of the sample size using a confidence interval of $95 \%$ and a $5 \%$ probability of existence of a problem. 
This resulted in a required sample size of 59 to enable the detection of feasibility problems. Due to the high attrition rate often reported in studies with FSWs and the lack of previous knowledge regarding clustering in brothels, it is unlikely that we will have all the recruited participants at follow up, thus we aim to recruit 200 participants to account for both aspects.

\section{Allocation Strategy}

The brothel is the unit of randomization and after baseline data collection, the brothels will be ordered alphabetically by name of brothel. Each brothel will be allocated a number sequence for random assignment to the experimental or the control conditions. To ensure balance in brothel size in both study groups, stratification by brothel size will be carried out to ensure mix of both large and small brothels in both groups. Allocation of brothels will be done by an independent member of the research team blind to the characteristics of the brothels and this individual will inform the pilot team on the status of each brothel. All FSWs within each selected brothel who give consent for the study will be eligible for enrolment in the study.

\section{Standard Intervention}

The Standard intervention is a behavioural intervention using the combination prevention approach consisting of peer mediated sessions on risks and vulnerabilities, condom use promotion and condom distribution. The peer sessions will be one-hour group discussions conducted within the brothel and each peer will be exposed to a minimum of six sessions during the intervention period. The peer sessions will be carried out within the brothel by selected FSWs trained as Peer Educators (PEs) by the project staff. Topics to be discussed during the group sessions include; life skills, sexuality, risk reduction, money and conflict management and consistent condom use. Project facilitators will be assigned to each brothel and the FSWs will be provided with hygiene kits, weekly distribution of female and male condoms and information on referral services available at drop in centres i.e. HIV Testing and Counselling (HTC) and syndromic management of Sexually Transmitted Infections (STIs). 


\section{Screening and recruitment}

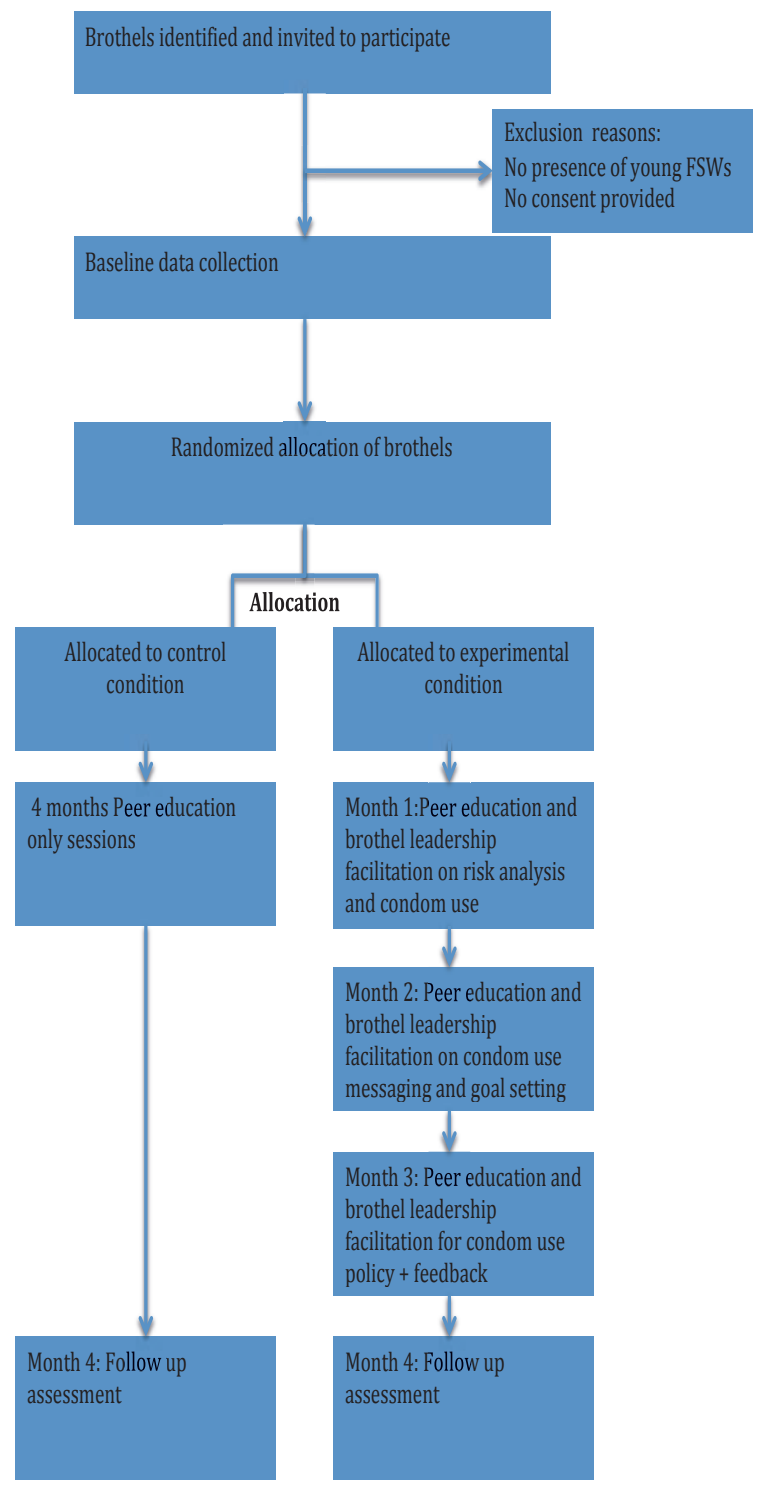

Figure 1: Study Flow chart 


\section{Brothel leadership intervention}

In addition to the activities described in the standard intervention, the pilot intervention will include using the brothel leadership (brothel managers, chairladies and owners) to deliver condom use messages to the FSWs and to promote a climate within the brothels for communication, condom negotiation and condom use with all sexual partners within the brothel. The messages and interactions for the intervention will focus on improving condom use and condom negotiation self-efficacy of the FSWs.

The messages will be differentiated to target the psychosocial issues surrounding condom use with the different partner types: clients and steady partners. These brothel leaders will be given a one-day workshop on facilitating the promotion of consistent condom use amongst the FSWs in their brothels using active learning and facilitation methods to encourage learning, identify barriers and facilitate consistent condom use. The workshop will be practice-oriented and provide opportunities to rehearse session delivery and condom demonstrations. The workshop will be facilitated by HIV prevention experts from the SHiPs for MARPs project with the modules covering the following topics: HIV knowledge, risk assessment and common misconceptions; discussions on benefits of condom use to the establishment and FSWs; group work on roles of gatekeepers for the improvement of condom use in brothels; role plays on condom demonstration and condom use negotiation. At the end of the workshop participants will be given leaflets showing the activities to be carried out by each brothel leader for the intervention. Project staff will also be assigned to support each brothel during the intervention period. After eight weeks, a refresher workshop will be conducted for the brothel leaders to discuss implementation milestones and issues encountered.

Brothel leaders are authority figures within the brothels and are able to regulate and oversee the activities of the peer educators and the FSWs within their brothels ensuring peer sessions are carried out and facilitating condom promotion activities within the brothel. Each leader will ensure that a minimum of six group sessions is carried out within the brothel. During these sessions, discussions on FSW's risk profile, condom demonstrations, free distribution of male and female condoms as well as the setting of rules and regulations to facilitate consistent condom use within the brothel will be carried out. New entrants within the brothel will also be taken under the wings of the brothel leaders to foster adherence by introducing them to the 


\section{Chapter 4}

consistent condom use policy in the brothel and supporting them to improve their self-efficacy in condom use. The group meetings by the brothel leadership will include all FSWs within the brothel and serve as platforms to address barriers to condom use and reinforce condom use through condom demonstrations. Posters and leaflets with condom use messages will be distributed and the chairladies and managers will be assisted at the end of the intervention to stock condoms for continued availability of condoms within the brothel.

\section{Consent Process}

The verbal consent process will be used to obtain consent for participation in the study as a result of the low literacy level of the FSWs. The interviewer will read the consent script to the participant. Once the script is read, the participant will be given time to ask questions. The participant will verbally agree to participate and the interviewer will sign the consent form indicating this verbal consent.

\section{Measurements}

The primary outcomes of this study are determining the feasibility of working with brothel leadership in deploying condom use messages within brothels (measurement: the number of brothels consenting to the intervention); the attrition rate of FSWs residing within the brothels (measurement: the proportion of FSWs and brothels completing the intervention in the intervention monitoring database); the adherence to intervention (measurement: number of sessions attended by each FSW). The secondary outcomes are to determine the feasibility of measuring the primary outcomes for the main trial (measurement: FSWs self-reported consistent condom use in the baseline and follow up assessments) and enhancing self-efficacy in condom use negotiation with all clients and partners of FSWs (measurement: FSWs selfreported self-efficacy regarding the ability to negotiate condom use with different partner types in the baseline and follow up assessments).

For the process outcomes, participants will be asked several questions at the end of the 16 weeks follow up period using interviewer administered semi-structured questionnaires. The process evaluation will measure the acceptability, suitability, content and mode of delivery (measurement: self-reported adequacy of the duration, content and delivery method of the intervention in the follow up assessment). 


\section{Statistical Analysis and Data management}

The overall recruitment and attrition rates of the brothels and participants for the intervention arm will be described. The Intra Cluster Correlation (ICC) and the effect size will be generated in addition to the attrition rates to enable sample size estimation required for a phase III trial. As the FSWs are nested in brothels, we will use a multilevel regression approach with three levels to assess the potential effects and the viability of the intervention on condom use behaviour. The first level consists of the repeated measures within the participants (baseline and follow-up measurements), the second level are the FSWs and the third level are the brothels, where the FSWs are nested.

Multilevel logistic regression will be used to analyse the effects on consistent condom use separately for steady partners and clients. The multilevel regression analysis was chosen because this allows for data missing at random, which is less strict than the requirement of data missing completely at random (Molenberghs \& Kenward, 2007). Each interviewed participant will be given a code and the questionnaires and data sets will be stored in a password-protected computer and only researchers will have access to the data.

\section{Discussion}

This paper presents the protocol that describes a pilot study to assess the feasibility and potential effects of an intervention aimed at increasing consistent condom use and improving condom negotiation skills of BB FSWs in Abuja, Nigeria. Should the current study demonstrate feasibility, outcomes can be used to design and inform a phase III pilot CRCT. The aim of the phase III pilot will be to further test the effectiveness of the behavioural intervention in improving consistent use of condoms by BB FSWs in Nigeria.

The mobility of sex workers is one of the challenges faced when programming for this target group (Wang et al., 2010). To minimize this, the intervention is designed such that the core messages and activities are delivered within a short time span, thereby enabling most of the FSWs to benefit from it before they may need to change their location. Formative research was conducted in collaboration with the target group and the brothel leaderships for the development of the interventions; this identified important issues for the development and relevance of the intervention. 


\section{Chapter 4}

Involving the brothel leaderships in the development process initially led to some resistance due to their perceived notion that the FSWs will become distracted and that they will lose the girls within their brothels. Assurance of the benefits of the intervention on the health of the FSWs and the reputation of the brothel establishment as a whole was provided. The brothel leaders were enthusiastic about the intervention and provided the needed support without which, it will be impossible to implement the intervention. 


\section{CHAPTER 5}

A cluster randomised pilot trial using

brothel leadership to improve condom use among brothel based female sex workers in Abuja, Nigeria 


\begin{abstract}
Support by brothel leaders and the promotion of a conducive environment for HIV prevention programs within brothel establishments are important to promote a safe working environment for brothel based female sex workers. This study assesses the effects of a cluster randomized pilot trial examining the use of brothel leaders to improve consistent condom use by FSWs residing in brothels and also assessed the feasibility of implementing a similar intervention on a broader scale. Ten brothels in Abuja, Nigeria were randomized and exposed to the experimental $(n=5)$ and control $(n=5)$ arms of the intervention. The feasibility of the intervention and consistent condom use outcomes by female sex workers with different partner types as well as condom negotiation self-efficacy were measured. Condom use outcomes and condom negotiation self-efficacy outcomes were analysed using multi-level mixed regression models. A total of 243 female sex workers were recruited into the study (control $n=66$ and experimental $n=177)$ and 107 of them (44\%) were available at 16 weeks follow-up. The intervention demonstrated feasibility and positive outcomes for consistent condom use with boyfriends and casual partners of female sex workers were obtained. The interaction effect between condition and time indicated increased consistent condom use with boyfriends in the experimental condition $(\mathrm{p}=0.02)$. Adherence to the intervention by the female sex workers was moderate with the mean sessions attended at $4.4(\mathrm{SD}=2.0)$. The attrition rate during the intervention was high due to mobility of the sex workers. The intervention showed feasibility and effect outcomes indicate promise in enhancing condom use with steady partners of brothel based female sex workers. The design of HIV prevention interventions may benefit from the inclusion of gatekeepers in the promotion of condom use within the brothel, but an adequately powered phase III trial is needed to inform large-scale implementation of this approach.
\end{abstract}

\title{
Published as
}

Uchenna O. Okafor, Rik Crutzen, Adebajo Sylvia, Okekearu Ifeanyi \& Bart Van den Borne. (2017) Using Brothel Leadership to Improve Condom Use among Brothel based Female Sex Workers in Abuja, Nigeria: Results of a Cluster Randomized Pilot Study. Global Journal of Health Science, 9(12) 
In Nigeria, Brothel Based Female Sex Workers (BB FSWs) have the second highest prevalence of HIV compared to other sub-populations within the country. The HIV prevalence for BB FSWs is twice that of their non-brothel based counterparts with prevalence rates of $19.4 \%$ and $8.6 \%$ respectively $(\mathrm{FMOH}, 2014)$. Although the HIV prevalence rate for BB FSWs has shown a decrease from 2010 to 2014, $(\mathrm{FMOH}, 2010,2014)$ the prevalence is still much higher than the general population prevalence of 3.4\% (FMOH, 2013). Furthermore, BB FSWs are reported to have higher number of clients and less correct knowledge about HIV transmission than the non-brothel based Female Sex Workers (NBB FSWs) in Nigeria (FMOH, 2014; Ikpeazu et al., 2014; Okafor, Crutzen, Okekearu, et al., 2017).

HIV transmission often involves the interaction of a range of social, community and institutional factors. Hence, HIV prevention efforts should incorporate at adequate scale these social and community level determinants in addition to the more widely used individualized approaches. Support by gatekeepers and the promotion of a conducive environment for HIV prevention programs within sex work establishments are key community and institutional factors that promote a safe working environment for FSWs and reduce their vulnerability to sexually transmitted infections including HIV/AIDs (Muñoz, Adedimeji, \& Olayemi, 2010; Richter, Chersich, Temmerman, \& Luchters, 2013).

At the individual level, behavioural factors such as unprotected sex are associated with increased vulnerability to HIV infection. Peer support and promotion of consistent condom use are core preventive strategies for the reduction of HIV and other sexually transmitted infections (STIs) among Female sex workers (FSWs) and their partners. Several studies have shown the effectiveness of behavioural interventions using peer mediated approaches to improve condom use among FSWs (Bhave et al., 1995; Feldblum et al., 2005; Ghys et al., 2002; Izugbara, 2007; Raul et al., 2002; Ray et al., 2001; Ulibarri et al., 2012; Wariki et al., 2012; Williams et al., 1992). Mobility of FSWs has also been shown by various studies to contribute to increased sexual risk behaviours by FSWs including the likelihood of unsafe sex and increased number of sexual partners (Kummarikunta et al., 2015; Wang et al., 2010). 


\section{Chapter 5}

Given the multifaceted factors influencing condom use amongst FSWs, social support from gatekeepers within the immediate environment of FSWs (i.e. brothel management, chairladies and owners of brothels) is a complex but important component in the promotion of safe working environment for FSWs residing in brothels (Dandona et al., 2015; Qiao et al., 2015; Yang et al., 2005). Previous studies have explored associations between condom use and social or environmental factors, including influence of gatekeepers and the working environment of FSWs (Li et al., 2010; Morisky et al., 2006; Qiao et al., 2015). These studies showed that combined interventions that educate FSWs and improve gatekeeper support promote positive condom use outcomes in sex work settings as well as create a supportive environment for HIV prevention efforts.

Environmental factors interact with individual cognitive factors to influence behaviour change. Educating and involving gatekeepers in the creation of a supportive environment for condom use and HIV prevention activities addresses components of such environmental factors i.e. influencing community and social norms within the FSW workplace as well as the enactment of consistent condom use regulations (Fawole \& Dagunduro, 2014; Hong et al., 2008; Kerrigan et al., 2003; Morisky et al., 2006; Yang et al., 2005; Zhang et al., 2011). Despite the availability of studies on the positive association between gatekeeper support and improvements in consistent condom use in Asia and the Philippines, limited information within the Nigerian context exists.

In the current study, we designed an intervention to assess the feasibility and effectiveness of including brothel leadership in the improvement of condom use outcomes by FSWs within the Nigerian commercial sex work context. The criminalization of sex work in the country and the social stigmatization of sex work necessitates a better understanding of prevalent environmental and structural barriers to using condoms (Kerrigan, Wirtz, et al., 2013). The stigmatization and criminalisation surrounding sex work in the country contributes to the mobility of FSWs and this makes it quite difficult to reach them with HIV prevention interventions for sustained periods thus posing significant challenges to prevention efforts (Fawole \& Dagunduro, 2014; NACA, 2014). This cluster randomized pilot study aims to gain more insight into the potentials of incorporating the supportive activities of brothel leaders in an intervention to improve 
A cluster randomised pilot trial using brothel leadership to improve condom use among FSWs consistent condom use by BB FSWs with all partners. Specific objectives of this study were to gain insights into:

1. the feasibility of recruiting brothel leaders and implementing the intervention

2. the attrition rate for female sex workers residing within the brothels;

3. the potential effect of the intervention on correct and consistent condom use outcomes for FSWs within brothels and with all partner types.

The outcomes will provide evidence to inform a larger phase III study and future HIV prevention efforts within the Nigerian context and beyond.

\section{Methods}

A cluster-randomized controlled trial was conducted randomizing brothels located in Abuja, Nigeria into experimental and control conditions. Randomization of the study participants at the brothel level was carried out to limit contamination between the two intervention groups. The control arm received a standard intervention while the experimental arm received the standard intervention combined with the brothel leadership intervention.

\section{Participants and Procedure}

FSWs were recruited from brothels in three communities in Abuja, the capital city of Nigeria and preliminary visits were paid to the brothel management and chairladies in charge of these brothels. Twelve brothels identified in these locations were selected and received invitation letters. The consent of the brothel management was sought after providing information about the study.

Brothels approached to participate in the study were randomly assigned to either the experimental or control conditions. Brothels were not blind to their condition as brothel leaders in the experimental condition were pooled together for trainings and discussions on the proposed intervention. One week before the start of the intervention, baseline information was collected from the FSWs residing in each brothel after informed consent was obtained. The brothel leaders in the experimental arm were provided with condoms and leaflets containing information on the intervention. FSWs were also provided with hygiene kits and weekly distribution of free male and female condoms all through the intervention duration. 


\section{Chapter 5}

\section{Inclusion Criteria}

The target group for the study consists of brothels within the three communities who provided consent for the study as well as females who reside in brothels; who reported sexual activities with men in exchange for money or benefits and provided verbal informed consent.

\section{Interventions}

Standard intervention: The messages and interactions for the intervention focus on improving consistent condom use. The standard intervention was a behavioural intervention for HIV prevention using peer sessions on risks and vulnerabilities, condom use promotion and condom distribution. Trained peer educators carried out one-hour group peer sessions weekly with the FSWs. Topics discussed during the group sessions include; life skills, sexuality, risk reduction, money and conflict management and consistent condom use. More detailed description of the interventions can be found in the protocol (Okafor, Crutzen, Adebajo, et al., 2017).

Brothel leadership intervention: In addition to the activities carried out in the standard intervention, the experimental group was exposed to the brothel leadership component which consisted of using trained brothel leaders (brothel managers, chairladies and owners) to deliver condom use messages to the FSWs and promote a conducive atmosphere within the brothels for communication condom negotiation and consistent condom use with all sexual partners within the brothel. The messages and interactions during the intervention focused on improving consistent condom use and self-efficacy in condom use negotiation. Brothel meetings were held weekly and each FSW was adequately exposed to the intervention when they had participated in six sessions. After 16 weeks, the FSWs in both conditions responded to the follow-up questionnaire administered by trained interviewers.

\section{Measurements}

Questionnaires were adapted from standardized models and survey instruments used in similar studies in Nigeria (FMOH, 2014; National Population Commission, 2014; UNAIDS, 2009a). Workshops were carried out with the interviewers and research specialists to discuss improvements to the assessment instrument as well as to train on questionnaire administration and the interviewing of illiterate participants. Assessments were carried out at baseline and 16 
weeks follow-up. At baseline, demographic characteristics of participants' age, marital status, educational attainment and availability of other sources of income were assessed. Knowledge of prevention of sexual transmission of HIV and rejection of major misconceptions were also assessed using the UNGASS indicator for most at risk populations (UNAIDS, 2009a). This consisted of five questions: Can one avoid getting HIV by using condoms every time? Can a healthy-looking person be HIV positive? Can one avoid HIV by staying faithful to an uninfected partner? (all true). And the following misconceptions: Can a person get HIV from mosquito bites? Can a person get HIV by sharing a toilet with an HIV infected person? (all false). The sum of the correctly answered knowledge questions was calculated (range: 0-5).

The primary outcomes of this study (in line with the objectives) are ease of recruitment of brothel leaders for condom use promotion and facilitation; the attrition rate of FSWs residing within the brothels; the evaluation of the intervention processes as well as the effect of the intervention on condoms use outcomes by FSWs with all partner types in order to inform adequate sample size estimation. Consistent condom use with different partner types was assessed with the questions; the last time you had sex with a client was a condom used and the last time you had sex with a non-paying partner was a condom used (ticked for boyfriend and casual partners separately). The responses were then dichotomized to 0 (No and Sometimes) and 1 (Yes). The secondary outcome of the study was enhancing condom negotiation selfefficacy with all clients and steady partners of FSWs. Condom negotiation self-efficacy was assessed with the questions: I feel confident in my ability to discuss condom use with my clients and I feel confident in my ability to discuss condom use with my boyfriend and casual partners. Participants had to respond on a five-point scale (0-4; strongly disagree-strongly agree).

Process outcomes were assessed during follow-up by asking the participants to respond "agree, disagree or neutral" to the following questions: the quality of the condom promotion activities in the brothels was good, the frequency of the monthly condom demonstration activities was adequate, the weekly brothel meeting is a suitable avenue for condom promotion activities, the condom promotion messages were adequate, the combination of peer education sessions and the condom promotion activities with the chairladies was effective, the chair ladies are effective facilitators of the condom promotion activities received in the brothel and the number of condoms received during the intervention was adequate. 


\section{Chapter 5}

\section{Analyses}

The ability to recruit brothels and its leadership for the intervention as well as adherence to the intervention by the FSWs was used to assess the feasibility of the study. Adherence was assessed by the number of intervention sessions (excluding the baseline or follow-up assessments) each FSW participated in (range 0-6). Attrition rates were calculated by the percentage of participants in the baseline assessment that were also present at the follow-up assessments.

The data were analysed using SPSS version 23. Descriptive statistics were used to describe the characteristics of the baseline sample. Differences between the conditions during baseline were assessed using $t$ tests for continuous variables and chi-square tests for discrete variables. This study constituted a design with 3 levels: The first level consisted of the repeated measures within the participants (baseline and follow-up measurements), the second level are the FSWs and the third level are the brothels, where the FSWs are nested. To determine the potential effectiveness of the program, we analysed the data with multi-level mixed logistic regression model for the outcomes condom use with clients, casual partners and boyfriends. Multi-level mixed linear regression model was used for the outcome self-efficacy (Bernhardt, Wang, \& Zhang, 2015; Sullivan, 2012). These models allow for dependencies among observations obtained for FSWs within a brothel as well as data missing at random (instead of completely at random) (Dziura, Post, Zhao, Fu, \& Peduzzi, 2013; Molenberghs \& Kenward, 2007). The effects of wave (baseline or follow-up) and condition, as well as their interaction were analysed; marital status, which differed between conditions at baseline (as described below), was entered as a predictor into the models. Main effects were considered significant if $P \leq .05$. Interaction effects were considered significant if $P \leq .10$.

\section{Ethical approval and consent to participate}

The study was approved by the Institutional Review Board (IRB) of the Institute of human virology, Nigeria. Protocol number: NHREC/10/15/2014a-026. Due to the illegal nature of sex work in the country, respondents did not want to sign the consent form. Hence, verbal informed consent was obtained from all participants. Permission was obtained from the brothel management and chairladies prior to the study. Respondents were free to decline to participate in the study or not to answer questions they were not comfortable with. 


\section{Results}

A cluster randomised pilot trial using brothel leadership to improve condom use among FSWs

A total of 10 brothels and 243 FSWs provided informed consent and participated in the baseline assessment for the intervention. The mean age of the participants at baseline was 28 years $(\mathrm{SD}=5.4)$ and no significant difference in age was observed between the experimental and control groups. FSWs in the control and experimental arms did not also significantly differ in educational attainment, age of commencing sex work and HIV knowledge. However, a significant difference was recorded for marital status with more participants in the experimental condition being single compared to the control condition (Table 1).

\section{Participation and attrition}

Figure 1 is a flow chart showing the brothels participating in the study. Twelve brothels were approached to participate in the study and were randomized into the control and the experimental conditions. Two brothels in the control condition withdrew their participation before the baseline assessment was carried out. The brothels withdrew due to its management not accepting to be part of the conduct of the intervention within the brothel.

Adherence to the sessions was calculated to be average with the mean session attended being 4.4(S. $\mathrm{D}=2.0)$ and $86(48.6 \%)$ completing all six sessions, $18(10.2 \%)$ completing five sessions, while $27(15.3 \%), 1(0.6 \%), 30(16.9 \%)$ and $15(8.5 \%)$ completed four, three two and no sessions respectively. Although the remaining ten brothels participated in the 16 weeks follow-up assessment, only 108 of 243 FSWs were part of the follow-up assessment; i.e., an attrition rate of $55.6 \%$. One brothel in the control group had only two FSWs present during the follow-up assessment as a result of a recent raid of the brothel by law enforcement. Just before the commencement of the intervention two brothels in the experimental condition had an influx of FSWs. 


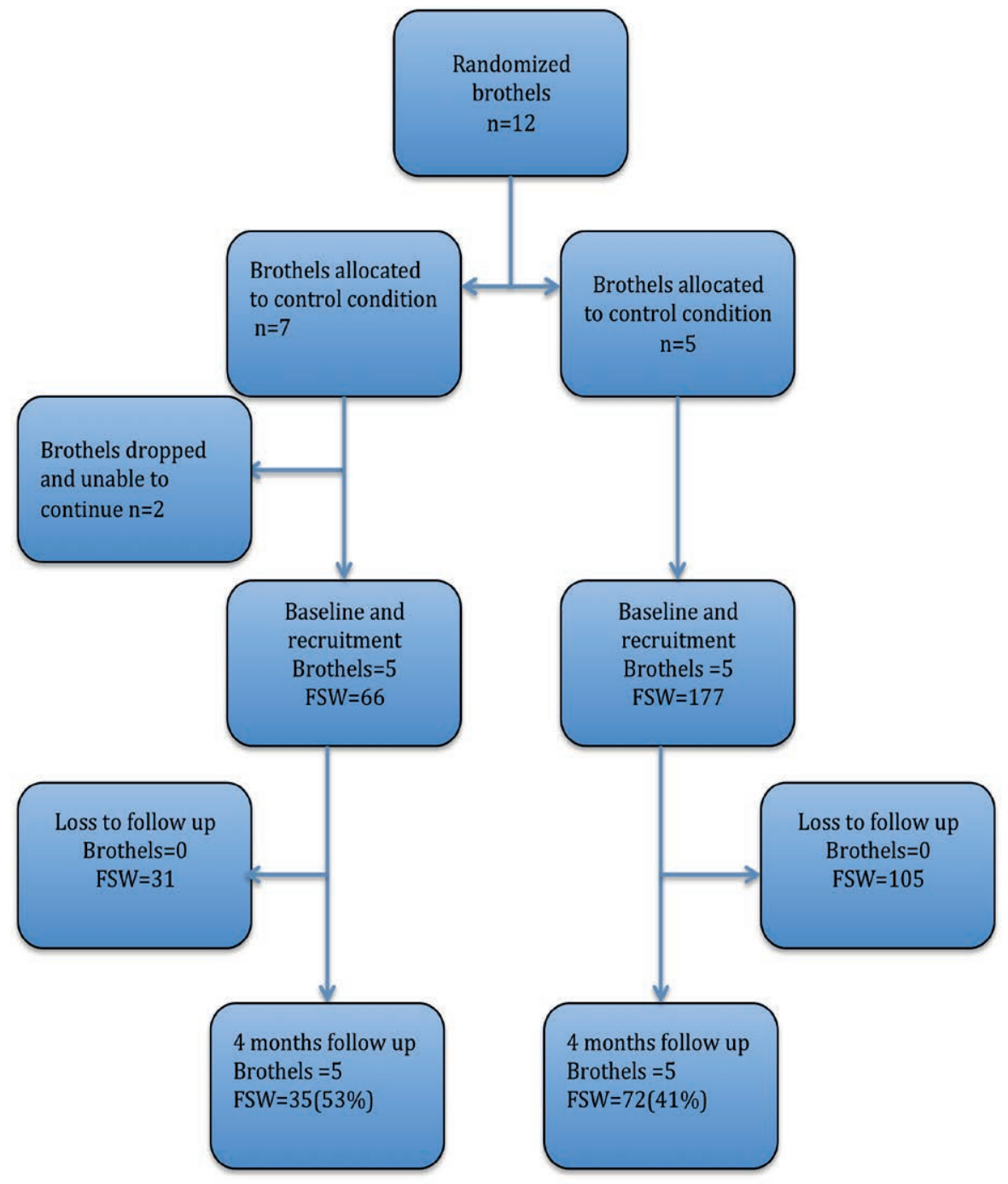

Figure 1: Participant flow chart 
A cluster randomised pilot trial using brothel leadership to improve condom use among FSWs

Table 1: Baseline participant characteristics and differences

\begin{tabular}{|c|c|c|c|c|c|c|}
\hline Characteristics & $\begin{array}{l}\text { Total } \\
n=243\end{array}$ & $\begin{array}{l}\text { Control } \\
\mathbf{n}=177\end{array}$ & $\begin{array}{l}\text { Experiment } \\
\text { al } \\
n=66\end{array}$ & $t(d f)$ & $X^{2}$ & $P$ \\
\hline Age of FSW & $\mathrm{n}=239$ & & & & & \\
\hline Mean Age (SD) & $28(5.4)$ & $28(4.9)$ & $29(5.8)$ & $0.3(234)$ & & 0.768 \\
\hline Age start sex work & $\mathrm{n}=215$ & & & & & \\
\hline Mean Age (SD) & $26(6.0)$ & $25(6.8)$ & $26(5.7)$ & \multirow[t]{2}{*}{$-1.4(213)$} & & \multirow[t]{2}{*}{0.169} \\
\hline $\begin{array}{l}\text { Education } \\
\text { Attainment }\end{array}$ & $\mathrm{n}=240$ & & & & & \\
\hline $\begin{array}{l}\text { Primary/No } \\
\text { education/Vocational }\end{array}$ & $148(61.7 \%)$ & $34(53.1 \%)$ & $114(64.8 \%)$ & & \multirow[t]{2}{*}{2.7} & \multirow[t]{2}{*}{0.101} \\
\hline Secondary/tertiary & $92(38.3 \%)$ & $30(46.9 \%)$ & $62(35.2 \%)$ & & & \\
\hline Marital Status & $\mathrm{n}=243$ & & & & & \\
\hline Married/co-habiting & $44(18.1 \%)$ & $19(28.8 \%)$ & $25(14.1 \%)$ & & \multirow[t]{2}{*}{7.0} & \multirow[t]{2}{*}{0.008} \\
\hline $\begin{array}{l}\text { Single/divorced } \\
\text { /widowed }\end{array}$ & $199(81.9 \%)$ & $47(71.2 \%)$ & $152(85.9 \%)$ & & & \\
\hline $\begin{array}{l}\text { Reported source of } \\
\text { income }\end{array}$ & $\mathrm{n}=243$ & & & & & \\
\hline Sex work only & $140(57.6 \%)$ & $32(48.5 \%)$ & $108(61.0 \%)$ & & \multirow[t]{2}{*}{3.1} & \multirow[t]{2}{*}{0.079} \\
\hline $\begin{array}{l}\text { Sex work and other } \\
\text { jobs }\end{array}$ & $103(42.4 \%)$ & $34(51.5 \%)$ & $69(39.0 \%)$ & & & \\
\hline Knowledge & $\mathrm{n}=226$ & & & & & \\
\hline Low knowledge & $184(81.4 \%)$ & $57(87.7 \%)$ & $127(78.9 \%)$ & & \multirow{2}{*}{2.4} & \multirow{2}{*}{0.123} \\
\hline High Knowledge & $42(18.6 \%)$ & $8(12.3 \%)$ & $34(21.1 \%)$ & & & \\
\hline
\end{tabular}




\section{Chapter 5}

Table 2: Baseline characteristics of intervention participants who completed or dropped out

\begin{tabular}{|c|c|c|c|c|c|}
\hline Characteristics & Completed & $\begin{array}{c}\text { Dropped } \\
\text { out }\end{array}$ & $t(d f)$ & $\mathbf{X}^{2}$ & $\mathbf{P}$ \\
\hline \multicolumn{6}{|l|}{ Age of FSW } \\
\hline Mean Age (SD) & $29(6.0)$ & $28(5.2)$ & $1.7(234)$ & & 0.085 \\
\hline \multicolumn{6}{|l|}{ Education Attainment } \\
\hline Primary/No education/Vocational & 56.7 & 65 & & \multirow[t]{2}{*}{1.7} & \multirow[t]{2}{*}{0.193} \\
\hline Secondary/tertiary & 43.3 & 35 & & & \\
\hline \multicolumn{6}{|l|}{ Marital Status } \\
\hline Married/co-habiting & 19.4 & 17.2 & & \multirow[t]{2}{*}{0.2} & \multirow[t]{2}{*}{0.670} \\
\hline Single/divorced/widowed & 80.6 & 82.8 & & & \\
\hline \multicolumn{6}{|l|}{ Knowledge } \\
\hline Low knowledge & 84.8 & 79.1 & & \multirow[t]{2}{*}{1.2} & \multirow[t]{2}{*}{0.281} \\
\hline High Knowledge & 15.2 & 20.9 & & & \\
\hline \multicolumn{6}{|l|}{ Consistent condom use } \\
\hline Boyfriends & 53.2 & 76.7 & & 11.1 & 0.001 \\
\hline Casual partners & 79.7 & 87.2 & & 1.5 & 0.221 \\
\hline Clients & 83.9 & 94.2 & & 6.5 & 0.011 \\
\hline \multicolumn{6}{|l|}{ Condition } \\
\hline Control & 26.5 & 27.6 & & \multirow[t]{2}{*}{0.033} & \multirow[t]{2}{*}{0.856} \\
\hline Experimental & 73.5 & 72.4 & & & \\
\hline
\end{tabular}

\section{Condom use outcomes}

Condom use with boyfriends, casual partners and clients increased for both the experimental and control arms of the intervention. However, the interaction between wave and condition for condom use with clients was not significant $(\mathrm{p}=0.68)$. Marital status was a significant predictor of condom use with clients $(\mathrm{p}=0.002)$ and showed that married FSWs are 2.4 times more likely to use condoms compared to their unmarried counterparts. Condom use with casual partners showed significant increase over time for both groups $(\mathrm{p}=0.04)$, but showed no significant interaction between wave and condition $(\mathrm{p}=0.45)$. The interaction between wave and condition 
showed a statistically significant effect for condom use with boyfriends $(\mathrm{p}=0.02)$. Consistent condom use with boyfriends for the experimental arm significantly increased at follow- up compared to the control arm which declined. Condom use outcomes are summarised in table 2, and figures 2,3 , and 4 .

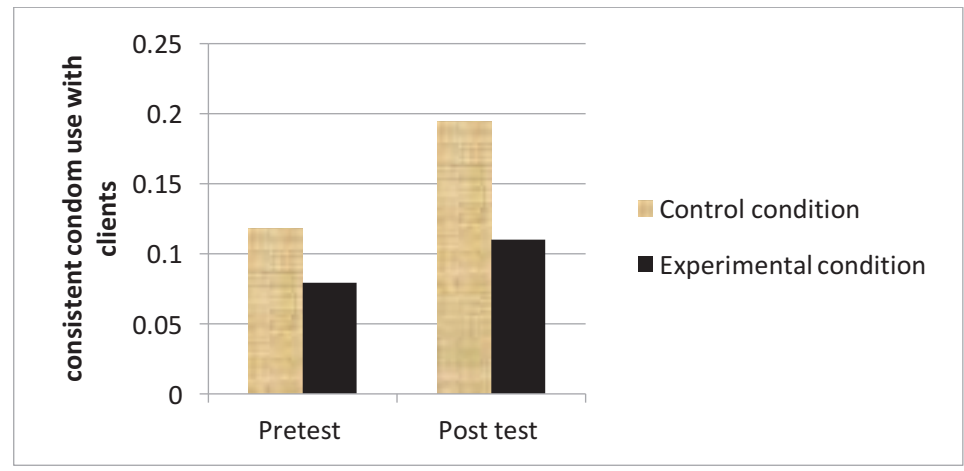

Figure 2: Estimated means for intervention effects on condom use with clients

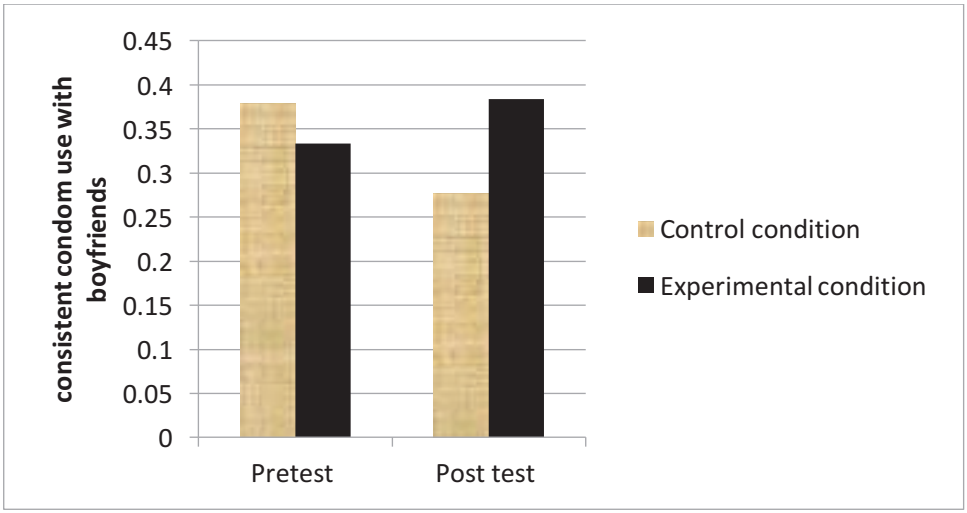

Figure 3: Estimated means for intervention effects on condom use with boyfriends 


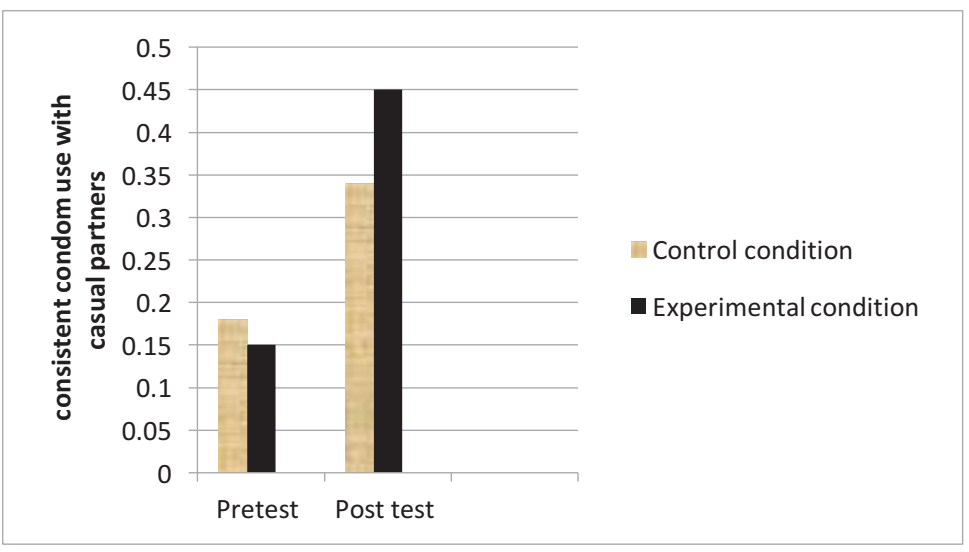

Figure 4: Estimated means for intervention effects on condom use with casual partners

\section{Condom negotiation self-efficacy outcomes}

Self-efficacy for condom negotiation with boyfriend and casual partners increased significantly over time for both the experimental and control conditions $(\mathrm{p}=0.02)$ with the experimental group showing more increase. However, the interaction between wave and condition was not significant $(\mathrm{p}=0.68)$. Self-efficacy for condom negotiation with clients showed a decline for both arms of the study and the interaction effect between wave and condition was also insignificant ( $\mathrm{p}=0.95$ ). Self-efficacy for condom use negotiation outcomes are summarized in table 3 , and figures 5 and 6 . 


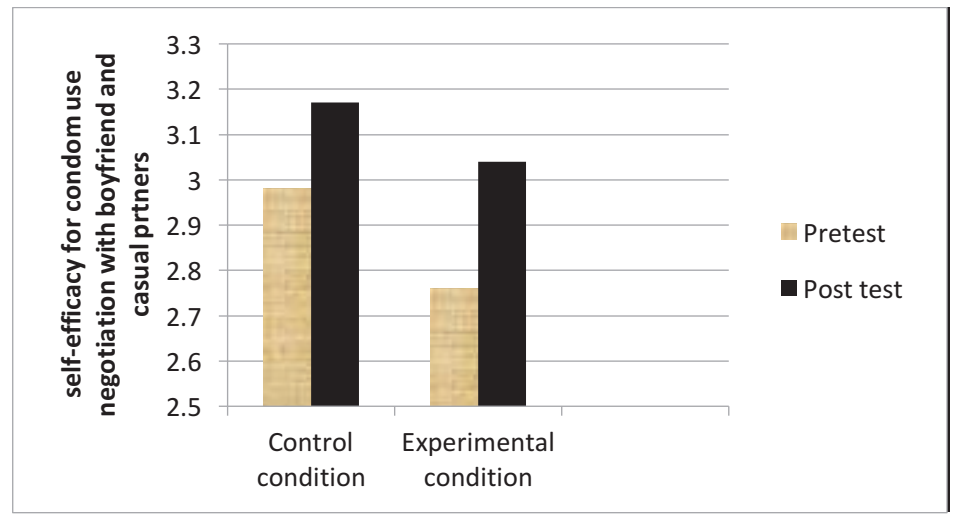

Figure 5: Estimated means for intervention effects on self-efficacy with boyfriend and casual partners

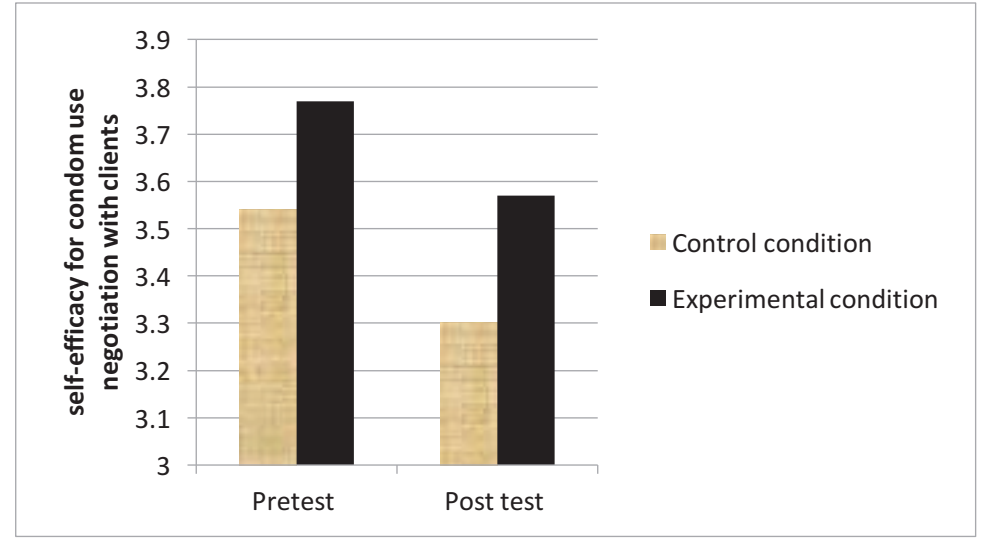

Figure 6: Estimated means for intervention effects on self-efficacy with clients

\section{Process Outcomes}

Process outcomes measured showed that above $80 \%$ of the participants in the experimental group during the follow-up assessments reported positive outcomes for most of the questions on the intervention quality, acceptability, content and delivery mode (Table 5). Eighty six percent of the participants reported that the condom promotion activities within the intervention was good and $82 \%$ also agreed that the chairladies were effective facilitators of condom promotion activities within the brothel. However, only 52.9\% were satisfied with the condoms provided during the intervention. 


\begin{tabular}{|c|c|c|c|c|c|c|}
\hline & 苛 & $\stackrel{n}{2}$ & $\stackrel{\overbrace = 1}{=}$ & $\begin{array}{l}n \\
\vdots \\
0 \\
-1\end{array}$ & $\stackrel{N}{\stackrel{N}{n}}$ & \\
\hline & 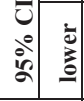 & @ె & $\begin{array}{l}\vec{\infty} \\
\vdots \\
0 \\
0\end{array}$ & 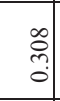 & $\stackrel{\circ}{\stackrel{-}{\leftrightarrows}}$ & \begin{tabular}{l}
$n$ \\
\multirow{2}{n}{} \\
$\infty$ \\
0 \\
0
\end{tabular} \\
\hline & 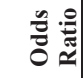 & $\stackrel{n}{n}$ & $\begin{array}{c}\bar{z} \\
0 \\
0 \\
0\end{array}$ & $\begin{array}{l}0 \\
\hat{n} \\
0\end{array}$ & $\stackrel{\text { ro }}{\mathrm{i}}$ & กิ \\
\hline$\stackrel{n}{g}$ & $A$ & $\stackrel{0}{\circ}$ & $\begin{array}{c}\infty \\
\\
0\end{array}$ & $\begin{array}{l}0 \\
\stackrel{0}{0} \\
0\end{array}$ & ปี & ปี \\
\hline 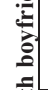 & - & : & ڤ్ & , $\stackrel{\overbrace{}}{\stackrel{?}{:}}$ & নิ & $\stackrel{\infty}{=}$ \\
\hline 吾 & 된 & 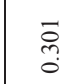 & $\begin{array}{l}0 \\
\dot{0} \\
0\end{array}$ & $\frac{\infty}{m}$ & जे & $\stackrel{ }{\stackrel{0}{0}}$ \\
\hline : & $\approx$ & $\frac{a}{3}$ & 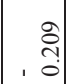 & 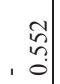 & $\frac{n}{0}$ & î. \\
\hline & 苛 & $\underset{\sim}{\Omega}$ & $\begin{array}{l}\stackrel{y}{a} \\
\text { o. }\end{array}$ & $\begin{array}{l}\stackrel{+}{4} \\
\stackrel{+}{+}\end{array}$ & $\stackrel{\circ}{\stackrel{\circ}{a}}$ & ฉั \\
\hline & 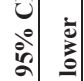 & $\stackrel{\infty}{\stackrel{0}{0}}$ & $\begin{array}{l}\text { t. } \\
\text { ô. } \\
0\end{array}$ & $\frac{\tilde{\rho}}{0}$ & ?̊ & $0^{\infty}$ \\
\hline & 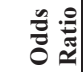 & $\begin{array}{l}0 \\
\infty \\
0 \\
0\end{array}$ & הุ & $\begin{array}{l}\vec{b} \\
\vdots \\
0\end{array}$ & $\stackrel{\substack{\infty \\
\hdashline}}{-}$ & $\underset{\substack{0 \\
0}}{0}$ \\
\hline 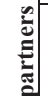 & $\sim$ & $\begin{array}{l}\stackrel{1}{\infty} \\
0 \\
0\end{array}$ & $\begin{array}{l}\vec{\sigma} \\
\dot{0}\end{array}$ & 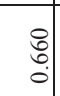 & $\stackrel{+}{+}$ & $\begin{array}{l}\text { fo } \\
\stackrel{0}{0}\end{array}$ \\
\hline 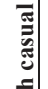 & $H$ & $\begin{array}{l}\infty \\
\text { స్ } \\
\text { o }\end{array}$ & $\begin{array}{l}0 \\
8 \\
\text { : } \\
\text { in }\end{array}$ & , & $\stackrel{\vec{n}}{\stackrel{0}{0}}$ & , \\
\hline 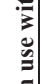 & 엥 & $\begin{array}{l}+ \\
\stackrel{\infty}{0} \\
\stackrel{0}{0}\end{array}$ & $\stackrel{n}{a}$ & $\begin{array}{l}\vec{\xi} \\
\text { o. }\end{array}$ & 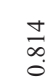 & ले \\
\hline نे & $\approx$ & . & , & 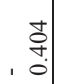 & $\vec{\sigma}$ & $\stackrel{2}{\frac{2}{0}}$ \\
\hline & 苛 & 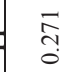 & $\underset{\vec{i}}{\stackrel{+}{二}}$ & 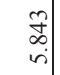 & $\stackrel{\hat{n}}{\hat{n}}$ & $\stackrel{n}{\stackrel{n}{+}}$ \\
\hline & 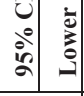 & $\stackrel{+}{\stackrel{0}{0}}$ & 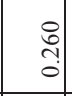 & $\begin{array}{l}n \\
n \\
\vdots \\
0\end{array}$ & ‡్ & $m$ \\
\hline & $\frac{n}{\tilde{c}}: \frac{0}{\tilde{\Xi}}$ & $\hat{o}$ & $\begin{array}{c}\vec{n} \\
\vdots \\
0\end{array}$ & 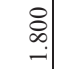 & $\begin{array}{l}\vec{\infty} \\
\stackrel{0}{0}\end{array}$ & ले \\
\hline & $\rightarrow$ & ๕. & $\begin{array}{l}\hat{a} \\
\hat{0}\end{array}$ & స్తి & $\begin{array}{l}\vec{\alpha} \\
\stackrel{0}{0}\end{array}$ & ठ̊. \\
\hline 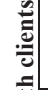 & $H$ & $\stackrel{\stackrel{+}{+}}{\stackrel{f}{+}}$ & 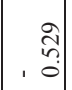 & $\begin{array}{l}0 \\
\infty \\
0 \\
0\end{array}$ & $\stackrel{7}{7}$ & $\vec{m}$ \\
\hline 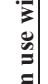 & 国 & $\stackrel{2}{3}$ & $\begin{array}{c}0 \\
\stackrel{9}{0} \\
\vdots \\
0\end{array}$ & $\begin{array}{l}\text { o. } \\
\\
0\end{array}$ & ò & 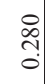 \\
\hline हैं & $\approx$ & 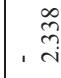 & $\begin{array}{r}0 \\
\stackrel{0}{0} \\
\stackrel{1}{0}\end{array}$ & $\begin{array}{l}\infty \\
\infty \\
0 \\
0\end{array}$ & , & $\begin{array}{l}\infty \\
0 \\
0\end{array}$ \\
\hline & 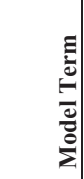 & 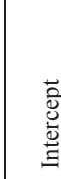 & $\sum_{\substack{\infty \\
3}}^{\infty}$ & 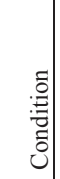 & 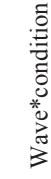 & $\stackrel{\text { 莺 }}{\Sigma}$ \\
\hline
\end{tabular}




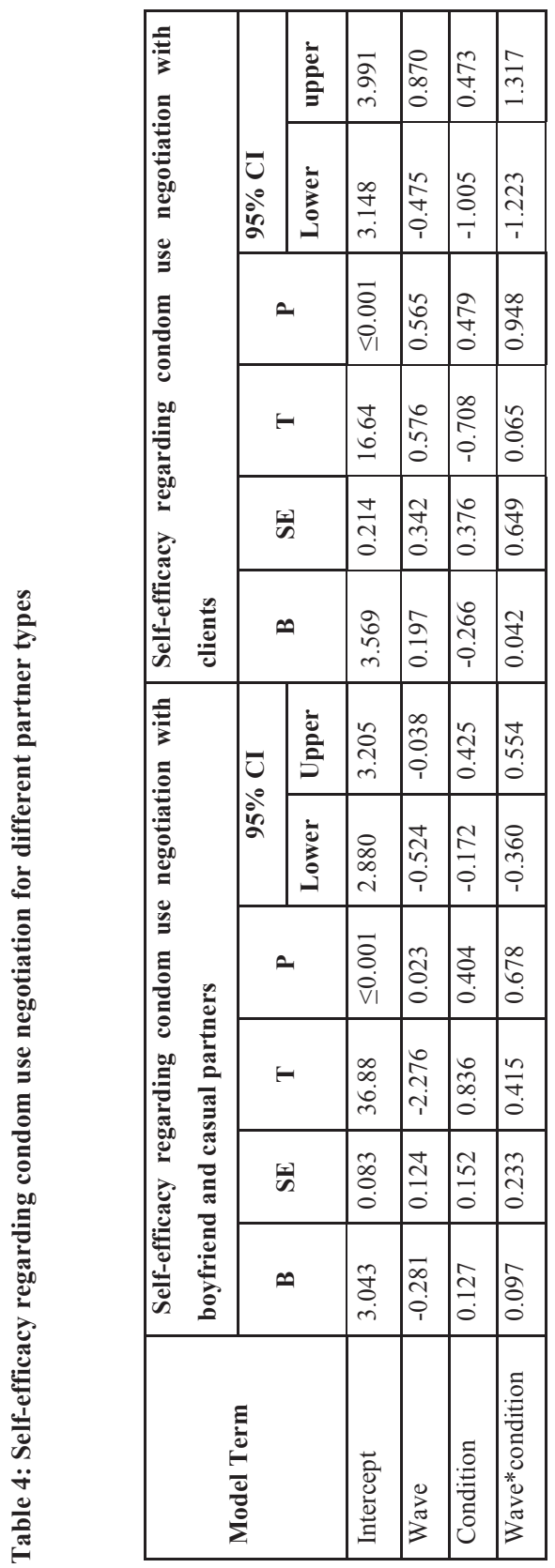




\section{Chapter 5}

Table 5: Process outcomes

\begin{tabular}{|l|l|l|l|}
\hline Process Outcome & Agree & Disagree & Neutral \\
\hline $\begin{array}{l}\text { The quality of the condom promotion activities } \\
\text { during the intervention was good }(\mathrm{n}=140)\end{array}$ & $\begin{array}{l}121 \\
(86.4 \%)\end{array}$ & $10(7.1 \%)$ & $9(6.4 \%)$ \\
\hline $\begin{array}{l}\text { The frequency of the monthly condom } \\
\text { demonstration was adequate }(\mathrm{n}=140)\end{array}$ & $\begin{array}{l}116 \\
(82.9 \%)\end{array}$ & $13(9.3 \%)$ & $11(7.9 \%)$ \\
\hline $\begin{array}{l}\text { The chairladies were effective facilitators of } \\
\text { the condom promotion activities in the brothel } \\
\text { (n=140) }\end{array}$ & $\begin{array}{l}115 \\
(82.1 \%)\end{array}$ & $12(8.6 \%)$ & $13(9.3 \%)$ \\
\hline $\begin{array}{l}\text { The weekly brothel meeting is a suitable } \\
\text { avenue for condom promotion activities } \\
\text { (n=141) }\end{array}$ & $\begin{array}{l}118 \\
(83.7 \%)\end{array}$ & $7(5.0 \%)$ & $16(11.3 \%)$ \\
\hline $\begin{array}{l}\text { The number of condoms received during the } \\
\text { intervention was adequate }(\mathrm{n}=140)\end{array}$ & $74(52.9 \%)$ & $31(22.1 \%)$ & $35(24.3 \%)$ \\
\hline $\begin{array}{l}\text { The condom promotion messages were } \\
\text { adequate (n=141) }\end{array}$ & $\begin{array}{l}116 \\
(82.3 \%)\end{array}$ & $10(7.1 \%)$ & $15(10.6 \%)$ \\
\hline $\begin{array}{l}\text { The combination of the education sessions with } \\
\text { condom promotion activities of the chairladies } \\
\text { was effective (n=141) }\end{array}$ & $\begin{array}{l}(815 \\
(2.6 \%)\end{array}$ & $4(2.8 \%)$ & $22(15.3 \%)$ \\
\hline
\end{tabular}

\section{Discussion}

The pilot study showed feasibility and indicates preliminary evidence of efficacy that can be used to inform sample size estimates when undertaking a larger phase III trial. Brothel owners and chairladies were willing to cooperate with the program to enhance condom use within the brothels. FSWs residing within the brothels were also willing to participate in the intervention and the study. The attrition rates recorded during the intervention was significant and could have been caused by various reasons i.e. seeking for more sexual partners, non-conducive climate and more sex work income. 
Mobility of female sex workers continues to pose a challenge to HIV prevention efforts and should be taken into consideration when designing such programs (Ramesh, Ganju, Mahapatra, Mishra, \& Saggurti, 2012; Wang et al., 2010). The high attrition rate observed during the pilot goes to further buttress this. Sample size estimations for similar programs should incorporate this possibility when calculating the required sample size to ensure studies are adequately powered. The recruitment of gatekeepers for trainings and their active participation in the facilitation of a conducive environment for condom use promotion within the brothel establishment is enhanced by educating them on the benefits to the establishment, the FSWs themselves and their immediate environment.

Our findings indicate also that the study had a positive effect in increasing condom use outcomes with boyfriends and casual partners. Unprotected sex with steady partners of FSWs remains a great concern for HIV prevention efforts across the globe and may contribute more to FSWs' HIV/STI risk (Fang et al., 2007; Zhao et al., 2008). Several publications in Nigeria (Asowa-Omorodion, 2000; Eluwa et al., 2012; FMOH, 2014) and other countries (Kayembe et al., 2008; Ulibarri et al., 2012; Voeten et al., 2007; Wang et al., 2007) have shown that FSWs' use condom more with their commercial clients compared to their steady partners. Most sex workers have at least one steady sexual partner at any given time (Kerrigan et al., 2003) and the study conducted by Murray et al indicates that perceived relationship intimacy is a strong predictor of consistent condom use among FSWs (Murray et al., 2007). FSWs view the use of condoms with their steady partners as an emotional barrier separating their professional lives as sex workers from their lives as girlfriends and mothers (Castañ eda, Ortiz, Allen, Garcia, \& Hernandez- Avila, 1996). Thus, convincing their steady partners to use condoms may call for a higher self-efficacy and control over their sexual activities (Bandura, 1994; Pickering et al., 1993 ; Walden et al., 1999).

Our intervention was developed using participatory approaches at the individual, community and organizational levels with FSWs, brothel leaders and HIV experts. The intervention targeted individual level changes (attitudinal changes for both brothel 


\section{Chapter 5}

leaders and FSWs) and socio-structural changes (increased access to condoms, condom use policy enactment at the brothel level and environmental changes). This is different from the typical micro level individual approach for the promotion of condom use and included an additional layer of influence and support from brothel managers and chair ladies for the facilitation of consistent condom use and condom negotiation selfefficacy. Future interventions for HIV prevention amongst this target group are encouraged to adopt this approach.

The pilot study is subject to the following limitations: firstly, the generalization of the study to other sex work settings and countries may be limited and should be carried out with caution. Measuring condom use and condom negotiation outcomes among FSWs is difficult and the self-reported nature of the result could be subject to social desirability bias. Lastly, the high attrition rate and the varied number of FSWs in the brothels may have affected the representativeness of the sample and the effect outcomes.

\section{Conclusion}

Our findings indicate the feasibility of engaging brothel leaders in condom promotion interventions within brothels and the possible benefits of this for HIV prevention efforts among BB FSWs in Nigeria. A larger pilot study to provide more insight to the roles and effects of gatekeeper engagement in promoting condom use within brothels including consistent condom use with steady partners is necessary.

In addition to the support provided by brothel leaders in this study, it is also important to note that supportive strategies and policies by the government and HIV/STI prevention programs remain crucial in the prevention of HIV and STIs with sex work populations. Further adequately powered studies should focus on investigating gatekeeper support in diverse sex work settings to facilitate effective HIV prevention programs for FSWs especially within the Nigerian context. 


\section{CHAPTER 6}

Perspectives of brothel leaders and HIV prevention experts 


\begin{abstract}
A qualitative study using in-depth interviews explored the perceptions and views of brothel leaders and HIV program experts on the acceptability and adoptability of using gatekeepers in interventions aimed at improving Female Sex Workers' condom use in Nigeria. Brothel leaders are an influential group within the female sex workers' social and physical environment and their attitudes, beliefs and actions can influence the immediate brothel environment and the adoption of interventions within the brothel. HIV prevention experts make key decisions on the content and strategies adopted for HIV prevention efforts and also influence the design and implementation of HIV prevention strategies within programs. Four themes illustrating the benefits and barriers of the inclusion of gatekeepers within the immediate environment of the female sex worker were identified. Results show that brothel leadership inclusion in HIV prevention efforts could exert potential positive influence on the immediate brothel environment. Brothel leaders can support the institution of establishment policies supporting consistent condom use by the female sex workers, promotion of HIV awareness, resolution of conflicts and harassments, support to new entrants into sex work and the reinforcement of protective behaviours among female sex workers. The decriminalization of sex work and the inclusion of gate keepers support into country HIV program guidelines may contribute to mitigating prevalent sociocultural factors limiting female sex workers' rights as well as their access to health services. The present study provides insights into the potential positive roles of brothel leaders in improving condom use and other HIV/AIDs related interventions for brothel based female sex worker in Abuja, Nigeria from the perspective of brothel leaders and HIV prevention experts.
\end{abstract}

\title{
Published as
}

Uchenna Okafor, Rik Crutzen, Egbe Awo \& Bart Van den Borne (2017), Perspectives of brothel leaders and HIV prevention experts on the role of gatekeepers on improving condom use by Female Sex Workers in Abuja, Nigeria, Global Journal of Health Science, 9(10) 


\section{Introduction}

Surveillance data by the federal ministry of health in Nigeria show that Female Sex Workers (FSWs) have a high HIV prevalence and record the second highest prevalence of HIV compared to other sub-populations in the country with a HIV prevalence rate of $19.4 \%$ (FMOH, 2014). An influential group of people within the FSWs' social and physical environment, who serve as gatekeepers, are those managing the FSWs (e.g., managers, chairladies, owners of establishments/brothels). They have a reciprocal financial relationship with FSWs and rely on FSWs to make money. Alternatively, FSWs are dependent on these gatekeepers for the use of their establishment for financial gain (Yang et al., 2005). Gatekeepers exert power and control over FSWs and the lack of gatekeeper support as well as abusive FSW-gatekeeper relationships can be barriers to preventive behaviours. An emphasis on making more money at the expense of safety, for example, may contribute to inconsistent condom use by the FSWs (Okafor, Crutzen, Okekearu, et al., 2017; Xia \& Yang, 2005). Sex work is criminalized and highly stigmatized in Nigeria resulting in FSWs operating clandestinely. Despite this, sex work continues to thrive in various forms with the brothel system as a one of the main types of sex work settings prevalent in the country. The vulnerability of FSWs and the increased risks faced as a result of the interplay between their sex, work settings and social factors influencing sex work in the country has been brought to the fore by the HIV epidemic. Sociocultural factors prevalent in the country, including laws, policies and societal norms, continue to limit the civil, social and economic rights of FSWs such as their access to health care, employment conditions, type of sex venue, trust in a stable partner, gender inequities, stigma and discrimination.

HIV prevention programs in Asia and the Dominican Republic have demonstrated how interactions between gatekeepers and FSWs can be used in a positive way and how such interactions can be incorporated to improve condom use practices (Hong et al., 2008; Li et al., 2010; Morisky et al., 2006; Xia \& Yang, 2005; Zang et al., 2014). Gatekeepers have also been shown in various studies to play significant roles in HIV risk reduction for FSWs including facilitating consistent condom use (Hong et al., 2008; Yang et al., 2005; Zang et al., 2014). HIV prevention programs that take into account the unique 


\section{Chapter 6}

roles of gatekeepers are crucial to enhance FSW health and HIV prevention efforts as a whole. In Nigeria and West Africa, limited research exists on the role of gatekeepers play in facilitating consistent condom use by FSWs. It is important therefore for research to provide more insights into this in order to inform future programming and strategies in the region.

A pilot behavioural intervention aimed at measuring the feasibility and suitability of using brothel leaders to improve condom use by Brothel Based (BB) FSWs was designed (Okafor, Crutzen, Adebajo, et al., 2017) and implemented. The attitudes, beliefs and practices of the brothel leaders can influence the immediate brothel environment of the FSW and the adoption of interventions within the brothel (Urada et al., 2013). Program experts are significant stakeholders in HIV prevention efforts for FSWs and determine the contents of HIV prevention programs while brothel leaders who have powerful relationships with the FSWs can make decisions on the use and adoption of the programs by the FSWs (Page, 2002). Hence, brothel leaders can influence the successful adoption of HIV prevention interventions. The diffusion of innovations theory by Rogers (Rogers, 2003; Rogers \& Kincaid, 1981) indicates that the adoption of an innovation is influenced by the quality of the innovation, the qualities inherent in the targeted individuals to adopt and use the innovation and the innovation's compatibility with the potential adopter or organization's norms and procedures. So, the design of a behavioural intervention to address inconsistent condom use by FSWs should be consultative and take into consideration the complexities within the immediate social environment the FSW interacts with in addition to the individual factors (Jana et al., 2004). This study explores the perceptions and views of brothel leaders and HIV program experts on the acceptability and adoptability of using gatekeepers in interventions aimed at improving FSW condom use in Nigeria. Perceptions of the suitability of this approach for these gatekeepers as well as views on possible improvements for HIV prevention interventions were also explored. This is necessary to gain more insights into the potential benefits of including this very influential group within the FSWs' immediate environment and their impact on the adoption of preventive behaviours by the FSWs. 


\section{Methodology}

A qualitative study using in-depth interviews was conducted to explore perceptions and views of brothel leaders and HIV prevention experts. Eighteen in-depth interviews were conducted in Abuja, Nigeria with thirteen brothel leaders (chairladies, managers and/or brothel owners) and five HIV prevention experts. The interviews focused on how brothel leaders and HIV prevention experts perceive the roles of gatekeepers in the promotion of consistent condom use by FSWs. Ten brothel managers, owners and chairladies of brothels within the Federal Capital Territory (FCT) who had been part of a previous pilot condom promotion intervention were invited and eight of them gave consent for the interview. Five additional brothel leaders, who did not participate in the pilot study, were selected from the location of focus and were participating in a peerled HIV prevention program implemented by the Society for Family Health (SFH) an indigenous non-governmental organization. In addition to this, five HIV prevention experts overseeing large-scale prevention efforts for FSWs in the country were also invited and interviewed.

\section{Interviews}

A semi-structured interview guide was prepared based on the diffusion of innovation (Rogers, 2003) and the stakeholder theory (Page, 2002) and the interviews were conducted between January and May 2017. The interview guide covered the following: 1) Knowledge of HIV transmission, prevention and management; 2) Benefits and barriers to brothel leadership inclusion; 3) Sexual practices of FSWs; 4) Program improvement.

\section{Data Collection and Analysis}

Interviews were recorded and transcribed verbatim and each interview transcript was reviewed for accuracy and correct representation of the responses of the participants. The data was analysed using Nvivo for MAC 11.3, which is a computer assisted qualitative data analysis tool to aid analysis and reporting. Each transcript was read and coded for prominent themes and ideas. This was then refined as appropriate as the data was further analysed. Another independent researcher coded a random selection of data 


\section{Chapter 6}

to look for new concepts and to establish consistency of coding. The independent researcher compared the emerging themes with the coding by the authors for new meanings and no new themes were identified.

\section{Results}

Characteristics of the interviewees are presented in Table 1. Six males and twelve females were interviewed. The perceptions of the participants in this study are presented under four broad themes; benefits of brothel leadership inclusion, barriers to brothel leadership inclusion, barriers to condom use, program and policy considerations.

Table 1: Overview of Interviewed Brothel Leaders and Program Experts

\begin{tabular}{|c|c|c|c|c|}
\hline No. & Gender & Status & Job status & $\begin{array}{l}\text { Intervention } \\
\text { Participation }\end{array}$ \\
\hline 1 & Female & Brothel Leader & Chair lady & Yes \\
\hline 2 & Male & Brothel Leader & Owner & Yes \\
\hline 3 & Female & Brothel Leader & Owner & No \\
\hline 4 & Female & Brothel Leader & Owner & No \\
\hline 5 & Female & Brothel Leader & Owner & Yes \\
\hline 6 & Male & Brothel Leader & Owner & No \\
\hline 7 & Male & Brothel Leader & Owner & No \\
\hline 8 & Female & Brothel Leader & Chair lady & Yes \\
\hline 9 & Female & Brothel Leader & Chair lady & Yes \\
\hline 10 & Female & Brothel Leader & Chair lady & Yes \\
\hline 11 & Female & Brothel Leader & Owner/Manager & Yes \\
\hline 12 & Female & Brothel Leader & Owner/Manager & No \\
\hline 13 & Female & Brothel Leader & Owner/Manager & Yes \\
\hline 14 & Female & HIV Prevention Expert & Government worker & $\mathrm{N} / \mathrm{A}$ \\
\hline 15 & Female & HIV Prevention Expert & Government worker & N/A \\
\hline 16 & Male & HIV Prevention Expert & Program manager & $\mathrm{N} / \mathrm{A}$ \\
\hline 17 & Male & HIV Prevention Expert & Program manager & $\mathrm{N} / \mathrm{A}$ \\
\hline 18 & Male & HIV Prevention Expert & Program manager & $\mathrm{N} / \mathrm{A}$ \\
\hline
\end{tabular}




\section{Benefits of brothel leadership inclusion}

\section{Conflict management}

A possible fall out of the enforcement of condom use within the brothel is conflict and violence from the clients and regular partners of the FSWs. The brothel leaders within the study explained their strategic role in curbing this within the brothel when it arises. A male brothel owner gives his account of how his influence managed such a situation in his brothel:

"Recently, some man came into the brothel and insists with the FSW that he will not use a condom. The girl brings the case to me and I had to talk to the man on the benefits to his health and that of the FSW if he uses condoms" (Chairlady)

Another female brothel leader explains a scenario where she had to mediate between the FSW and a client and prevented violence:

"A complaint was brought to me by a client who reported that he negotiated sex without condom with one of the girls in the brothel for a much higher price. The girl collected the money and insists that she will not allow him get what he paid for because she did not want to contact HIV. I had to resolve the issue and ask the girl to give back the money." (Chairlady)

Managing harassment from law enforcement is another role for brothel leaders mentioned by both experts and the participating brothel leaders. Law enforcement agents for different reasons often raid sex work establishments. HIV prevention experts mention the role brothel leaders can play in the reduction of harassment of FSWs by law enforcement and their perceptions on the criminalization of sex work in the country: "Brothel owners are critical in the process of reaching out to law enforcement agents to reduce the harassment of FSWs" (Male HIV prevention expert)

"Even HIV program managers and service providers are sceptical because the law is not very clear in terms of the criminalization of sex work. Some argue that it is criminalized because the law states that solicitation is a crime. Yet it is unclear who is soliciting who, the FSW or the client? So, a lot of education and clarification is needed 


\section{Chapter 6}

for us to create an enabling environment where we can propose organized-supported care and prevention interventions for FSWs." (Male HIV prevention expert)

\section{Support to new entrants and young FSWS}

The immaturity and naivety of new entrants into sex work is a key concern in HIV prevention efforts. Brothel leaders believe they have a strategic role within the brothel to educate new entrants appropriately and improve their self-efficacy. A chair lady gives her account of how she educates new FSWs within her brothel:

"When new girls come from the village who have never done this before and don't even know how to speak English, I show them how to use condom and even demonstrate it with her first client. I also teach her how to get over her shame and insist on condom use. I advised her that she should not drink much so that none of her clients can take advantage of her without using condoms." (Chairlady)

Experts explained their views on new entrants and how they contribute to the HIV burden in the country. A female expert with the national HIV/AIDs response explains the outcome of the epidemic appraisals conducted in the country regarding new entrants to sex work:

"The number of newly enrolled or initiated FSWs was made up of the young girls who didn't know anything about HIV prevention. Looking at this age group from the studies we have conducted shows that they bear a higher burden of the epidemic and this emphasizes the need to target them specifically during programming." (Female HIV prevention expert)

\section{Establishment of a conducive environment for HIV awareness and protective} behaviours

Brothel leaders affirmed the added value their inclusion could bring to HIV prevention interventions particularly towards improving condom use by the FSWs within the brothels. Brothel owners who were part of the pilot intervention agreed that an important role they could play towards providing a conducive environment within the brothels was the adoption of the "No condom- no sex" approach within their brothels. 
They believe this can be enforced in different ways within the establishments by its leadership and supports collectivization of FSWs towards consistent condom use.

"During the evenings, my assistant and I go around to see the condoms used by the girls'. We try to identify girls who seem to have a lot of customers coming to them and go and check them for condom use with the clients." (Chairlady)

HIV prevention experts explain that in most brothels, the brothel managers or owners are the custodians of the commodities and can sell them at a very subsidized rate and ensure that appropriate conditions for adherence to the "no condom no sex rule" within the brothel exists. Prevention experts explain their views on how brothel leaders can positively influence consistent condom use and foster linkages to health services for the FSWs within the brothel:

"Having the no condom, no sex rule among them is important and needs to be enforced. The brothel owners, managers and chairladies need to know about it and lead in enforcing it." (Female HIV prevention expert)

"Brothel leaders could also help in facilitating linkages to other health interventions for FSW i.e. STI management, antiretroviral therapy and HIV testing services." (Male HIV Prevention Expert)

Both brothel leaders and experts acknowledge that the reputation of the brothel benefits immensely from the implementation of the HIV prevention interventions and state that efforts should be made to educate the brothel leaders on this towards enhancing their understanding of the health benefits to the FSWs and getting their consent and buy-in for the implementation of the program.

"For the 'No condom, no sex' strategy to take hold within the brothel, you need the approval of the brothel owners but again you also need to paint a picture of the benefits to the brothel owners because they are business minded." (Male HIV prevention expert) 


\section{Chapter 6}

\section{HIV/AIDs Awareness creation and Prevention Efforts}

Many participants who were brothel leaders explained the activities adopted by them towards improving the risk perception of the FSWs within their establishment. Many participants, both those who had been part of the pilot intervention and those who had not, reported that they had personal talks and sometimes group discussions with the FSWs on HIV prevention and condom use and this could positively contribute to enhancing the risk perception of the FSWs and improve their condom use behaviour with their clients.

"I show them, how to use condom, how to wear the condom using the penile model, I tell them not to allow the man to fix the condom because he can use his fingers to burst it. If they wear it wrongly, it should be thrown away and a new one used." (Chairlady)

"I talk to the FSWs sometimes. I sit with them and discuss many things about sexually transmitted infections. I even discuss with the male clients, some tell me they do not enjoy sex with condom but I tell them the benefits of condom use." (Female brothel owner)

Participants who were HIV prevention experts explained the evolution of HIV intervention efforts in the country towards empowering FSWs and putting them at the forefront in the planning and design of programs. The Minimum Prevention Package of Interventions (MPPI), which is the domesticated version of the global combination prevention approach, involves the combination of biomedical, structural and behavioural interventions. The prevention experts explain that the adoption of this approach in the country has led to the involvement of FSWs and their communities in the design and implementation of HIV prevention interventions.

"The involvement of the target population is key and also bringing in the community where they exist to support their behaviour change also strengthens the approach." (Male HIV prevention expert)

"The adoption of the minimum prevention package of interventions approach has enabled a lot of sex workers who would have been keeping away from implementing partners to come out and be closer so they can assess services, and information on prevention, care and support. They can be part of the facilitating team to promote 
behaviour change communication as part of policy and being the voice for other sex workers." (Male HIV prevention expert)

There was clear recognition by the experts that in the light of limited resources and the epidemic appraisals conducted in Nigeria, there is need to maximize the impact of HIV interventions by focusing interventions on key populations identified to be at high risk. They mentioned the identification of FSWs as a key population affected by the HIV epidemic in Nigeria and explained the evolution of the country's guidelines for the tailored implementation of HIV prevention programs for this target group.

\section{Barriers to Brothel leadership inclusion}

\section{Inappropriate Attitude}

For the inclusion of brothel leadership in HIV prevention programs to be successful, specific attitudes are required of the brothel leaders to effectively foster a conducive atmosphere and environment for consistent condom use and other HIV prevention behaviours by the FSWs. Some brothel leaders mentioned being jovial, approachable, considerate, firm and kind, as some necessary attitudes required of a brothel leader without which their ability to foster such an environment will be hindered.

"You should apply wisdom, talk to them amicably and not with anger. Talk to them politely like a friend, approach the individual in a good manner so that the person will give you his or her attention." (Female brothel owner)

"We should be jovial with the customers and the girls. If you are jovial with your girls, they will not hide anything from you. I am very jovial with my girls and joke with them a lot. This makes them come close to me." (Female brothel owner)

Participants report that these attitudes are not just required to facilitate a conducive atmosphere within the brothel but also to support young FSWs and new entrants into sex work to integrate and effectively adopt consistent condom use behaviours within the establishment. 


\section{Chapter 6}

\section{Lack of HIV-related Knowledge}

In this study, the brothel leaders interviewed showed some knowledge of HIV and its prevention methods. The brothel leaders who participated in the pilot study showed knowledge of the high prevalence within the country and could describe correctly some methods of HIV prevention. Consistent condom use was mentioned by all as the most effective method of prevention, especially within the sex work environment. The brothel leaders who participated in the pilot intervention showed better knowledge of HIV compared to those who did not. They mentioned that prior to the intervention, they had various misconceptions about HIV and participating in the HIV intervention helped to dispel this. A brothel owner gives account of her misconceptions on HIV prevention and transmission:

"Before we believe that this sickness, STI disease or HIV, we can get it through toilet or through sharing something with someone. But since the intervention started and taught us how to take care of ourselves, we have now realized that HIV and STI diseases come through sex without condom. If you don't use condom consistently, HIV can be transmitted." (Chairlady)

HIV prevention experts within the study also acknowledge that sensitizing the brothel leaders on HIV, its prevention and management is important if their roles in fostering HIV prevention efforts within the brothels will be achieved.

"This can be included as part of the structural component of combination prevention interventions. If you get the brothel managers, owners, and chairladies involved in decision making, they are more likely to make the environment conducive for service providers to provide necessary services and make commodities available for sex workers either free or commercially." (Male HIV prevention expert)

\section{Non-acceptance of HIV prevention responsibility}

For most interventions to be successful, the start-up phase, which includes acceptance of all components of the intervention and consent by the participants, is important. Brothel leaders recognize the various benefits the brothel can gain from the implementation of HIV prevention interventions and their active participation in 
promoting condom use by the FSWs. Benefits mentioned include increased profits, better reputation as a 'clean brothel' and healthier FSWs (which could also increase profits due to less sick days off work). The brothel owners explain that sometimes clients try to assess the brothel to ascertain condom use by the girls.

"Some client come to check if we use condoms or not. For example, they can come and say they want sex without condom and if the girl says yes, they will say they want to urinate and then disappear without coming back again." (Chairlady)

In addition to the above, experts also mention that efforts need to be made to educate brothel leaders on the benefits of the interventions to the profitability and reputation of the brothel by program managers.

"For the implementation of the interventions and the institution of condom use rules in the brothels, you need the approval of the brothel owners. You need to educate them on the benefits of the intervention on the profitability of the business." (Male HIV prevention expert)

\section{Barriers to condom use}

Condom use barriers can impede efforts made by FSW towards correct and consistent condom use with all partners. There was a clear recognition of these barriers by the brothel leaders. Many brothel leaders mentioned excessive alcohol intake and substance abuse as major barriers to inconsistent condom use by FSWs.

“Some girls that take drugs like 'igbo' (a local illicit non-injectable drug), some take drugs to hide their self, you know some girls they will say 'aah! If I didn't take anything, I will be very shy to hustle, 'so they use to take all these things." (Chairlady)

Clients' offering FSWs more money for sex without condom was another recognized barrier to consistent condom use. The high level of poverty experienced by most FSWs, may negatively influence their susceptibility to enticements for non-condom use with clients. The influence of more money on consistent condom use by FSW varies and can be dependent on the FSWs' beliefs and assertiveness. A female brothel owner who did 


\section{Chapter 6}

not participate in the pilot intervention explains how some FSWs in her brothel discuss non-use of condoms with their clients:

"There are some girls, who sometimes will sit down and thinking I cannot hear, are discussing how a man comes and gives her N10 000, for sex without condom, she collects it and agrees and says she takes an analgesic to flush it out afterwards" (Female brothel owner)

Conversely, some of the brothel owners gave instances within their brothels where the FSWs were insistent on condom use despite the client offering more money for noncondom use. Another consistent reason given by the participants for the non-use of condoms by the FSWs is the presence of boyfriends who put pressure on them not to use condoms for sexual acts with them. A participant gave an instance from her brothel: "I have this girl that has a boyfriend around and whenever this girl is not around, the boyfriend will come to the brothel and pick another FSW. This was a constant problem with them." (Chairlady)

Some participants also mentioned non-availability of condoms as a barrier to condom use by the FSWs. The brothel leaders recognized the need to always have condoms available in the brothels either for free or sold at subsidized rates within the brothel highlighting the important role they as brothel leaders can play in ensuring the constant availability of condoms within the brothel.

"I need the organizations to support me with condoms so I can provide them to the girls and help them. They usually are reluctant to spend their money on condoms." (Female brothel owner)

HIV prevention experts also discussed the unique roles brothel leaders can play in ensuring the constant availability of condoms in the brothels to facilitate condom use by the FSWs and her partners.

"I think that brothel mangers have a role to play in making sure that the brothel never runs out of condoms by ensuring that they have condoms for sale or for free available 
always thus deterring inconsistent condom use in the brothel." (Male HIV prevention expert)

The perceived risk to HIV infection by the FSWs has fundamental influence on participants' HIV related behaviour decisions and the adoption of HIV prevention interventions targeted at them. Many brothel leaders in this study mention how the prospect of being paid higher for sex without condom now has little or no appeal for the girls and the different ways the FSWs engage with and deal with various attempts by their clients to pay them higher for sex without condom. A brothel leader describes her view:

"So, everybody is careful, even if they bring one million and say they should do without condom, the girls' will shout and push the person outside saying.... 'See this 'mugu' (abusive word) he wants me not to use condom." (Chairlady)

"About this condom before, money can make the FSWs not to use condom but now, they have known that HIV doesn't show on the face, and it is not only HIV that is the disease that can kill, we have other STI diseases. So the program people taught them all these things and I don't think that somebody will expose herself to all those dangers again without using condom." (Male, brothel owner)

Many brothel leaders reported, also that these practices sometimes do not extend to the boyfriends and regular partners of the FSWs. They mention the sentimental attachment some girls have with their regular partners and boyfriends which leads to not using condoms consistently with them.

"These boyfriends, they will come like one week, two weeks and then they will say to the girls; Ahhh! we have known for long now, I like you, let us go straight without condom from now" (Chairlady)

"This boyfriend issue; some of the girls' have boyfriends and have sex without condom with them. I tell them that it is better to use a condom whenever you want to meet your 


\section{Chapter 6}

boyfriend because you do not know where he has gone and if he is exposed or even HIV positive." (Chairlady)

\section{Program and Policy considerations}

The criminalization of sex work in the country continues to impede the strides taken towards controlling the epidemic within this population. Experts mention the vagueness of the current legislation on soliciting for sex and sex work criminalization as bottlenecks, which continually compromise prevention efforts and program implementation.

The experts also explain that currently the HIV prevention interventions mainly consult with gatekeepers in sex work settings during advocacy at the entry stage of the interventions. They mention that it is important to include within existing guidelines and strategies the extent of gatekeepers' inclusion in interventions, as this will aid its institutionalization by relevant stakeholders.

"A clear definition of the extent to which gatekeepers should be involved in program implementation is needed and this will serve as guidance for the various actors implementing HIV programs in this environment. It will also guide the funding mechanisms to allocate funds and insist on its inclusion for all interventions." (Female HIV prevention expert)

"If our guidelines include this and capacity is built on this, it will embed the brothel leadership inclusion within the standard HIV interventions for FSWs in the country and let all stakeholders see it as an important component that improves their programming. This will make sure it is part of the system and improve its sustainability." (Female prevention expert) 


\section{Discussion}

This study focuses on the perspectives of brothel leaders and HIV prevention experts on gatekeeper inclusion to current HIV prevention interventions for FSWs. Our findings show that the inclusion of gatekeepers within the immediate environment of

the FSW can exert a positive influence on the institution of establishment policies on consistent condom use by the FSWs, promoting awareness to HIV/AIDs, conflict resolution and reinforcing protective behaviours among the FSWs. Similar studies support our findings that brothel leaders are strategically placed and possess the requisite authority to facilitate and support the promotion of a conducive social and physical environment in the brothel thus empowering the FSWs to negotiate condom use and other safe sex behaviours (Li et al., 2010; Morisky et al., 2006; Visrutaratna \& Lindan, 1995).

The orientation and support provided to new entrants into sex work and young FSWs on HIV prevention, consistent condom use and self-efficacy in the negotiation and use of condoms is another perceived contribution brothel leaders can provide in current efforts to curb the epidemic (Morisky et al., 1998). Improving gatekeepers' supportive role towards consistent condom use may help to empower FSWs in their negotiation of condom use with clients and regular partners without fear of being punished or losing jobs (Yang et al., 2005).

The attitude of the brothel leader is important if he/she would be able to positively influence the FSWs and create a conducive environment for the implementation of HIV prevention interventions (Visrutaratna \& Lindan, 1995). Lack of HIV knowledge and the non-acceptance of their HIV prevention responsibility are other barriers which may impede the activities of brothel leaders in HIV prevention efforts (Yang et al., 2005). This is consistent with findings from other studies showing that FSW and gatekeeper knowledge of HIV/AIDs is important for the enhancement of HIV prevention efforts (FMOH, 2014; Huang, Henderson, Pan, \& Cohen, 2004; Li et al., 2010; Yang et al., 2005). Gatekeepers who lack knowledge regarding safe sex, might exhibit negative or 


\section{Chapter 6}

neutral attitudes toward condom use and other protective behaviours (Visrutaratna \& Lindan, 1995). Hence, these brothel leaders may view their responsibilities in brothels primarily as maintaining and operating their business and thus show limited enthusiasm towards HIV prevention interventions (Egger et al., 2000; Yang et al., 2005). According to the Joint United Nations Program on HIV and AIDs (UNAIDS), the success of the $100 \%$ condom use programs among establishment-based FSWs in some countries in Asia suggests that HIV prevention efforts for FSWs should be a jointly owned responsibility by establishment gatekeepers, local health authorities, program managers as well as the FSWs themselves (Rojanapithayakorn, 2006; UNAIDS, 2000). A perceived barrier to consistent condom use from the current study is the non-availability of condoms in the brothels. Brothel leaders can facilitate the uninterrupted availability of condoms in the establishment by stocking condoms for commercial sale at a subsidized rate or free to FSWs and clients. Studies show that clients and FSWs are more likely to use condoms when free or affordable condoms are available at the workplace (Egger et al., 2000; Morisky, Stein, et al., 2002).

Our findings show that FSWs' consistent and correct condom use with all partners is an important component of their risk reduction. Brothel leaders can enhance FSWs' HIV/AIDs awareness in their establishment and thereby increase their awareness of HIV-related risks, which may positively influence condom use with their clients, boyfriends and regular partners. Inconsistent condom use with regular partners and boyfriends by FSWs remains problematic and still requires significant attention from both gatekeepers and HIV prevention experts. This conclusion is in line with recommendations in similar studies (Adeneye et al., 2013; Asowa-Omorodion, 2000; Morisky et al., 2006; Murray et al., 2007; Okafor, Crutzen, Adebajo, et al., 2017).

While Nigeria's MPPI strategy for HIV prevention for FSWs is a domesticated version in line with the global UNAIDS combination prevention approach (UNAIDS, 2010), the limited consideration it places on the inclusion of gatekeepers within the immediate environment of the FSWS on HIV prevention efforts in Nigeria is evident (NACA, 2014). Similarly, no peer reviewed studies on interventions for gatekeeper support in 
HIV prevention programming exists in Nigeria. However, numerous studies exist in countries in Asia and the Dominican Republic and have shown that this is an important component which should be considered if gainful strides will be made towards curbing the epidemic (Morisky, Pena, \& TV, 2002; Yang et al., 2005). Additional studies to support the inclusion of gatekeepers in HIV prevention interventions for sex workers are needed to explore country specific social and policy considerations for its implementation within the Nigerian context. Program managers, sex workers and their gatekeepers need to work together to design this approach and explore all possible scenarios where this inclusion is viable.

Despite the fact that this study allows us to address previously unexplored questions with this target group in Nigeria, a limitation of this study might be the social desirability bias. Brothel leaders may have provided socially desirable responses, which may overestimate their views in terms of being positive about the role of gatekeepers. Secondly, the study location limits the generalizability of the findings since the study was conducted in the administrative capital of Nigeria, which may accommodate more affluent sex work establishments, compared to other locations and in rural areas of the country.

\section{Conclusion}

The present study provides additional evidence on the potentially positive role of gatekeepers in HIV/AIDs related interventions for FSWs in Nigeria. It is expected that their inclusion into current programming will enhance the achievement of HIV/AIDs related milestones. 



\section{CHAPTER 7}

\section{General Discussion}




\section{Chapter 7}

The research presented in this thesis aims to provide much needed data on the possible roles gate keepers within the immediate environment of Female Sex Workers (FSWs) can play in enhancing consistent use of condoms and the promotion of a conducive environment for HIV prevention interventions. Numerous studies exist on condom use for HIV prevention among FSWs in Nigeria, however, only a few studies explored the influence that the support provided by key actors within their social environment have on the adoption of healthful behaviours and the promotion of consistent condom use specifically (Muñoz et al., 2010). Hence, several empirical studies were conducted to explore existing information on behavioural interventions to improve consistent condom use by FSWs as well as the feasibility and the views of key stakeholders on the inclusion of identified gatekeepers in HIV prevention efforts for BB FSWs in Nigeria. This chapter provides a general discussion of the findings presented in this thesis and highlights the methodologies used for the conduct of the research. It also highlights implications and recommendations for policy and future research drawing conclusions from the main findings.

\section{Main Findings}

\section{Vulnerability of Female Sex Workers}

Sex work is criminalized and highly stigmatized in Nigeria resulting in FSWs operating clandestinely. The vulnerability of sex workers and the increased risks faced as a result of their work settings and social factors influencing sex work in the country has been brought to the fore by the HIV epidemic. Key to HIV transmission among FSWs is their sexual behaviour of which no or inconsistent condom use and the large number of sexual partners they have, play major roles. HIV prevalence profiles across subpopulations in the country illustrate the disproportionate HIV burden experienced by FSWs and highlight the need to sustain efforts towards improving their access to interventions and health services.

Young FSWs and new entrants into sex work in particular, are more vulnerable to sexually acquired HIV than the older FSWs who are more experienced in navigating the social and gender power plays in the profession especially regarding safer sex and condom use (Gunturu, 2015; Sarkar, Bal, \& Mukherjee, 2016). Strategies that enable 
HIV prevention interventions to target this sub-group and implement behaviour change programs aimed at improving their sexual health and equipping them to navigate their high-risk environment should be adopted (Onwuliri \& Jolayemi, 2005). The findings from this research also show that FSWs residing in brothels have higher HIV prevalence and are less educated than their non-brothel based counterparts (Chapter 2).

Low perception of risk to HIV/AIDS, non-availability of condoms as well as alcohol and substance abuse leading to intoxication and inability to negotiate safe sex with partners were some of the identified barriers to condom use by FSWs. Poverty and low economic status make women especially vulnerable to HIV infection and other health inequalities which in turn may lead them to engage in sex work to make a living and support their families. This can also increase their susceptibility to enticements for more money in exchange for non-use of condoms (Chapter 2 and 6).

A systematic review of behavioural interventions implemented in sub-Saharan Africa assessing the effectiveness and process outcomes related to condom use to identify gaps and inform future research needs in HIV prevention programs for this target group is presented in Chapter 3. The findings showed that the interventions employed peer and staff-mediated approaches for consistent condom use messaging. Most studies measured self-reported condom use and only few studies reported non-increase in condom use with clients. Inconsistent condom use with boyfriends and casual partners was however, reported in many of the studies. This emphasizes the need to incorporate activities and strategies aimed at addressing relevant high-risk behaviours and the need to empower FSWs to deal with the social inequalities prevalent within their immediate environment. The findings of this thesis further corroborated existing literature on the vulnerability of Brothel based FSWs (BB FSWs) to HIV infection and prevalent inconsistent condom use with their sexual partners. It also showed more inconsistent condom use with their boyfriends and regular partners.

\section{Brothel leadership roles in HIV prevention efforts}

The pilot study described in Chapters 4 and 5 utilized a cluster randomized pilot trial approach to gain insights into the potentials of an intervention incorporating brothel leadership activities and support to improve consistent condom use by FSWs. The pilot 


\section{Chapter 7}

intervention addressed personal determinants as well as social and environmental conditions prevalent within the brothel aimed at influencing beneficial condom use behaviour in the brothel. The activities by brothel leaders were used to promote a conducive social environment for consistent condom use towards incentivising the FSWs' motivation to use condoms consistently with all partners. In addition, selfefficacy in condom negotiation and outcome expectations for condom use were also influenced by their activities.

The findings showed that it was feasible to engage brothels and include its leadership into HIV prevention efforts and the enactment of consistent condom use regulations in the brothel. Brothel owners, managers and chairladies were willing to cooperate with the program to enhance condom use within the brothels. Educating them on the benefits to be gained from the intervention by the establishment and the FSWs contributed significantly to motivating them and influencing their cooperation. In addition, the pilot showed first indications of positive effects in increasing condom use outcomes with boyfriends, casual partners and clients of FSWs suggesting the positive influence brothel leaders' decisions and practices exert on the immediate environment of the FSWs and their condom use behaviours. Future studies with considerably larger sample sizes are needed to achieve sufficiently tighter confidence intervals that allow stronger conclusions regarding these effects (Peters \& Crutzen, 2017). High attrition rates were experienced during the pilot study. This underscores the possible adverse effects of FSWs' mobility/migration on HIV prevention efforts. It is important that this should be considered when designing future HIV prevention programs as studies have shown that frequently mobile FSWs report recent HIV risk activities (Kummarikunta et al., 2015; Wang et al., 2010).

The qualitative study (described in Chapter 6) explored the perceptions of brothel leaders and HIV prevention experts on perceived benefits and barriers to brothel leadership inclusion in HIV prevention efforts and its effects on consistent condom use by FSWs. In addition, the triangulation of the findings of the quantitative pilot study designed and conducted in chapter 4 and 5 and the qualitative study conducted in chapter 6 strengthened the interpretation of the results obtained in this thesis. The 
results of the qualitative study aligned with the findings of the pilot study. Thus, further suggesting the conferment of positive benefits to HIV prevention efforts by the inclusion of the brothel leadership in interventions aimed at improving consistent condom use by FSWs.

The inclusion of gatekeepers within the immediate environment of the FSWs can exert a positive influence on HIV prevention interventions especially with the institution of establishment policies on consistent condom use, promoting awareness of HIV/AIDS, conflict resolution and reinforcing protective behaviours among the FSWs. Providing support to new entrants into sex work and young FSWs on HIV prevention, consistent condom use and self-efficacy in the negotiation and use of condoms are other possible contributions brothel leaders can provide in the current efforts to curb the epidemic. Another pertinent benefit of their inclusion is the creation of awareness of perceived HIV/AIDS risk and consequences of inconsistent use of condom with regular partners and boyfriends. This situation remains problematic and still requires significant attention from both gatekeepers and HIV prevention experts as suggested by several studies conducted in Nigeria and other countries around the world (Adeneye et al., 2013; Adu-Oppong et al., 2007; Asowa-Omorodion, 2000; Ulibarri et al., 2012; Wang et al., 2007; Zhao et al., 2008).

\section{Methodological Considerations}

A mixed methods approach was utilized in the conduct of the research for this thesis with both qualitative and quantitative methods used to explore the potential of brothel leaders as facilitators of consistent condom use. The cross-sectional study using secondary data from a nationally representative sample of FSWs was used in chapter 2 to explore the differences in HIV prevalence and high-risk behaviour of FSWs. The studies in chapter 4 and 5 used a Cluster Randomized Controlled Trial (CRCT) approach to investigate the feasibility and effects of a pilot intervention which enabled the investigation of outcomes at both individual and brothel-levels with the brothels assigned as clusters. The use of the CRCT allowed us to study changes at the brothel level avoiding contamination within clusters and the use of multilevel analysis enabled multivariate analysis of outcomes and accommodated for data missing due to attrition (e.g. due to the mobility of FSWs). 
The qualitative study described in chapter 6 used in-depth interviews to explore the perceptions of relevant stakeholders. Semi-structured questionnaires were designed and used to obtain data. The qualitative study provided more depth and context to the interpretation of the quantitative research conducted and further highlighted the value that social support from gatekeepers within the immediate environment of FSWs offer. The study showed that brothel leadership could support new entrants and young FSWs in the brothel to improve their self-efficacy and consistent condom use, enact and enforce consistent condom use policies within the brothels for both FSWs and their partners and also reduce intimidation, harassment and violence to FSWs. These are especially important in the creation of a conducive environment for condom use uptake in brothels as well as the enhancement of HIV prevention efforts generally.

A key strength of this thesis is the use of both qualitative and quantitative methods which enabled the triangulation of the results obtained from the studies. The inductive approach used in the qualitative study enabled the identification of data driven themes and ensured the internal validity of the findings. The instruments used for data collection were adapted from standardized models used in similar studies in the subSaharan Africa. This study is the first of its kind evaluating and documenting the effects of gatekeeper inclusion and support for consistent condom use in Nigeria. The thesis provides a better understanding of the environmental factors to be considered in addressing condom use amongst FSWs residing in brothels in Nigeria and can be applied to other sex work sub-populations and countries with similar contexts.

Some limitations to the quantitative studies were identified. Although, the pilot study demonstrated the feasibility of the intervention piloted, nonetheless, a fully powered study with larger cluster sample size is required to increase the accuracy of estimation of effect outcomes. Measurement of condom use and condom negotiation among the FSWs posed some difficulty and the self-reported nature of these outcomes was subject to social desirability bias. Most respondents had low literacy levels and could not read the questionnaires on their own. The participants' responses may have been influenced by the interviewers' presence and the way the questions were delivered. To mitigate these limitations, questionnaires were well constructed and pretested with a 
representative sample and the interviewers were adequately trained on questionnaire administration and the interviewing of illiterate participants. However, other methods could also be used to further mitigate negative interviewer-effects like for example the use of self-completion methods for data collection where possible. Another method to reduce social desirability bias for this target group is the prior identification of questions prone to social desirability bias and controlling for bias by the use of a combination of direct and indirect questions (Myung-Soo, 2000).

The frequent migration of FSWs led to high attrition rates and loss to follow-ups during the intervention and this posed significant difficulties in engaging the participants for sustained periods. To mitigate the effect of this on the intervention, we provided repeated dosage of the interventions to enable prevention efforts reach FSWs who may migrate to and from the brothel at different times during the intervention timeframe. The sample size of the pilot study was increased considerably to accommodate the high attrition rates and loss to follow up due to migration. Further research is needed to identify and tailor strategies towards engaging mobile FSW populations who migrate from the intervention base. Further research to understand the mobility and motivation of FSWs for migration might also be helpful for the design of effective HIV prevention interventions. In addition, studies exploring the possible use of mobile phones to reach them irrespective of their location may also be useful.

Brothels recruited for the study were obtained from a pool of brothels with prior exposure to HIV prevention efforts by NGOs and the government. This may have influenced the ease of recruitment into the study and the positive outcomes obtained. In addition, the study location for this study is more affluent compared to most locations in the country and thus, may not be representative of the rural and less affluent areas. More studies including brothels located in rural settings and those without prior exposure to HIV prevention interventions may improve the generalisability of the results.

The qualitative approach used in Chapter 6 to explore the views of brothel leaders and HIV prevention experts could be extended by considering the views of the FSWs 


\section{Chapter 7}

themselves after being exposed to the intervention. Although the FSWs' inputs were included in the design phase of the intervention, their views on the benefits of including gatekeepers within their immediate environment at the end of the intervention would have provided richer insights into both barriers and facilitators, and ultimately result in a better understanding of the roles brothel leaders may play in HIV prevention efforts.

\section{Theoretical Considerations}

The use of constructs derived from the Social Cognitive Theory (SCT) provided valuable insights into behavioural determinants and active learning approaches for the promotion and adoption of condom use behaviours (Glanz \& Viswanath, 2008). Several studies (Snead et al., 2014; Strathdee et al., 2009) have demonstrated that SCT-framed interventions are successful at improving condom use and reducing sexual risk behaviour by improving individuals' behavioural skills and perceptions of their self-efficacy to use condoms through a dynamic inter-relationship between the individual and the environment. This thesis supports previous research on the usefulness of SCT constructs on interventions to improve condom use. However, we did not measure FSWs' perceptions of the different supportive activities carried out by the brothel leaders to influence the immediate brothel environment. Obtaining their views may provide more understanding to further refine gatekeeper engagement for the improvement of consistent condom use by FSWs, and to gain more insight into SCT constructs at the level of FSWs.

Insights from the diffusion of innovation (Rogers, 2003) and stakeholder (Page, 2002) theories were also used within the work presented in this thesis. It is acknowledged that the adoption of an intervention or innovation is largely influenced by not only the quality of the intervention but also the characteristics inherent in the target population. Although this study did not characterize potential adopters or measure the stages of adoption for the intervention, further research on the adoption characteristics of potential targets of the intervention is needed to guide future intervention design for FSWs. The exploration of these concepts influencing the design and adoption of interventions to promote positive condom use behaviours for FSWs should also include adoption characteristics for relevant gatekeepers. 


\section{Implications for Practice}

The criminalization of sex work in Nigeria continues to impede the strides taken towards controlling the epidemic within this population. The social exclusion and stigma associated with sex work in the Nigerian society contributes to the multiple vulnerabilities experienced by FSWs and may influence their access to HIV prevention and health services. Health promotion experts should consider the incorporation of strategies aimed at soliciting the active participation of gatekeepers within the immediate environment of FSWs and explore various motivational schemes to facilitate their consciousness of their health promotion responsibilities for HIV prevention efforts. Gender power plays and social inequities in relationships between FSWs and their steady partners are some barriers experienced by HIV prevention experts in efforts to improve consistent condom use by FSWs with their boyfriends and casual partners. FSWs prefer not to use condoms with their steady partners in a bid to foster increase intimacy, closeness and trust. The use of condoms with their steady partners could also be perceived as a sign of infidelity and give rise to mistrust (Sanders, 2002; Varga, 1997). Further research to identify and develop multilevel interventions addressing the influence of these factors on the consistent use of condoms with FSW steady partners is recommended.

Access to HIV prevention interventions and health services is important, and includes physical access (availability), financial access (affordability) and cultural access (acceptability). Several studies have explored approaches to improve the availability, accessibility and affordability of health interventions and services as well as the barriers experienced by FSWs especially towards accessing sexual and reproductive health services (Davis et al., 2016; Jie et al., 2012; Varga, 1997). This thesis recommends that emphasis should be placed on stakeholders and systems that increase access to HIV prevention programs and services tailored to the needs of FSWs.

It is also important to include within existing guidelines and strategies in the country, the extent of gatekeepers' inclusion in structural components of HIV prevention interventions to aid its institutionalization by relevant stakeholders. This necessitates the conduct of more research to further inform feasibility and streamline expectations on its implementation and adoption. These studies can also explore feasibility of 


\section{Chapter 7}

implementation for other typologies of sex work as well as geographical and socioeconomic differences influencing sex workers' vulnerability within the country. Nigeria's Minimum Prevention Package of Interventions (MPPI) strategy for HIV prevention for FSWs feeds from the global UNAIDS combination prevention approach (UNAIDS, 2010), the limited consideration it places on the inclusion of gatekeepers within the immediate environment of the FSWs in HIV prevention efforts in Nigeria is evident and this thesis recommends addressing it (NACA, 2014). In addition to the support provided by brothel leaders in this study, it is also important to note that supportive strategies and policies by the government remain crucial in the prevention of HIV and STIs with sex work populations.

\section{Conclusion}

This thesis has provided an understanding of the possible roles brothel leaders can play in HIV prevention efforts to improve consistent condom use by FSWs residing in brothels in Nigeria. The information herein can be used to develop future interventions to address relevant barriers to FSW consistent condom use and improve HIV prevention efforts for this target group. The experiences from the cluster randomized pilot trial can help in conducting more extensive evaluations on the involvement of brothel leadership in enhancing condom use by FSWs. It is also important to identify and address relevant environmental factors other than brothel leadership in influencing the adoption of healthful behaviours among FSWs. 


\section{REFERENCES}


Adeneye, A. K., Adeneye, A. A., Mafe, M. A., \& Adeiga, A. A. (2013). Pattern of condom use and perceived risk of HIV infection among female sex workers in selected Brothels in Ogun State, Nigeria. International Journal of Public Health and Epidemiology 2(5), 90-100.

Adu-Oppong, A., Grimes, R. M., Ross, M. W., Risser, J., \& Kessie, G. (2007). social and behavioral determinants of consistent condom use among female commercial sex workers in Ghana AIDS Education and Prevention, 19(2), 160-172.

Ahonsi, B., Tawab, N., Geibel, S., Kalibala, S., Okal, J., Mane, B., .. Green, E. (2014). HIV/AIDS vulnerabilities, discrimination, and service accessibility among Africa's youth: insights from a multi-country study. Retrieved from Abuja, Nigeria:

Asamoah-Adu, A., Weir, S., Pappoe, M., Kanlisi, N., Neequaye, A., \& Lamptey, P. (1994). Evaluation of a targeted AIDs prevention intervention to increase condom use among prostitutes in Ghana. AIDS, 8, 239-246.

Asowa-Omorodion, F. (2000). Sexual and health behaviour of commercial sex workers in Benin city, Edo state, Nigeria. Health Care for Women International, 21(4), 335 345. doi:10.1080/073993300245186

Bandura, A. (1994). Social cognitive theory and exercise of control over HIV infection. 1994. p. 25-60 In: DiClemente RJ, Peterson JL, editors. Preventing AIDS: theories and methods of behavioral interventions. doi:10.1007/978-1-4899-1193-3_3

Baral, S., Beyrer, C., Muessig, K., Poteat, T., Wirtz, A. L., Decker, M. R., . . Kerrigan, D. (2012). Burden of HIV among female sex workers in low-income and middleincome countries: a systematic review and meta-analysis Lancet, 12(7), 538-549.

Bartholomew, L. K., Parcel, G. S., Kok, G., Gottlieb, N. H., \& Fernández, M. E. (2011). Planning Health Promotion Programs: an Intervention Mapping Approach (3rd ed.). San Francisco, CA: Jossey-Bass.

Bekker, L., Johnson, L., Cowan, F., Overs, C., Besada, D., Hillier, S., \& Cates, W. (2015). Combination HIV prevention for female sex workers: what is the evidence? Lancet, $385,72-87$.

Bernhardt, P. W., Wang, H. J., \& Zhang, D. (2015). Statistical methods for generalized linear models with covariates subject to detection limits. Statiscs in Biosciences, 7(1), 68-89. doi:10.1007/s12561-013-9099-4

Bhave, G., Lindan, C. P., Hudes, E. S., Desai, S., Wagle, U., Tripathi, S. P., \& Mandel, J. S. (1995). Impact of an intervention on HIV, sexually transmitted diseases, and condom use among sex workers in Bombay, India. AIDS, 9(Supp 1), 21-30.

Bukenya, J., Vandepitte, J., \& Kwikiriza, M. (2013). Condom use among female sex workers in Uganda. AIDS Care 25(6), 767-774.

Carney, T., Petersen Williams, P. M., \& Parry, C. D. H. (2016). IthubalethuIntervention to Address Drug Use and Sexual HIV Risk Patterns among Female 
Commercial Sex Workers in Durban, South Africa. Journal of Psychoactive Drugs, 48(4), 303-309.

Castan eda, X., Ortiz, V., Allen, B., Garcia, C., \& Hernandez- Avila, M. (1996). Sex masks: The double life of female commercial sex workers in Mexico City. Culture, Medicine, and Psychiatry, 20(2), 229-247. doi:10.1007/BF00115863

Charania, M. R., Crepaz, N., Guenther-Gray, c., Henny, K., Liau, A., Willis, L. A., \& Lyles, C. M. (2011). Efficacy of Structural-Level Condom Distribution Interventions: A Meta-Analysis of U.S. and International Studies,1998-2007. AIDS and Behavior, 15(7), 1283-1297. doi:10.1007/s10461-010-9812-y.

Chatterji, M., Murray, N., London, D., \& Angelwicz, P. (2005). The factors influencing transactional sex among young men and women in 12 sub-Saharan countries. Social Biology 52, 56-72.

Chersich, M. F., Luchters, S., Ntaganira, I., Gerbase, A., Lo, Y. R., Scorgie, F., \& Steen, R. (2013). Priority interventions to reduce HIV transmission in sex work settings in sub-Saharan Africa and delivery of these services. International Aids Society 16(1), 17980. doi:10.7448/IAS.16.1.17980

Cochrane. (2011). Handbook for Systematic Reviews of Interventions (Vol. 5.1.0): John Wiley \& Sons Ltd.

Cwikel, J. G., Lazer, T., Press, F., \& Lazer, S. (2008). Sexually transmissible infections among female sex workers: an international review with an emphasis on hard-to-access populations. Sex Health 5, 9-16.

Dandona, R., Dandona, L., Gutierrez, J. P., Anil, G. K., McPherson, S., Samuels, F., \& Bertozzi, S. M. (2015). High risk of HIV in non-brothel based female sex workers in India. BMC Public Health 5, 87. doi:10.1186/1471-2458-5-87

Davis, A., Meyerson, B. E., Aghaulor, B., Brown, K., Watson, A., Muessig, K. E., . . . Tucker, J. D. (2016). Barriers to health service access among female migrant Ugandan sex workers in Guangzhou, China. International Journal for Equity in Health, 15, 170. doi:10.1186/s1293

de Bruin, M., Viechtbauer, W., Schaalma, H. P., Kok, G., Abraham, C., \& Hospers, H. J. (2010). Standard care Impact on effects of Highly Active Antiretroviral Therapy Adherence Interventions Archives of Internal Medicine, 170(3), 240-250.

Dhana, A., Luchters, S., Moore, L., Yves, L., Roy, A., Scorgie, A., \& Chersich, M. F. (2014). Systematic review of facility-based sexual and reproductive health services for female sex workers in Africa. Globalization and Health, 10, 46. doi:10.1186/17448603-10-46

Dziura, J. D., Post, L. A., Zhao, Q., Fu, Z., \& Peduzzi, P. (2013). Strategies for Dealing with Missing Data in Clinical Trials: From Design to Analysis. Yale Journal of Biology and Medicine, 86(3). 
Egger, M., Pauw, J., Lopatatzidis, A., Medrano, D., Paccaud, F., \& Smith, G. D. (2000). Promotion of condom use in a high-risk setting in Nicaragua: A randomized controlled trial. Lancet, 355, 2101-2105.

Eluwa, G., Strathdee, S. A., Adebajo, S., Ahonsi, B., Azeez, A., \& Anyanti, J. (2012). Sexual risk behaviors and HIV among female sex workers in Nigeria. Acquired Immune Deficiency Syndrome, 61(4), 507-514. doi:10.1097/QAI.0b013e31826dfb41

Ezirim, I., Ogungbemi, K., Daniel, U., Blanchard, J., \& Ezire, O. (2015). Evidence from epidemic appraisals in Nigeria. African Evaluation Journal, 3(2).

Fang, X. Y., Li, X. M., \& Yang, H. M. (2007). Profile of female sex workers in a Chinese county: does it differ by where they came from and where they work? World Health Population, 9, 46-64.

Fawole, O. I., \& Dagunduro, A. T. (2014). Prevalence and correlates of violence against female sex workers in Abuja, Nigeria. African Journal Health Science, 14(2). doi:10.4314/ahs.v14i2.4

Feldblum, P. J., Hatzell, T., Van Damme, K., Nasution, M., Rasamindrakotroka, A., \& Grey, T. W. (2005). Results of a randomised trial of male condom promotion among Madagascar sex workers. Sexually Transmitted Infection, 81, 166-173. doi:10.1136/sti.2004.010074

Fitch, J. T., Stine, C., Hager, W. D., Mann, J., Adam, M. B., \& McIlhaney, J. (2002). Condom effectiveness: factors that Influence risk reduction. Sexually Transmitted Diseases,, 29(12), 811-817.

FMOH. (2010). Nigeria integrated biological and behavioural surveillance survey 2010 Retrieved from Abuja, Nigeria:

FMOH. (2013). National HIV \& AIDS and Reproductive Health Survey, 2012 (NARHS Plus II). Retrieved from Abuja, Nigeria:

FMOH. (2014). Nigeria integrated biological and behavioural surveillance survey Retrieved from Abuja Nigeria

Foss, A. M., Hossain, M., Vickerman, P. T., \& Watts, C. H. (2007). A systematic review of published evidence on intervention impact on condom use in sub-Saharan Africa and Asia. Sexually Transmitted Infections 83, 510-516.

Ghys, P. D., Diallo, M. O., EttieÁgne-Traore, V., Kalé, K., Tawil, O., Caraël, M., . . . Greenberg, A. E. (2002). Increase in condom use and decline in HIV and sexually transmitted diseases among female sex workers in Abidjan, Cote d'Ivoire, 1991 \pm 1998 . AIDS, 16, 251-258. doi:10.1097/00002030-200201250-00015

Glanz, K., \& Viswanath, K. (2008). Health Behaviour and Health Education; Theory, Research and Practice (4th ed.): Jossy Bass. . 
Gruber von Kerenshazy, J. (2007). Working with brothel owners to promote HIV prevention: challenges and future directions. Exchange on HIV/AIDS, sexuality and gender.

Gunturu, S. R. (2015). Need of unique attention on young \& new sex worker -In HIV prevention. Journal of Nursing care, 4(4).

Hong, Y., Fang, X., Li, X., Liu, Y., \& Li, M. (2008). Environmental support and HIV prevention behaviors among female sex workers in China. Sexually Transmitted Diseases, 35(7), 662-667. doi:10.1097/OLQ.0b013e31816b322c

Hong, Y., \& Li, X. (2008). Behavioral studies of female sex workers in China: A literature review and recommendation for future research. AIDS and Behavior, 12(4), 623-636.

Huang, Y., Henderson, G. E., Pan, S., \& Cohen, M. S. (2004). HIV/AIDS risk among brothel-based female sex workers in China: assessing the terms, content, and knowledge of sex work. Sexually Transmitted Diseases, 31(11), 695-700.

Huang, Y., Muessig, K., Zhang, N., \& Mamanb, S. (2015). Unpacking the 'structural' in a structural approach for HIV prevention among female sex workers: A case study from China. Global Public Health, 10(7), 852-866

Ikpeazu, A., Momah-Haruna, A., Mari, B. M., Thompson, L., \& Ogungbemi, K. (2014). An appraisal of female sex work in Nigeria - Implications for designing and scaling up HIV prevention programmes. PLoS ONE, 9(8). doi:10.1371/journal.pone.0103619

Izugbara, C. (2007). Constituting the unsafe: Nigerian sex workers' notions of unsafe sexual conduct. African Studies Review, 50(3), 29-49. doi:10.1353/arw.2008.0025

Jana, S., Basu, I., Rotheram-Borus, M., \& Newman, P. (2004). The Sonagachi project: A Sustainable community intervention program. AIDS Education and Prevention, 16(5), 405-414.

Jie, W., Xiaolan, Z., Ciyong, L., Moyer, E., Hui, W., Lingyao, H., \& Xueqing, D. (2012). A qualitative exploration of barriers to condom use among female sex workers in China. PLoS ONE, 7(10).

Johnson, B. L., von Haefton, I., Fishbeina, M., Kasprzykb, D., \& Montanob, D. (2001). Factors influencing IDU and non-IDU female commercial sex workers' intentions to always use condoms for vaginal sex with their regular partner. Psychology, Health and Medicine 6(2), 207-222.

Karon, J. M., \& Wejnert, C. (2012). Statistical methods for the analysis of time-location sampling data. Journal of Urban Health, 89(3), 565-586.

Kayembe, P. K., Mapatano, M. A., Busangu, A. F., Nyandwe, J. K., Musema, G. M., \& Kibungu, J. P. (2008). Determinants of consistent condom use among female commercial sex workers in the Democratic Republic of Congo:Implications for 
interventions Sexually Transmitted Infection 84, 202-206. doi:10.1136/sti.2007.028324

Kerrigan, D., Ellen, J. M., Morenoc, L., Rosario, S., Katz, J., Celentano, D. D., \& Sweat, M. (2003). Environmental-structural factors significantly associated with consistent condom use among female sex workers in the Dominican Republic. AIDS, 17, 415-423. doi:10.1097/00002030-200302140-00016

Kerrigan, D., Fonner, V. A., Stromdahl, S., \& Kennedy, C. E. (2013). Community empowerment among female sex workers is an effective HIV prevention intervention: a systematic review of the peer-reviewed evidence from low- and middle-income countries. AIDS and Behavior, 17(6), 1926-1940.

Kerrigan, D., Wirtz, A., Baral, S., Decker, M., Murray, L., Poteat, T., . . Beyrer, C. (2013). The global HIV epidemics among sex workers. Retrieved from Washington DC:

Kok, G., Gottliebb, N. H., G.Y, P., Mullenb, P. D., Parcel, G. S., Ruiter, R. A., . . . Bartholomew, L. K. (2015). A Taxonomy of Behavior Change Methods; an Intervention Mapping Approach. Health Psychology Review 10(6), 297-312. doi:10.1080/17437199.2015.1077155

Kummarikunta, G., Mathapati, C. R., \& Halli, S. S. (2015). Mobility as a Differential Factor of HIV Among Female Sex Workers in Belgaum District, Karnataka, India. Journal of HIV/AIDS \& Social Services 14(2), 223-238. doi:10.1080/15381501.2014.942486

Laga, M., Alary, M., Nzila, N., Manoka, A. T., Tuliza, M., Behets, F., . . . Piot, P. (1994). Condom Promotion, Sextually Transmitted diseases treatment, and decling incidence of HIV 1 Infection in Female Zairian Sex workers Lancet, 344(8917), 346348.

Li, Q., Li, X., Stanton, B., Fang, X., \& Zhao, R. (2010). A multilevel analysis of gatekeeper characteristics and consistent condom use among establishment-based female sex workers in Guangxi, China. Sexually Transmitted Diseases 37(11), 700705. doi:10.1097/OLQ.0b013e3181e1a2b2

Luchters, S., Chersich, M. F., Rinyiru, A., Barasa, M., King'ola, N., Mandaliya, K., . . . Temmerman, M. (2008). Impact of five years of peer-mediated interventions on sexual behavior and sexually transmitted infections among female sex workers in Mombasa, Kenya. BMC Public Health 8, 143.

Mbirimtengerenji, N. D. (2007). Is HIV/AIDS Epidemic Outcome of Poverty in SubSaharan Africa? Croatian Medical Journal, 48(5), 605-617.

Mckee, N., Betrand, J. T., \& Becker, A. B. (2004). Strategic Communication in HIV/AIDs epidermics F. Edition (Ed.)

Molenberghs, G., \& Kenward, M. (2007). Missing data in clinical studies. Missing data in clinical studies Vol. 61. doi:10.1002/9780470510445 
Moore, L., Chersich, M. F., Steen, R., Reza-Paul, S., Dhana, A., Vuylsteke, B., . . . Scorgie, F. (2014). Community empowerment and involvement of female sex workers in targeted sexual and reproductive health interventions in Africa: a systematic review. Globalization and Health, 10(47). doi:DOI: 10.1186/1744-8603-10-47

Morisky, D., Pena, M., \& TV, T. (2002). The impact of the work environment on condom use among female bar workers in the Philippines. Health Education and Behaviour 29, 461-472.

Morisky, D., Stein, J. A., Chiao, C., Ksobiech, K., \& Malow, R. (2006). Impact of a social influence intervention on condom use and sexually transmitted infections among establishment-based female sex workers in the Philippines: A multilevel analysis. Health Psychology, 25(5), 595-603. doi:10.1186/1471-2458-8-143

Morisky, D. E., Stein, J. A., Sneed, C. D., Tiglao, T. V., Liu, K., Detels, R., \& Temponko, S. B. (2002). Modeling personal and situational influences on condom use among establishment-based commercial sex workers in the Philippines. AIDs and Behavior, 6, 163-172. doi:doi:10.1023/A:1015401315918

Morisky, D. E., Tiglao, T. V., \& Sneed, C. D. (1998). The effects of establishment practices, knowledge and attitudes on condom use among Filipino sex workers. AIDS Care, 10, 213-220.

Muñoz, J., Adedimeji, A., \& Olayemi, A. (2010). 'They bring AIDS to us and say we give it to them': Socio-structural context of female sex workers' vulnerability to HIV infection in Ibadan Nigeria. Journal of Social Aspects of HIV/AIDS, 7 (2 ).

Murray, L., Moreno, L., Rosario, S., Ellen, J., Sweat, M., \& Kerrigan, D. (2007). The role of relationship intimacy in consistent condom use among female sex workers and their regular paying partners in the Dominican Republic. AIDS and Behavior, 11, 463470. doi:10.1007/s10461-006-9184-5

Myung-Soo, J. (2000). Controlling social-desirability bias via method factors of direct and indirect questioning in structural equation models. Psychology and Marketing, 17(2), 137-148.

NACA. (2010). National HIV/AIDS Strategic plan for Nigeria 2010-2015. Retrieved from

http://www.nationalplanningcycles.org/sites/default/files/country_docs/Nigeria/hiv_pl an_nigeria.pdf website:

NACA. (2014). National Guidelines for Implementation of HIV Prevention Programs for Female Sex Workers in Nigeria Retrieved from

Nagot, N., Ouedraogo, A., Ouangre, A., Cartoux, M., Defer, M. C., Meda, N., \& Van de Perre, P. (2005). Is Sexually Transmitted Infection Management Among Sex Workers Still Able to Mitigate the Spread of HIV Infection in West Africa? . Acquired Immune Deficiency Syndromes, 39(4), 454-458. 
National Population Commission. (2014). Nigeria Demographic and Health Survey 2013. Retrieved from

Ngugi, E., Chakkalackal, M., Sharma, A., Bukusi, E., Njoroge, B., Kimani, J., . . . Bwayo, J. J. (2007). Sustained Changes in Sexual Behavior by Female Sex Workers After Completion of a Randomized HIV Prevention Trial. Acquired Immune Deficiency Syndromes, 45(5), 588-594.

Ngugi, E., Wilson, D., Sebstad, J., Plummer, F. A., \& Moses, S. (1996). Focused Peer mediated educational programs among female sex workers to reduce sexually transmitted disease and Human Immunodeficiency virus transmission in Kenya and Zimbabwe. Infectious diseases, 174(S240-7).

Odek, W. O., Busza, J., Morris, C. N., Cleland, J., Ngugi, E. N., \& Ferguson, A. G. (2009). Effects of Micro-Enterprise Services on HIV Risk Behaviour Among Female Sex Workers in Kenya's Urban Slums. AIDS and Behaviour, 13, 449-461.

Okafor, U. O., Crutzen, R., Adebajo, S., Okekearu, I., \& van Den Borne, H. (2017). Using brothel leadership to promote condom use among brothel-based Female Sex Workers in Abuja, Nigeria: Study protocol for a cluster randomized pilot trial. $B M C$ Pilot and feasibility studies 3(10). doi:10.1186/s40814-017-0124-0

Okafor, U. O., Crutzen, R., Aduak, Y., Adebajo, S., \& Van den Borne, H. W. (2017). Behavioural interventions promoting condom use among female sex workers in subSaharan Africa: a systematic review. African Journal of Aids research, 16(3), 257-268. doi:10.2989/16085906.2017.1358753

Okafor, U. O., Crutzen, R., Okekearu, I., Adebajo, S., \& Van Den Borne, H. (2017). HIV prevalence and high risk behaviour of young brothel and non-brothel based female sex workers in Nigeria. BMC Research Notes, 10, 380. doi:10.1186/s13104-017-27128

Onwuliri, V. A., \& Jolayemi, O. M. (2005). Reaching vulnerable and high risk groups in Nigeria AIDS in Nigeria: A Nation on the Threshold (pp. 309-320): Harvard University Press.

Outwater, A., Nkyama, L., Lwihula, G., O'Connor, P., \& Leshabari, M. (2000). Patterns of partnership and condom Use in Two communities of female sex workers in Tanzania. Journal of the Association of Nurses in AIDS Care, 11(4), 46-54.

Page, C. G. (2002). The determination of organization stakeholder salience in public health. Journal of Public Health Management and Practice, 8(5), 76-84.

Parcesepe, A. M., L'Engleb, K. L., Martin, S. L., Green, S., Sinkele, S., Suchindran, C., . . . Kingola, N. (2016). The impact of an alcohol harm reduction intervention on interpersonal violence and engagement in sex work among female sex workers in Mombasa, Kenya: Results from a randomized controlled trial. Drug and Alcohol Dependence, , 161, 21-28. doi:10.1016/j.drugalcdep.2015.12.037 
Patterson, T. L., Semple, S. J., Fraga., M., Bucardo, J., \& De la Torre, A. (2006). A sexual risk reduction intervention for female sex workers in Mexico: Design and baseline characteristics. Journal HIV/AIDS \& Social Services, 5, 115-137.

Peterman, T. A., Lin, L. S., \& Newman, D. R. (2000). Does measured behaviour reflect STD risk? An analysis of data from a randomized controlled behavioral intervention study. Sexually Transmitted Diseases, 27, 446-451.

Peters, G.-J. Y., \& Crutzen, R. (2017). Knowing exactly how effective an intervention, treatment, or manipulation is and ensuring that a study replicates: accuracy in parameter estimation as a partial solution to the replication crisis. Retrieved from osf.io/preprints/psyarxiv/cjsk2.

Pickering, H., Quigley, M., Pépin, J., Todd, J., \& Wilkins, A. (1993 ). Effects of post test counselling on condom use among prostitutes in the Gambia. AIDS, 7(271), 273.

Platt, L., Grenfell, P., Fletcher, A., Sorhaindo, A., Jolley, E., \& Rhodes, T. (2013). Systematic review examining differences in HIV, sexually transmitted infections and health-related harms between migrant and non-migrant female sex workers. Sexually Transmitted Infection, 89(4), 311-319.

Platt, L., Jolley, E., Rhodes, T., Hope, V., Latypov, A., \& Reynolds, L. (2013). Factors mediating HIV risk among female sex workers in Europe: A systematic review and ecological analysis. BMJ Open 3(7). doi:10.1136/bmjopen-2013-002836

Prüss-Ustün, A., Wolf, J., Driscoll, T., Degenhardt, L., Neira, M., \& Calleja, J. M. G. (2013). HIV due to female sex work: regional and global estimates. PLoS ONE, 8(5). doi:10.1371/journal.pone.0063476

Qiao, S., Li, X., Zhang, C., Zhou, Y., Shen, Z., \& Tang, Z. (2015). Social Support and Condom Use Among Female Sex Workers in China. Health Care for women international 36, 7. doi:10.1080/07399332.2014.971952

Ramesh, S., Ganju, D., Mahapatra, B., Mishra, R. M., \& Saggurti, N. (2012). Relationship between mobility, violence and HIV/STI among female sex workers in Andhra Pradesh, India. BMC Public Health 12, 764. doi:10.1186/1471-2458-12-764

Raul, K., Kimani, J., Nagelkerke, N. J., Fonck, K., Keli, F., \& MacDonald, K. S. (2002). Reduced HIV risk taking and low HIV incidence after enrolment and risk reduction counselling in a sexually transmitted disease prevention trial in Nairobi Kenya Acquired Immune Deficiency Syndromes, 30(1), 69-72. doi:10.1097/00042560200205010-00009

Ray, S., van De Wijgert, J., Mason, P., Ndowa, F., \& Maposhere, C. (2001). Constraints faced by sex workers in use of female and male condoms for safer sex in urban Zimbabwe. Urban Health 78(4). doi:10.1093/jurban/78.4.581 
Richter, M., Chersich, M. F., Temmerman, M., \& Luchters, S. (2013). Characteristics, sexual behaviour and risk factors of female, male and transgender sex workers in South Africa. Culture, Health \& Sexuality, 15(7), 759-773. doi:10.7196/SAMJ.6170

Roger, A. J. (2016). Sexual Activity Without Condoms and Risk of HIV Transmission in Serodifferent Couples When the HIV-Positive Partner Is Using Suppressive Antiretroviral Therapy. Journal of the American Medical Association,, 316(2).

Rogers, E. M. (2003). Diffusion of innovations (5th ed.): Simon and Schuster.

Rogers, E. M., \& Kincaid, D. L. (1981). Communication networks: Toward a new paradigm for research. Newyork: Free Press.

Rojanapithayakorn, W. (2006). The 100\% condom use programme in Asia. Reproductive Health Matters., 14(28), 41-52.

Sanders, T. (2002). The condom as psychological barrier: Female sex workers and emotional management. Feminism \& Psychology, 12, 561-566. doi: $10.1177 / 0959353502012004016$

Sandoy, I., Zyaambo, C., Michelo, C., \& Fylkesnes, K. (2012). Targeting condom distribution at high risk places increases condom utilization-evidence from an intervention study in Livingstone, Zambia. BMC Public Health, 12(10). doi:10.1186/1471-2458-12-10

Sarkar, K., Bal, B., \& Mukherjee, R. e. a. (2016). Young age is a risk factor for HIV among female sex workers-An experience from India. Journal of infection, 53(4), 255-259.

Scorgie, F., Chersich, M. F., Ntaganira, I., Gerbase, A., Lule, F., \& Lo, Y. R. (2012). Socio-demographic characteristics and behavioral risk factors of female sex workers in sub-saharan Africa: a systematic review. AIDS and Behavior 16(4), 920-933.

Seeley, J., Watts, C. H., Kippax, S., Russell, S., Heise, L., \& Whiteside, A. (2012). Addressing the structural drivers of HIV: a luxury or necessity for programmes? Journal of the International AIDS Society, 15(Suppl 1), 17397.

Shahmanesh, M., Patel, V., Mabey, D., \& Cowan, F. (2008). Effectiveness of interventions for the prevention of HIV and other sexually transmitted infections in female sex workers in resource poor setting: a systematic review. Tropical Medicine and international Health 13(5), 659-679.

Shiva, R. M., \& Sanjeev, R. N. (2015). Differentiated typology of sex work and implications for HIV prevention programs among female sex workers in Nepal. Frontiers in Public Health, 3(36). doi: 10.3389/fpubh.2015.00036

Smith, L., Powers, K. A., Kashuba, A. D., \& Cohen, M. S. (2011). HIV-1 treatment as prevention: the good, the bad, and the challenges Current Opinion in HIV and AIDS 6(4), 315-325. 
Snead, M. C., O'Leary, A. M., Mandel, M. G., Kourtis, A. P., Wiener, J., Jamieson, D. J., . . Margolis, A. D. (2014). Relationship between social cognitive theory constructs and self-reported condom use: Assessment of behaviour in a subgroup of the Safe in the City trial. BMJ Open, 4(12). doi:10.1136/bmjopen-2014-006093.

Steen, R., Vuylsteke, B., DeCoito, T., Ralepeli, S., Fehler, G., Conley, J., . . . al, e. (2000). Evidence of declining STD prevalence in a South African Mining Community following a core-group intervention. Sexually Transmitted Diseases, 27(1).

Steen, R., Wheeler, T., Gorgens, M., Mziray, E., \& Dallabetta, G. (2015). Feasible, efficient and necessary, without exception - working with sex workers interrupts HIV/STI transmission and brings treatment to many in need. PLoS ONE. doi:10.1371/journal.pone.0121145

Stoebenau, K., Heise, L., Wamoyi, J., \& Bobrova, N. (2016). Revisiting the understanding of "transactional sex" in sub-Saharan Africa: A review and synthesis of the literature. Social Science \& Medicine 168, 186-197.

Stoebenau, K., Hindin, M. J., Nathanson, C. A., Rakotoarison, C. G., \& Razafintsalama, V. (2009). ".......But then he became my sipa': the implications of relationship fluidity for condom use among women sex workers in Antananarivo, Madagascar. American Journal of Public Health 99(5), 811-819. doi:10.2105/AJPH.2007.118422.

Strathdee, S. A., Mausbach, B., Lozada, R., Staines-Orozco, H., Semple, S. J., Abramovitz, D., . . . Patterson, T. L. (2009). Predictors of sexual risk reduction among Mexican female sex workers enrolled in a behavioral intervention study. Acquired Immune Deficiency Syndrome, 51(1), S42-46.

Sullivan, L. M. (2012). Essentials of Biostatistics in Public Health (R. Riegelman Ed. 2nd ed.): Jones and Bartlett Learning.

Thomsen, S. C., Ombidi, W., Toroitich-Ruto, C., Wong, E. L., Tucker, H. O., \& Homan, R. (2006). A prospective study assessing the effects of introducing the female condom in a sex worker population in Mombassa. Sexual Transmitted Infection, 82, 397-402.

Ulibarri, M. D., Strathdee, S. A., Lozada, R., \& Magis-Rodriguez, C. (2010). Intimate Partner Violence among Female Sex Workers in Two Mexico-U.S. Border Cities: Partner Characteristics and HIV Risk-behaviors as Correlates of Abuse. Psychological Trauma, 2(4), 318-325. doi:10.1037/a0017500

Ulibarri, M. D., Strathdee, S. A., Lozada, R., Staines-Orozco, H. S., Abramovitz, D., \& Semple, S. (2012). Condom use among female sex workers and their non-commercial partners: Effects of a sexual risk intervention in two Mexican cities. International Journal of STD \& AIDS, 23(229-234). doi:10.1258/ijsa.2011.011184

UNAIDS. (2000). Evaluation of the 100\% condom programme in Thailand. Retrieved from Geneva Switzerland: 
UNAIDS. (2008). Report on the global HIV/AIDS epidemic 2008. Retrieved from Geneva

UNAIDS. (2009a). Monitoring the declaration of commitment on HIV/AIDS : Guidelines on construction of core indicators; 2010 reporting. Geneva: UNAIDS.

UNAIDS. (2009b). UNAIDS Guidance Note on HIV and Sex Work. Retrieved from http://www.unaids.org/sites/default/files/sub_landing/files/JC2306_UNAIDSguidance-note-HIV-sex-work_en.pdf website:

UNAIDS. (2010). Combination HIV prevention:Tailoring and coordinating biomedical, behavioural and structural strategies to reduce new HIV infections. Retrieved from www.unaids.org/sites/default/files/media_assets/jc2007_combination_prevention_pap er_en_pdf website:

UNAIDS. (2011). World Aids Day Report 2011. How to get to zero: Faster,Smarter, Better. Retrieved from

UNAIDS. (2014). The GAP Report, Assessed 31st July 2017 on http://www.unaids.org/sites/default/files/media_asset/UNAIDS_Gap_report_en.pdf. Retrieved from Geneva

UNAIDS. (2016). Global AIDs update 2016 http://www.who.int/hiv/pub/arv/globalAIDS-update-2016_en.pdf?ua=1 (Report). Retrieved 18 July 2017, from UNAIDS

UNFPA. (2003). UNFPA \& young people. Retrieved from http://www.unfpa.org/adolescents

Urada, L. A., Morisky, D. E., Hernandez, L. I., \& Strathdee, S. A. (2013). Social and structural factors associated with consistent condom use among female entertainment workers trading sex in the Philippines. AIDS and Behaviour, 17(2), 523-535. doi:10.1007/s10461-011-0113-x

Vandepitte, J., Lyerla, R., Dallabetta, G., Crabbé, F., M Alary, M., \& Buvé, A. (2006). Estimates of the number of female sex workers in different regions of the world. Sexually Transmitted Infection, 82(Suppl III), 18-25.

Varga, C. A. (1997). The Condom Conundrum: Barriers to Condom Use among Commercial Sex Workers in Durban, South Africa. The African Journal of Public Health, 1, 174-188.

Venkatesh, K. A., Flanigan, T. P., \& Mayer, K. H. (2011). Is expanded HIV treatment preventing new infections? Impact of antiretroviral therapy on sexual risk behaviors in the developing world. AIDS, 25(16), 1939-1949.

Viechtbauer, W., Smits, L., Kotz, D., Budée, L., Spigt, M., Serroyeng, A., \& Crutzen, R. (2015). A simple formula for the calculation of sample size in pilot studies Journal of Clinical Epidemiology, 68(11), 1375-1379. 
Visrutaratna, S., \& Lindan, C. P. (1995). 'Superstar' and 'model brothel': developing and evaluating a condom promotion program for sex establishments in Chiang Mai, Thailand. AIDS, 9(1), 69-75.

Voeten, H. A., Egesah, O. B., Varkevisser, C. M., \& Habbema, J. D. (2007). Female sex workers and unsafe sex in urban and rural Nyanza, Kenya: Regular partners may contribute more to HIV transmission than clients. Tropical Medicine and International Health, 12(2), 174-182. doi:10.1111/j.1365-3156.2006.01776.x

Walden, V. M., Mwangulube, K., \& Makhumula-Nkhoma, P. (1999). Measuring the impact of a behaviour change intervention for commercial sex workers and their potential clients in Malawi. Health Education Research, 14(4), 545-554. doi:10.1093/her/14.4.545

Wang, C., Hawes, S. E., Gaye, A., Sow, P. S., Ndoye, I., \& Manhart, L. E. (2007). HIV prevalence, previous HIV testing, and condom use with clients and regular partners among Senegalese commercial sex workers Sexual Transmitted Infection, 83, 534-540. doi:10.1136/sti.2007.027151

Wang, H., Chen, R. Y., \& Sharp, G. B. (2010). Mobility, risk behavior and HIV/STI rates among female sex workers in Kaiyuan City, Yunnan Province, China. BMC Infectious Diseases, 10, 198. doi:10.1186/1471-2334-10-198

Wariki, W. M., Ota, E., Mori, R., Koyanagi, A., Hori, N., \& Shibuya, K. (2012). Behavioral interventions to reduce the transmission of HIV infection among sex workers and their clients in low- and middle-income countries. Cochrane database Systemmatic Reviews, 2. doi:10.1002/14651858.CD005272.pub3

Wechsberg, W. M., Luseno, W. K., Lam, W. K., Parry, C. D., \& Morojele, N. K. (2006). Substance Use, Sexual risk and Violence; HIV prevention intervention with sex workers in pretoria. AIDS and Behavior, 10(2).

Weller, S. (2002). Condom effectiveness in reducing heterosexual HIV transmission. Cochrane database.

WHO. (2011). Preventing HIV among sex workers in sub-Saharan Africa: A literature review(ISBN 9789241501279 (NLM classification: WC 503.71). Retrieved from http://apps.who.int/iris/bitstream/10665/44549/1/9789241501279_eng.pdf website:

WHO. (2013). Global and regional estimates of violence against women, 2. Retrieved from http://apps.who.int/iris/bitstream/10665/85239/1/9789241564625_eng.pdf,

WHO. (2015). Six innovations in Africa which changed the course of their HIV epidemics. Retrieved 19th July 2017, from WHO http://apps.who.int/iris/bitstream/10665/198066/1/WHO_HIV_2015.47_eng.pdf

WHO. (2016a). Consolidated guidelines on the use of antiretroviral drugs for treating and preventing HIV infection. Retrieved from http://apps.who.int/iris/bitstream/10665/208825/1/9789241549684_eng.pdf?ua=1 
WHO. (2016b). Global health sector strategy on HIV, 2016-2021(WHO/HIV/2016.05). Retrieved from http://apps.who.int/iris/bitstream/10665/246178/1/WHO-HIV2016.05-eng.pdf?ua $=1$

WHO. (2016c). Progress report 2016: Prevent HIV, Test and Treat All Retrieved from http://apps.who.int/iris/bitstream/10665/251713/1/WHO-HIV-2016.24-eng.pdf?ua=1

Williams, B. G., Taljaard, D., Campbell, C. M., Gouws, E., Ndhlovu, L., \& Van Dam, J. (2003). Changing patterns of knowledge, reported behaviourand sexually transmitted infections in a South African gold mining community. AIDS, 17(14).

Williams, E., Lamson, N., Efem, S., Weir, S., \& Lamptey, P. (1992). Implementation of an AIDs prevention program among prostitutes in the Cross river state of Nigeria Acquired Immune Deficiency Syndrome, 6 (2).

Wilton, J., \& Broeckaert, L. (2013). Treatment as prevention: do the individual prevention benefits translate to the population level? http://www.catie.ca/en/pif/fall2013/treatment-prevention-do-individual-prevention-benefits-translate-populationlevel, Assessed 20th December 2016. Retrieved from

World Bank. (2012). Nigeria Maps the HIV `epidemic future of HIV fight. .

Xia, G., \& Yang, X. (2005). Risky sexual behavior among female entertainment workers in China: implications for HIV/STD prevention intervention. AIDS Educucaiton and Prevention, 17(2), 143-156.

Yadav, G., Saskin, R., \& Ngugi, E. (2005). Associations of Sexual Risk Taking Among Kenyan Female Sex Workers After Enrollment in an HIV-1 Prevention Trial. Acquired Immune Deficiency Syndromes, 438, 329-333.

Yang, H., Li, X., Stanton, B., Fang, X., Zhao, R., Dong, B., . . Hong, Y. (2005). Condom use among female sex workers in China: Role of gatekeepers. Sexually Transmitted Diseases, 32(9), 572-580. doi:10.1097/01.olq.0000175418.48665.95

Zang, C., Li, X., \& Hong, Y. (2014). Relationship between female sex workers and gatekeeper: The impact on female sex worker's mental health in China. Psychology, Health and Medicine, 19(6).

Zhang, H., Liao, M., Nie, X., Pan, R., Wang, C., Ruan, S., . . . Jiang, B. (2011). Predictors of consistent condom use based on the Information-Motivation-Behavioral Skills (IMB) model among female sex workers in Jinan, China. BMC Public Health, 11(1). doi:10.1186/1471-2458-11-113

Zhang, X., Temmerman, M., Li, Y., Luo, W., \& Luchters, S. (2013). Vulnerabilities, health needs and predictors of high-risk sexual behaviour among female adolescent sex workers in Kunming, China. Sexually Transmitted Infections, 89, 237-244. 
Zhao, J., Song, F., \& Ren, S. (2012). Predictors of Condom Use Behaviors Based on the Health Belief Model (HBM) among Female Sex Workers: A Cross-Sectional Study in Hubei Province, China. PLoS ONE, 20.

Zhao, R., Wang, B., Fang, X., Li, X., \& Stanton, B. (2008). Condom use and selfefficacy among female sex workers with steady partners in China. AIDS Care, 20, 782 790. doi:10.1080/09540120701694030 



\section{SUMMARY}


The existence of a conducive social environment to enhance consistent condom use with all sexual partners and the reduction of high risk sexual behaviours are some important goals of HIV prevention interventions designed for FSWs. FSWs have been identified as a core group in the transmission of HIV and other sexually transmitted infections (STIs) in Nigeria, and together with their partners, they account for $40 \%$ of new HIV infections in the country. This high HIV prevalence among female populations involved in sex work in Nigeria has heightened interest in HIV prevention programming for this sub-population.

Several empirical studies were conducted in this thesis to explore consistent condom use by Brothel Based (BB) FSWs and to investigate the positive influence gatekeepers within the immediate environment of FSWs could exert on their consistent condom use behaviours with their clients and regular partners. Chapter 2 gives an insight into HIV prevalence and sexual risk behaviour of young FSWs (aged 15-24 years) in Nigeria focusing on the differences between the two main subgroups of FSWs in the country; BB and Non-Brothel Based (NBB) FSWs. Secondary data analysis of a nationally representative cross-sectional study showed higher HIV prevalence (21.0\% vs. $15.5 \%)$ for young BB FSW compared to the NBB FSWs as well as less consistent condom use with boyfriends ( $26.3 \%$ vs. $45.5 \%$ ) and casual partners (55.1\% vs. $61.1 \%)$. The findings also showed that BB FSWs were less educated and had higher daily number of sexual partners than the NBB FSWs. However, risk of HIV infection due to injecting drug use (6.6\% vs. $1.2 \%)$ and sexual partner violence (16.9\% vs $7.3 \%)$ were higher in NBB compared to BB FSWs. The findings of the study showed the vulnerability of both groups of FSWs and is useful as the first level of needs assessment for this thesis and future HIV prevention interventions.

Chapter 3 reports the findings of a review on behavioural interventions promoting consistent condom use amongst FSWs in sub-Saharan Africa. The effectiveness, intervention content, process and condom use outcomes from 18 eligible interventions (described in 20 studies) conducted in sub-Saharan Africa were reviewed. The review showed that varied approaches were combined and utilised by the behavioural 
interventions within these studies including health education by peers, health workers and project staff as well as activities by brothel owners and brothel managers. The interventions showed positive consistent condom use outcomes with paying clients of FSWs, however, some studies recorded inconsistent condom use with the regular nonpaying partners of FSWs. None of the studies within the review included evaluations to measure outcomes on the inclusion of gatekeepers within the immediate environment of the FSWs.

Chapter 4 describes the protocol for a feasibility study using a cluster randomized pilot trial approach to study the feasibility and acceptability of brothel leaders (chairladies, managers and owners) to provide support and facilitate consistent condom use by FSWs residing in brothels. The intervention activities included free male and female condom distribution, HIV prevention messages on condom use and condom negotiation skills to increase self-efficacy in handling social and gender power plays within their immediate environment. Randomization of brothels into experimental and control conditions with a minimum total sample size of 200 participants was proposed. Recruitment of participants will be carried out from within the brothels recruited for the study with each brothel assigned as a cluster. The control condition will receive a standard intervention consisting of a minimum of six interactive sessions with Peer Educators (PE) engaging their peers through group discussions and one on one interaction using pre-designed HIV prevention messages. The experimental condition will receive the standard intervention as well as interactive sessions with the brothel leadership (chairladies and brothel managers) to facilitate consistent condom use and appropriate condom use policies, conditions and messaging. Both interventions will be delivered over a maximum period of 16 weeks and quantitative assessments will be carried out at baseline and at 16 weeks follow up. The findings will inform feasibility of intervention and sample size estimation for the design of a larger Phase III trial on HIV prevention for this target group in Nigeria.

In Chapter 5, the results of the cluster randomised pilot trial designed in Chapter 4 are presented. The study assesses the potential effects of using brothel leaders to promote a conducive and supportive environment for consistent condom use by FSWs, and also investigates the feasibility of implementing a similar intervention on a broader 


\section{Summary}

scale. Ten brothels in Abuja, Nigeria were randomized and exposed to the experimental $(n=5)$ and control $(n=5)$ arms of the intervention. The feasibility of the intervention, consistent condom use outcomes for FSWs with different partner types and condom negotiation self-efficacy were measured. Condom use outcomes and condom negotiation self-efficacy outcomes were analysed using multi-level mixed regression models. A total of 243 FSWs were recruited into the study (control $n=66$ and experimental $n=177)$ and 107 of them (44\%) were available at 16 weeks follow-up. Positive outcomes for consistent condom use with both clients and steady partners of FSWs were obtained and the intervention demonstrated feasibility. Adherence to the intervention by the FSWs was moderate and the attrition rate was high during the intervention due to FSWs mobility. The results indicate that brothel leaders within the immediate environment of FSWs can exert positive influence for consistent condom use. Brothel leaders can be recruited into HIV prevention efforts and HIV interventions may benefit from their inclusion especially for consistent condom use outcomes.

Chapter 6 describes a qualitative study aimed at exploring the perceptions of brothel leaders and HIV prevention experts on the inclusion of gatekeepers within the immediate environment of FSWs into HIV prevention efforts. In-depth interviews were conducted to explore the perceptions and views of brothel leaders and HIV program experts on the acceptability and roles of gatekeepers in interventions aimed at improving FSW condom use in Nigeria. Brothel leaders are an influential group within the FSWs' social and physical environment and their attitudes, beliefs and actions can influence the immediate brothel environment and the adoption of interventions within the brothel. HIV prevention experts make key decisions on intervention content and strategies adopted for HIV prevention efforts and also influence the design and implementation of HIV prevention strategies within programs. Results show that brothel leadership can support the institution of establishment policies supporting consistent condom use by the FSWs, promotion of HIV awareness, resolution of conflicts and harassments, support to new entrants into sex work and the reinforcement of protective behaviours among the FSWs. The decriminalization of sex work and the inclusion of gatekeepers' support into country HIV program guidelines may contribute to mitigating micro-level sociocultural factors limiting FSWs' rights as well as their access to health services. This qualitative study provides insights into the potential 
positive roles of brothel leaders in improving condom use and other HIV/AIDs related interventions for brothel based FSWs in Abuja, Nigeria.

Finally, the general discussion highlights the main findings, reflects on the strengths and limitations of the study, and provides suggestions for further research. The findings in this thesis suggest that the inclusion of brothel leaders in HIV prevention interventions exerts positive influence on consistent condom use by BB FSWs with different partner types and facilitates individual and community level efficacy in condom negotiation. 



\section{VALORIZATION}




\section{Valorization}

The research presented in this thesis adds value to existing knowledge on the relevance of gatekeepers within the immediate environment of female sex workers (FSWs) in enhancing HIV prevention efforts. Consistent use of condoms is documented as one of the most effective strategies for prevention of sexual transmission of HIV and also as a cost effective public health approach for population level HIV prevention. The Strengthening HIV prevention for Most at Risk Populations (SHiPs for MARPs) program, a behavioural intervention for HIV prevention for key populations within which most of this research is based, is adopting some recommendations from this thesis to facilitate consistent condom use by FSWs within the country using brothel leadership.

Results reported in this thesis emphasize the increased vulnerability to HIV of brothel based female sex workers compared to their non-brothel based counterparts. It further underscores the importance of the social context surrounding sex work and its influence on the social norms and culture prevalent within sex work establishments in line with similar studies conducted in other countries in Asia and the developed world. The research described in chapters 5, 6 and 7 identifies different positive roles brothel leadership plays in improving consistent condom use by brothel based FSWs within the Nigerian context which is currently lacking in published literature. Consistent condom use with all sexual partners is necessary to reduce HIV transmission and improve the health and wellbeing of FSWs. The attitudes, beliefs and practices of brothel leaders can influence the immediate environment within which FSWs reside and consequently have impact on their adoption of consistent condom use behaviours. Involvement and participation of brothel leaders in HIV prevention programs provides social support including condom availability and access, as well as the establishment of policies supporting consistent condom use by FSWS. The resolution of conflicts and harassments and support provision to new entrants into sex work are also important benefits derived from their inclusion.

The economic consequences of HIV infection can translate into deleterious effects such as a reduction in labour supply and productivity as well as reduced economic growth. The social and economic value of this research is highlighted by its investigation of 
relevant demographic and social factors influencing the vulnerability of female sex workers to HIV/AIDs. Identifying these factors provides a platform to better understand how they can be addressed within current programs. An important economic milestone to be achieved by this research is a reduction in the individual health expenditure for the female sex work population. This also extends to the health expenditure for the sexual networks of FSWs and the wider society who are also indirectly affected.

The findings described in this thesis conforms with existing research showing that condom use behaviour is influenced by a continuous interplay between individual and environmental factors. It is important that HIV prevention programs focusing on improving condom use behaviours should address these multiple levels of influence. The additional costs to be incurred by the inclusion of gatekeepers to HIV prevention interventions is minimal and any drawbacks identified is outweighed by the added value. Prevention is cost effective, and the additional costs incurred with the inclusion of brothel leadership into prevention programmes can be submerged within current peer and community mediated approaches without significantly increasing the funding amount.

Our findings suggest a complementary research perspective addressing and evaluating the inclusion of brothel leaderships' influence on consistent condom use with different FSW sexual partner types especially their non-paying partners. This study also calls for the creation of consistent condom use awareness amongst clients and non-paying sexual partners of female sex workers towards improving their knowledge and use of condoms.

This study is the first of its kind in Nigeria documented in peer-reviewed publications and brings to the fore the paucity of data on environmental factors influencing FSW sexual health in the country. Additional studies further investigating the effect of both individual and environmental (i.e. support from gatekeepers) factors are needed to inform the design and implementation of future HIV prevention interventions targeting condom use behaviours of female sex workers. Such studies should involve policy 


\section{Valorization}

makers, development agencies, prevention experts, FSWs and gate keepers to ensure that the results are acceptable to all parties involved. The documentation of more studies will support in-country guideline improvement and can be used to influence funding priorities and future implementation efforts.

This research targets government policy makers, the ministry of health, program implementers and relevant regulatory and funding mechanisms including bilateral donors, the United Nations and other multilateral donors. It has practical implications for public health policy in HIV prevention in the country. The revision of the current guidelines for the implementation of HIV prevention interventions for female sex workers in the country should take into account the results of this research. The existing guideline developed in 2014 merely identifies gatekeepers as entry points into sex work establishments during the start off of interventions. Gate keepers within the immediate environment of FSWs are influential and our findings recommend their active participation as facilitators and mediators within interventions addressing condom use behaviour. Gatekeepers can set up and enforce consistent condom use policies within their establishments and make it mandatory for both FSWs and their clients. It is important that gatekeepers are made aware of their unique role in HIV prevention efforts and are supported to contribute to influencing community norms and practices. Concerted efforts should be made by program managers and health agencies to prioritize gate keeper inclusion in the implementation of health interventions for sex workers and other key populations at risk of HIV infection. 


\section{ACKNOWLEDGEMENTS}


My $\mathrm{PhD}$ Journey and the successful completion of this doctoral dissertation was made possible with the support of several people who contributed in various ways. I am very proud and grateful that I had many people made this achievement possible by providing support and encouragement throughout this great life experience.

I would like to express my sincere gratitude to every one of them. Firstly, I am extremely grateful to my supervisor at the department of health promotion, Prof Bart Van den Borne. This feat was possible only because of the unconditional support you provided. The valuable guidance, scholarly inputs and consistent encouragement I received throughout my research work strengthened my research skills and broadened my research perspective. Thank you for all your teaching and support, I consider myself very blessed to have had you as my supervisor. I learnt a lot from your years of experience and your guidance has resulted in the maturation of my research abilities during this journey

To my co-supervisor Dr Rik Crutzen, I learnt a lot from your amicable and positive personality and disposition. I am very grateful for how you were always available to clarify my uncertainties despite your very busy schedule. It was a great opportunity to do my doctoral programme under your guidance and to learn from your research expertise. I benefitted a lot from your valuable critics and comments on my data analysis and manuscript write-ups as well as how you made sure I was introduced into the world of critiquing other research works in peer review journals.

I thank Dr. Sylvia Adebajo, Country Director, Population Council International, Nigeria who was my co-supervisor for the support provided during the design phase of my research and through my research work. I also thank the management of Society for Family Health, Nigeria and especially the SHiPs for MARPS team for their support throughout the various phases of my research; Mr Ifeanyi Okekearu, I am grateful for the support provided during the data collection phase of my research and the access provided to all the brothels and program materials on the SHiPs for MARPS project. To Chieme, Samuel, Sylvia, Faruna, Emeka, Egbe, Adaora, Ogechukwu, and Yauri, thank you for all the support you provided at various points in my research work. 
The Netherlands ministry of foreign affairs funded this doctoral research and without their financial support, this doctoral dissertation would not have been possible. I also thank the CAPHRI institute and the Health Promotion Department for the opportunity given to not just myself, but also to other international $\mathrm{PhD}$ students. To Leon, Patricia, Francine and Kim. I am very grateful for all your kind support and how you made sure my research experience in Maastricht went smoothly and was enjoyable. To Lori, who always sorted out all my issues before they became issues, thank you very much for your support. Thank you to Mariella, who opened the doors to her home when I had difficulties. To Dora, Ricky and Tina, it was great knowing you all and staying with you. To my fellow PhD students and Postdocs at the department, Kwaku, Chite, Roy, Juliette, Azeez, Ahmed, Michael, Martha, Lusajo and Aziza, I express my gratitude for your company and friendship throughout my $\mathrm{PhD}$ Journey.

I owe a lot to my Mother, thank you for your support and encouragement at every stage of my life and especially all the sacrifices you made during my $\mathrm{PhD}$ journey. To my Dad who would have loved to see this achievement come through, I miss you. I am indebted to both of you for all the love given to me all through my life.

To my loving husband, Frank and my beloved Sons, Chidubem and Kemdi, who give me so much happiness, joy and pride in life. Dear Frank, thank you for all your understanding and encouragement especially for those times when I had to leave you and the kids for a long time to be in Maastricht for my studies. I appreciate all the support and efforts you made to make sure my studies were free of hassles. I also thank my siblings Ifeoma, Emeka, Nkechi, Ijeoma, Tobenna, my aunt Doris and my in-laws for all their good wishes.

Above all, I owe it all to Almighty God, my good Father, for guiding me through all the difficulties and granting me the wisdom, health and strength to undertake this research and enabling me come to its successful completion. I have experienced Your guidance day by day and I will keep on trusting you for my future. Thank you, Lord. 



\section{CURRICULUM VITAE}




\section{Curriculum Vitae}

Uchenna Onyekachi Okafor was born in Lagos, Nigeria on the $19^{\text {th }}$ of February 1980. After receiving a bachelor degree in Pharmacy from the Obafemi Awolowo University, Nigeria in 2005, she joined the National Institute for Pharmaceutical Research and Development in Abuja Nigeria and in 2007, she moved to work on a HIV/AIDS prevention and treatment project at the Society for Family Health (SFH) Nigeria. As a public health specialist, she has worked for over 12 years' designing, managing and evaluating public health interventions for vulnerable populations in Nigeria.

In 2012, she obtained a master's degree in Public Health from Obafemi Awolowo university, Nigeria and in 2013 started her work on HIV prevention project for key populations through a USAID funded project implemented by SFH. In January 2014, she received a scholarship award from the Netherlands Ministry of Foreign affairs through the Nuffic fellowship program to pursue her $\mathrm{PhD}$ studies at Maastricht University, Netherlands. Her studies focused on HIV prevention for female sex workers in Nigeria which is reported in this dissertation.

\section{Publications}

Okafor, U. O., Crutzen, R., Okekearu, I., Adebajo, S., \& Borne, H. (2017). HIV prevalence and high risk behaviour of young brothel and non-brothel based female sex workers in Nigeria. BMC Research Notes 10, 380. doi:10.1186/s13104-017-2712$\underline{8}$

Okafor, U. O., Crutzen, R., Aduak, Y., Adebajo, S., \& Van den Borne, H. W. (2017). Behavioural interventions promoting condom use among female sex workers in subSaharan Africa: a systematic review. African Journal of Aids research, 16(3), 257-268. doi:10.2989/16085906.2017.1358753

Okafor, U. O., Crutzen, R., Adebajo, S., Okekearu, I., \& Borne, H. (2017). Using brothel leadership to promote condom use among brothel based Female Sex Workers in Abuja, Nigeria: Study protocol for a cluster randomized pilot trial. BMC Pilot and feasibility studies 3(10). doi:10.1186/s40814-017-0124-0 
Uchenna Okafor, Rik Crutzen, Egbe Awo \& Bart Van den Borne (2017), Perspectives of brothel leaders and HIV prevention experts on the role of gatekeepers on improving condom use by Female Sex Workers in Abuja, Nigeria, Global Journal of Health Science, 9(10)

Uchenna O.Okafor, Rik Crutzen, Adebajo Sylvia, Okekearu Ifeanyi \& Bart Van den Borne (2017), Using Brothel Leadership to Improve Condom Use among Brothel based Female Sex Workers in Abuja, Nigeria: Results of a Cluster Randomized Pilot Study. Global Journal of Health Science, 9(12) 
